Bolm. Zool., Univ. S. Paulo $9: 17-143,1985$

\title{
CHAVE DE IDENTIFICAÇÃO E LISTA DE REFERÊMCIAS BIBLIOGRÁFICAS PARA AS ESPEECIES CONTINENTAIS SULAMERICANAS DE VIDA LIVRE DA ORDEM CYCLOPOIDA (CRUSTACEA, COPEPODA)
}

JANET W. REID

Department of Invertebrate Zoology, Na tional Museum of Natural History,Smith sonian Institution, Washington, D.C. 20560 U.S.A. (recebido em 22.VIII.1984).

RESUMO - Uma chave ilustrada é fornecida para auxiliar na identificação das 108 espécies, subespécies e formas de Cope poda, Cyclopoida (Crustacea) de vida livre, conhecidas da A= mérica do Sul continental, incluindo as Ilhas Malvinas/Falklands, Aruba e Curaçaa. Estão incluidos os membros dos gêneros predominantemente marinhos, que podem ocorrer em estuá rios e lagoas salobras. Cada especie è suprida de uma lista de referéncias bibliogräficas.

ABSTRACT - An illustrated key is presented to aid in the identification of the 108 species, subspecies and forms of free-living cyclopoid copepods (Crustacea) which have been recorded from continental South America, including the Falklands Islands/Malvinas, Aruba and Curaçao. Included are those members of predominantly marine genera which may occur in estuaries and brackish lagoons. For each species a list of bibliographic references is supplied.

\section{INTRODUÇÃO}

1. Consideraçōes gerais

Calanoida, Cyclopoida e Harpacticoldea são as três ordens de copépodos que incluem a maior parte das formas de vida livre. Estas, juntas com as formas parasitas, consti tuem a subclasse Copepoda da classe Crustacea do filo Arthro poda. Estes micro-crustáceos se encontram em quase todos os corpos de água do mundo, bem como nos habitats permanentemen te mol hados. Eles são frequentemente abundantes e constituem parte importante da cadeia alimentar aquática. 0 grupo com preende espécies herbívoras, omnivoras ou carnívoras que se alimentam de detritos, fitoplancton, pequenos invertebrados e outros microorganismos. Por sua vez, servem como alimento de muitos invertebracos, peixes jovens e peixes planctófagos. 
São tambēm hospedeiros intermediārios na transmissão de para sitas de pelxes, aves e mamíferos, como, por exemplo, da drā cunculose humana. Por tudo isso torna-se necessário o conhecimento deste grupo para uma melhor compreensāo ecolögica de qualquer sistema aquatico.

o estudo dos copépodos das águas continentais da Amēri ca do Sul começou no sēculo passado com as primeiras explorâ ções de pesquisadores europeus, principalmente na Argentina, Chile, sul do Brasil e bacia do Amazonas (Dana, 1848; Gay, $1849,1854)$. Infelizmente, as informaçōes referentes à taxonomia deste grupo se encontram atualmente espalhadas em re vistas periódicas do mundo inteiro, em mais de cinco línguas. Num passado recente foram iniciados esforços a fim de organi zar a informação relativa aos membros sulamericanos das or = dens Calanoida e Harpacticoidea. As listas bibliográficas de Björnberg (1964), Fernando \& Smith (1982), Loffler (1981), e Pezzani (1978) propiciam um contato inicial com a literatu ra. De valor especial tambëm são a chave provisória de Brehm (1958) para a familia Diaptomidae dos Calanoida, e a lista das especies da mesma familia fornecida por Brandorff(1976) A monografia exaustiva de Lang (1948) e os trabalhos de Jako bi (1969a, b, 1972 e outros), de Lلffler (1961a, 1963) e dē Noodt (1972a,b, 1973) são pontos iniciais para o estudo da ordem Harpacticoidea.

Para quem quiser se envolver com a taxonomia dos Cyclo poida, existem como base as listas bibliogräicas mencionadas acima e alguns artigos. Dentre estes podem ser citados os de Lindberg (1954a,b, 1956a) que contêm algumas chaves de identificação para värios gêneros, assim como listas das espécies encontradas até as datas réferidas, $e \circ$ de Ringuelet (1958a) que fornece chaves de identificaçăo para as espêcies argentinas. A chave para copépodos Cyclopoida e Calanoida cu banos de Smith \& Fernando (1980) inclui vărias espécies sula mericanas. Chaves mundiais para os membros de vảrios gêneros existem espalhadas na literatura cientifica, embora estas. sendo escritas principalmente por e para especialistas, frequentemente não apresentam ilustrações ou explicaçōes exa tas dos termos utilizados.

Tendo em vista estas corsiderações, resolvi elaborar u ma chave de identificação para todos os representantes da or dem Cyclopoida registrados atê o presente no continente sula mericano, bem como nas ilhas de Aruba, Curaçao e Malvinas. $\bar{A}$ chave servirâ também como lista de referéncias bibliográfi cas para cada espécie incluída, tal informação näo estando disponivel nas outras listas bibliográficas existentes. Na preparação da chave, não tentei resolver todos os problemas taxonômicos, muitos dos quais devidos às insuficiências de coletas e informaçōes nas descrições originais. 0 propósito desta chave é de ajudar o pesquisador a identificar, o mais exatamente possível, a forma com que ele está trabaihando, e de alertā-lo para a possibilidade de confusão entre espêcies muito próximas. Por isso incluí as descrições de sub-espé cies, quando existentes, mencionei as diferenças de nomencla tura e relacionei os sinónimos comumente encontrados. Outros sinônimos foram listados por Lindberg (1954a). Inclui para 


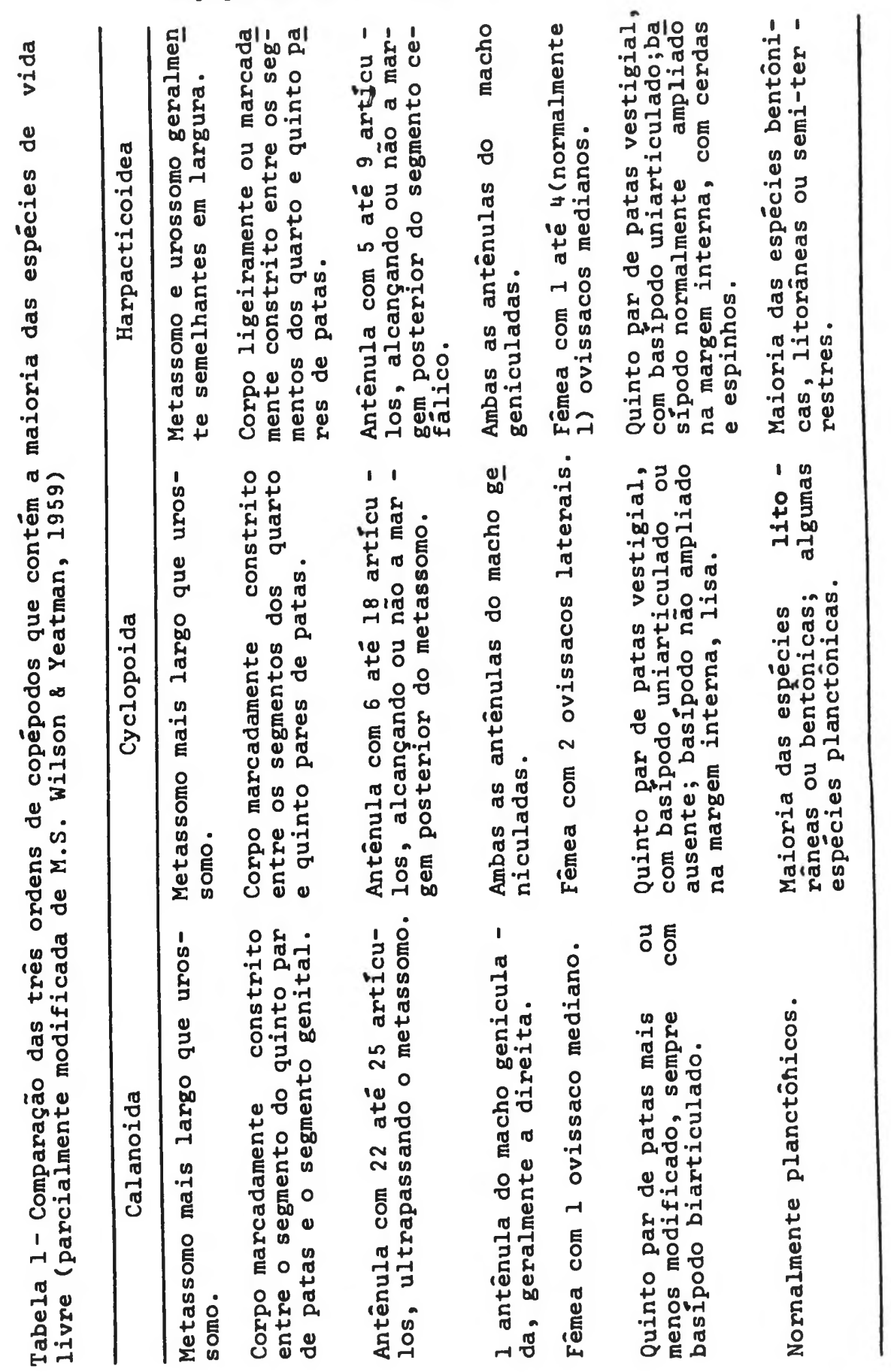


sada espécie uma lista dos trabalhos feitos na Amêrica do Sul e Central que tratam da sua distribuição, taxonomia e/ou ecologia geral, mais os trabalhos de outras partes do mundo que possuem importância especial.

A ordem Cyclopoida, em particular as formas de àgua do ce, é considerada taxonomicamente difícil. Vărios problemas resultaram de diferenças na nomenclatura e de coletas inade quadas, ou da natureza biológica dos animais, as variaçōes morfológicas e em certos casos o polimorfismo (Nilssen,1979). Os caracteres morfométricos utilizados para distinguir as es pécies são extremamente sutís, esse fato faz com que seja nê cessāria a tomada de medidas muito exatas e uma comparaçāo cuidadosa com a literatura. Caracteres morfométricos pouco considerados em épocas passadas, como por exemplo a forma do receptáculo seminal da feemea, estão sendo mais utilizados ho je em dia (Kiefer, 1981). Nas dêcadas recentes, tem-se mos = trado a existência, em vắrios géneros, de complexos de for mas, pouco distintos morfometricamente, mas bem isolados eco logicamente ou na reprodução (Einsle, ig70; Frenzel, 1976 , 1977; Price, 1958; Wyngaard \& Chinnappa, 1982). Esta será u ma área fértil para futuras pesquisas. O pesquisador atual é todavia obrigado a definir, da melhor maneira possível, as formas e locais de coleta sobre as quais ele se refere na li teratura cientifica.

\section{A anatomia dos Cyclopoida}

As ordens Calanoida, Cyclopoida e Harpacticoidea podem ser distinguidas entre si pela forma geral do corpo, o habitus, e pela forma e número de artículos dos vários apêndices (Tabela I, Figs. 1-3). Seguindo a denominação de M.S. Wil son \& Yeatman (1959), o corpo pode ser considerado como divi dido em uma parte anterior, metassomo, e uma parte posterior, uros8omo. Considera-se incluido no urossomo o segmento genital e trè̀s segmentos posteriores (os abdominaia), sendo - último o segmento anal. O metassomo, chamado por alguns au tores de cefalotórax, inclui a regiāo da cabeca e do tórax A parte anterior da cabeça se estende no rostro, que muitas vezes é reduzido ou ausente. A cabeça apresenta cinco pares de apêndices, cuja ordem no sentido ântero-posterior é: antê nulas, antenas, mandibulas, maxilulas e maxilas (Figs. 4-8, 10). O tórax apresenta seis pares de apêndices, cuja ordem no sentido ãntero-posterior é: um par de maxilipedes (Fig. 9), quatro pares de patas natatórias (Figs. 11-14) e um quin to par de patao (Fig. 15). As patas natatórias são geralmente pouco diferenciadas e o quinto par de patas é reduzido ou vestigial nos Cyclopoida.

o primeiro segmento do corpo, chamado segmento oefälico, resulta da fusão da cabeça e do primeiro segmento toráci co. 0 segmento cefálico entäo apresenta todos os cinco pares de apêndices anteriores, mais os maxilipedes. Ảs vezes 0 segundo segmento toräcico, que apresenta o primeiro par de patas natatórias, se encontra fundido com o segmento cefálico. De maneira semelhante, os dois segmentos posteriores do 
metassomo podem ser completa ou parcialmente fundidos. Então, de acordo com o gênero ou espécie, o metassomo poderia ser composto de seis, cinco ou quatro segmentos.

Sob o termo pegas bucaio estão geralmente incluidas as mandibulas, maxilulas, maxilas e os maxilipedes Estas peças não são normalmente utilizadas na taxonomia ao nivel de espé cie, embora possuam importância em niveis superiores.

Entre os Cyclopoida, as antênulas do macho são geniculadas e preênseis, sendo utilizadas para agarrar a fêmea durante a cópula (Fíg. 10). As antênulas da fêmea são simples e se adelgaçam gradualmente da inserção na cabeça até o últi mo articulo (Fig. 4) E muito mais facil a contagem do número de artículos da antênula da fêmea que, por sua vez, é geralmente diferente daquele do macho.

Todas as patas são birremes, isto ê, com una parte basal biarticulada (basipodo), que apresenta um ramo externo (exópodo) e um ramo interno (endópodo). A antênula sempre, e às vezes a antena, a mandíbula e o quinto par de patas per deram um dos ramos. As patas natatórias são menos modifica = das, sempre formadas por dois ramos, cada um geralmente biou triarticulado e mais raramente uniarticulado. Cada articu lo apresenta um certo número de espinhos e cerdas. A fórmulă de espinhos utilizada por vários autores è o número de espinhos externos e terminais presentes no articulo terminal do exópodo da primeira à quarta pata natatória. Assim, a fórmula de espinhos das patas mostradas nas Figs. 11-14 é 3.4 .4 .3 . As dimensões do artîculo terminal do endópodo da quarta pata (comprimento e largura) são muito utilizadas na separação de espêcies. Também são utilizados os comprimentos relativos dos dois espinhos ou cerdas apicais deste articulo (Fig.14) os basipodos de cada par de patas natatórias são ligados por uma placa basal, que e muitas vezes armada de espinulos na margem ou face anterior. A forma das placas basais do primei ro e quarto par de patas natatórias è muitas vezes ütil na separação de espécies

Existe uma gradação entre "espinhos" e "cerdas". Os es pinhos são mais fortes, e geralmente mais curtos, podendo ser lisos ou serrilhados. As cerdas são longas e finas, 1 i sas ou plumosas.

0 quinto par de patas (Fig. 15) se localiza no último segmento do metassomo, e no animal inteiro estā geralmente escondido pelas patas natatórias. A quinta pata consta de um, dois ou tres articulos. A contagem destes articulos torna-se às vezes dificil nos Cyclopoida devido à fusão ocasional do articulo proximal com o tegumento do corpo. Se ocorrer a fusão, esta pode ser reconhecida pela presença de uma cerda ou espinho lateral à inserção aparente do artículo distal da pa ta.

O urossomo começa com o segmento genital e termina com - par de processos chamados ramos caudais, ou por vários autores "ramos furcais" ou "I aminas caudais" (Fonseca \& Bjornberg, 1976; Oliveira, 1954). No caso normal, as seguintes cerdas estão presentes na porção distal de cada ramo caudal, do lado interno para o externo: uma cerda apical interna, uma cerda apical mediana interna, uma cerda apical mediana exter 
na, e uma cerda apical externa (denominação de C.E.F Rocha, 1981). O ramo caudal apresenta também uma cerda iateral, às vezes inserida dorsolateralmente; e uma cerda dorsal (Fig. 16).

Na fêmea, o primeiro segmento abdominal está fundido com o segmento genital; o segmento inteiro recebe então o no me de segmento genital. Por isso o número total de segmentos no urossomo è geralmente cinco no macho e quatro na fênea, em bora existam casos de fusão de segmentos em um sexo ou outrō. o segmento genital possui um sexto par de patas vestigiais em ambos os sexos. Estas são mais desenvolvidas no macho do que na fêmea, e são frequentemente confundidas com as quin tas patas por iniciantes.

No lado ventral do segmento genital da fêmea se locali za o receptăculo eminal, cuja forma é importante na taxonomia de alguns gêneros ( $F$ ì. I5). Âs vezes torna-se difícil distingui-lo em espécimes preservados durante muito tempo.

Os sexos podem ser distinguidos pelos caracteres do urossomo, das antênulas, do sexto par de patas e às vezes também pelo quinto par de patas. As fêmeas adultas são facil mente reconhecidas quando carregam sacos de ovos presos late ral ou dorsalmente no segmento genital ou espermatóforos, de positados pelo macho na abertura genital da fêmea durante $\bar{a}$ cópula.

Existem onze ou doze etapas de desenvolvimento: cinco ou seis de larvas do tipo năuplio e seis adicionais de copepóditos, dos quais o último é o adulto. Os copepóditos imatu ros podem ser confundidos com o adulto. Existem espécies cu= jos adultos possuem antênulas curtas e/ou exópodos e endópodos das patas natatórias com somente dois articulos, uma situação que è semelhante àquela dos copepóditos I a III. Nestas fases larvais, no entanto, as patas ainda são incomple tas e em menor número. Os copepóditos IV e $V$ podem ser reconhecidos por terem o ültimo segmento do urossomo mais longo que aquele do adulto. Na última muda este segmento se divide em duas partes, das quais a parte posterior fica mais curta que a anterior.

Normalmente, somente os adultos são utilizados na taxo nomia, sendo esta baseada em grande parte nos caracteres das quintas patas e nas proporçōes das formas sexualmente matu ras. Apesar disso, o desenvolvimento naupliar de vărias espé cies sulamericanas tem sido descrito (Auvray \& Dussart, 1966; BjErnnerg, 1972; M.A.J. Carvalho, 1971; Cicchino, 1974 ; Dukina, 1956; Ewerg, 1930; Fanta, 1976 ; Fonseca \& Almeida Prado, 1979 b; Gouvêa, 1978; Kiefer, 1973; Lucks, 1929; Man fredi, 1923,1925 ; Zacarias \& Zoppi de Roa, 198i). Destes _ Cicchino(1974) e Kiefer (1973) fornecem valorosas discussōes da anatomia comparativa dos nâuplios, bem como chaves de $i$ dentiflcação das etapas e dos gêneros estudados

\section{Métodos de coleta, preservação e dissecção}

Copêpodos ciclopóides ocorren em quase todos os ambien tes aquâticos imagináveis, ou seja, em lagos, rios, brejos poças, poços, fontes quentes (Brehm, 1936b), tanques de bro- 
méllas, e até em àgua retida em cascas de Castanhas-do-Pará (Herbst, 1962). Embora algumas espécies sejam importantes no plâncton, a maioria das espécies de Cyclopolda se encontra na zona litorânea de corpos de ăgua, isto ê, em ambientes lênticos contendo algas bentônicas e macrōfitas. 0s animais podem ser coletados mais facilmente com redes de pláncton convencionais. Redes de boca menor servem para coletas em po ças ou brejos.

0 material pode ser fixado no campo em formol a 3-4t com borato de sốdio adicionado como tampão. Se a amostra estiver chela de matêria vegetal e de detrito antes da fixação, recomenda-se a adição de umas gotas do corante vital "Rosa de Bengala" dissolvido em água. Após uma hora ou mais, para permitir a absorção do corante, o formol pode ser adicionado e o vidro agitado. o corante se impregna nos animais, tornan do-os cor-de-rosa brilhante e assim facilitando a separação destes de matêrias estranhas, utilizando-se um microscopio estereoscôpico.

Para conservar animais inteiros por longo periodo de tempo, é desejãvel colocá-los em uma solução de etanol a 70 t e glicerina a 1\%. Não é recomendável deixấlos em solução de formol, porque as cerdas ficam frágeis com o tempo. 0 uso da solução de etanol-glicerina evita este problema e, se por in fortunio a solução se evaporar, a glicerina manterá os ani = mais molhados.

Para prepará-lo para dissecção, o animal pode ser trans ferido para uma solução aquosa de glicerina a 208 . Após algu mas horas ou dias, a água se evapora e deixa o animal em gli cerina pura (o tempo de evaporaçao será menor se o material fốr colocado em uma câmara de evaporação) En seguida podese proceder o exame e disseç̧ão do material utilizando-se um microscópio estereoscópico.

Para melhorar o contraste dos tegumentos, è ütil a adi ção do corante "Negro de Clorazol" (Chlorazol Black E") dis" solvido em água, à solução de glicerina antes do começo da fase de evaporação. E necessário corar os animais fortemen te, pois muito do corante será perdido para o melo.

Na dissecção podem ser utilizadas agulhas finas montadas em palitos de madeira com araldite. Agulhas de tungstê nio, de $0,005 \mathrm{~mm}$ diâmetro, que tenham sido afiadas mergulhan do as pontas em nitrato de sôdio fundido, são recomendadas por Coull (1977). São satisfatórios alfinetes entomológicos de aço inoxidâvel tipo "minuten nadeln".

o corpo do animal pode ser separado mais facilmente en tre os segmentos 4 e 5 do metassomo (os que apresentam ō quarto e quinto pares de patas respectivamente). Assim torna -se mais visivel o quinto par de patas, ligado ao segmento posterior do metassomo. Também são geralmente visiveis os exópodos das patas restantes mais as antênulas e os ramos cau dais. E frequentemente possível a identificação sem continuar a disseç̧ão. Se fôr necessário, as patas restantes podem ser isoladas separando-se dorsalmente os segmentos do corpo. Cada segmento terá um par de patas. Finalmente serão separadas as antênulas e as peças bucais. Cada peça pode ser monta da permanentemente em lâminas no meio preferido. 
Um meio satisfatörio ê aquele de Reyne: dissolver 10 8 de hidrato de cloral em $10 \mathrm{ml}$ de água destilada; adicionar 2,5 mI de glicerina e mexer com um bastão de vidro; adicio nar 68 de goma arábica e mexer cuidadosamente tentando evi tar bolhas; deixar uma semana antes de utilizar. A goma sốli da e ägua podem ser substituidas por $12 \mathrm{ml}$ de goma arábicá li̊quida, encontrada normalmente em papelarias. 0 meio deve ser protegido da luz.

A serie das peças do animal pode ser montada em duas ou trés lâminas, cada parte em sua prôpria gota do meio e co berta por uma lamínula. Assim fica mais făcil manipular cada lạinula, até que se coloque a peça na posição preferida. Após dois ou três dias numa câmara de evaporação, o meio vai se endurecer. En climas úmidos è necessârio emoldurar as laminulas com uma substância dura; para isso serve esmalte incolor.

Para a observação dos detalhes é necessārio o uso de um microscópio, de preferência com contraste de fase. As vezes è necessário também o uso da objetiva com óleo de imer são. Medidas podem ser feitas utilizando-se uma ocular micro métrica.

Pode ser montado um animal inteiro, sustentando a lami nula com três ou quatro pedaços de laminulas, colocados nos seus cantos.

E desejâvel fazer uma ficha de referência para cada animal, anotando a data e local de coleta, dados de medidas. e no verso, um esboço da localização das peças na lâmina ou lâminas.

4 U uso da chave

As descriçōes de espécies da ordem Cyclopoida baseiamse principalmente nas fêmeas, pois faltam as vezes nos ma chos, alguns caracteres estruturais, ou estes são modifica dos. No entanto, se faltar fêmeas na coleção, a chave permite a identificação de machos até o nivel de gênero com razoá vel confiança. Nota-se que os machos são geralmente menores que as fêmeas, às vezes alcançando somente a metade do com primento destas. Os caracteres utilizados na chave são aqueles das fêmeas, com exceçōes anotadas.

A chave não inclui os membros de gêneros inteiramente marinhos, que podem invadir ocasionalmente as águas salobras das regióes costeiras estuarinas. São incluídas, no entanto, as värías espécies dos gêneros Halicyolops e Oithona que habitarn águas doces ou salobras dos rios e estuários do continente. Algumas espécies de distribuição cosmopolita, mas cujos registros na América do Sul são duvidosos, foram incluídas também. Os registros do Distrito Federal são os da autora.

Alêm de obras princlpalmente taxonômicas, foram incluí das muitas que contêm na maior parte informação ecolögica oū biolögica, especialmente as referentes à América do Sul e Central, o Mar das Caraíbas e áreas subtropicais da Amêrica do Norte. Dentre estas estão as de Bonetto \&artínez de Fer 
rato (1966); Epp \& Lewis (1980); Fanta (1976); Fonseca(1976); Infante (1978); Infante st al. (1979); Matsumura-Tundisi (1972); Olivier (1955); Ringuelet (1958 b, 1959, 1962, 1972); Ringuelet et al. (1955, 1965); Santos (1970); Teixeira et al. (1965) e Tundisi (1963, 1970). Obras taxonómicas especi almente recomendáveis para o iniciante são os compéndios dé Dussart (1969), Gurney (1933), Kiefer (1929b,1978b), Mon chenko (1974), Rylov (1948), G.0. Sars (1913, 1914), e Yeatmąn (1959), que fornecem informação básica taxonômica, biológica e ecológica sobre muitas espécies cosmopolitas. Os ar tigos na lista de referências para cada espécie que contêm figuras e/ou discùssões taxonômicas valorosas são marcados com um asterisco (*)

Existe sempre a possibilidade de encontrar uma espécie anteriormente não descrita ou registrada na América do Sul Por isso é imperativo a comparaçáo dos espécimes com as descriçōes detalhadas na literatura cientifica. Näo è desejāvel a dependência exclusiva da chave para finalizar uma iden tificação.

\section{Chave para a seção Gnathostoma, ordem Cyclopoida}

I. Chave para familias:

la. Palpo da mandíbula composto de mais de 1 artículo (Figs.25-27)..... .......... .... . ...2 1b. Palpo da mandíbula reduzido a uma protuberấncia ar redondada, armada com 2 a 3 cerdas, ou palpo da mandíbula ausente (Figs. 6, 34, 36) . ... .......

. . . . .... ... . familia Cyclopidae (III) 2a.(1) Antena bi- ou triarticulada..familia Oithonidae (II) 2b. Antena tetraarticulada (exceto Pterinopsyllus). . . ..... familia Cyclopinidae

A famillia Cyclopinidae é predominantemente litorânea marinha. Representantes dos gêneros Procyclopina e Cyclopi nopsis foram encontrados em ăguas salobras estuarinas sulame ricanas (Herbst, 1955) Wells (1967) forneceu uma chave parā os gêneros da família. Lindberg (1953) fez uma revisão da sub-familia Cyclopininae, fornecendo chaves para gêneros e espécies. As espécies da familia Cyclopinidae não foram in cluidas nesta chave.

A familia Oithonidae è tambèm predominantemente mari nha. Contudo, alguns membros do gênero oithona habitam a àgua doce, estuários e lagoas costeiras sulamericanas, e es tes foram incluídos na chave. Não foram incluídas as espé cies predominantemente oceânicas que às vezes invadem àguas salopras e têm sido registradas destas águas na América do Sul e no Mar das Carailbas: Oithona (Dioithona) minuta $T$. Scott, 1894; 0. (D.) oculata Farran, 1913; 0. atlantica Farran, I908; 0 . colcarva Bowman, 1975 (muitas vezes confundida com 0 . brevicornis Giesbrecht, 1891 , que provavelmente não está presente na costa atlântica); o. decipiens Farran 1913 ; 0. frigida Giesbrecht, 1902; 0. frigida var.poeudofrí- 
gida Rosendorn, 1917 ; 0 . helgolandica Claus, 1863 ; 0 . nana Giesbrecht, 1892 ; 0 . plumifera Baird, 1843 ; 0 . robusta Giesbrecht, 1892 ; 0 . setigera Dana, 1853 ; 0 . similis Claus, 1866; 0. oimplex Farran, 1913; 0 . spinirostris Claus, 1863 ; 0 . tenuis Rosendorn, 1917; e possivelmente 0 . brevicornis na costa pacifica sulamericana (Bacon, 1971; Björnberg, 1959. $1963,1971,1972,1981$; Boltovskoy, 1978/1979; Calef \& Gri ce, 1967; J.P. Carvalho, 1945, 1952; Cervigōn, 1962 ; Cervi gôn \& Marcano, 1965 ; Coker \& Gonzälez, 1960 ; Cuzon du Rest, 1963; Davis, 1950; Farran, 1929; Ferrari \& Bowman, 1980; Fon seca \& Björnberg, 1976; Giesbrecht, 1895; Gonzälez \& Bowman, 1965; Grice, 1956, 1960a,b; Hensen, 1911; Hopkins, 1966

1977 ; Kanaeva, 1960; Kidd \& Sander, 1979; Kiefer, 1929b; King, 1950; Kolesnikov \& Alfonso, 1973; Legarê, 1961, i964; Lind berg, 1954a,b; Michel \& Foyo, 1976; Moore \& Sander, 1979; Mo ryakova \& Campos, 1973; Oliveira, 1945a,b, 1946; Owre \& Foyo, $1964 a, b, 1967$, 1972 ; Pallares, 1968 ; Rosendorn, 1917 ; Sander \& Moore, 1978; T Scott, 1914; Sewell, 1948; Turner, 1981, 1982; Wellershaus, 1970; C B. Wilson, 1942, 1950; Youngbluth, 1979 ; Zacarias \& Zoppi de Roa, 1981; Zoppi de Roa, 1961)

Lindberg (1954b), Shuvalov (1980) Wellershaus (1970) forne ceram chaves mundiais para o gênero, e Bjornberg (1981) in cluiu värias espécies costeiras na sua chave para as espé cies do sudoeste do Oceano Atlântico.

II. Chave para as espēcies de Oithona, habitantes de águas doces e salobras sulamericanas:

1a. Exópodo da quarta pata natatória com 0,0 e 1 espi nho externo nos articulos proximal a terminal respec

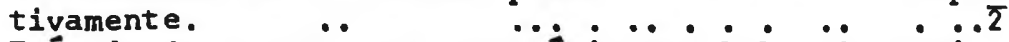

1b. Exópodo da quarta pata natätốria com $\dot{i}, \dot{i}$ e $\dot{2}$ espi nhos externos nos artículos proximal a terminal respectivamente .... .... .... .. ....... . .5

2a. (1) Articulos terminais dos exốpodos da primeira e segun da patas natatórias com 3 espinhos ou cerdas na margem externa; articulo proximal do exópodo da terceira pata natatória com 1 espinho externo.... .. . .3

2b. Articulos terminais dos exópodos da primeira e segun da patas natatórias com 2 espinhos na margem exter na; artículo proximal do exópodo da terceira pata na taţória sem espinho externo....... ......... . $\frac{4}{4}$ 3a. (2) Exópodo da primeira pata natatória com espinhos fortes nas margens externas dos articulos (Figs. 17-19) - ... Oithona amazonica amasonica Burckhardt, 1912 Brasil (bacia do rio Amazonas); limitada à Ánêrica do Sul. Rios e lagos (o registro no Atlântico Sul de Bjornberg, 1963, e provavelmente erróneo); àgua doce. Fêmea 0,60-0,61 mm; macho 0,55-0,57 mm; Ver Bran dorff (1977, 1978), Brandorff et al. (1982), Burck hardt $\left(1913^{*}\right)$, Ferrari \& Bowman (1980*), Hardy $(1978,1980)$, Kiefer (1929b, 1956), Lindberg (1954a, b), Rosendorn (1917*), Sewell (1948), Wellershaus (1970). 
3b. Exōpodo da primeira pata natatória com cerdas finas nas margens externas dos artículos (Fig. 20)...... . Oithona amasonica continentalis Lindberg, 1954 a Possivelmente sinónimo de 0 . amaxonica sensu stricto (ver discussão de Ferrari \& Bowman, 1980). Brasil (Amazonas); limitada à América do Sul. Rios; água do ce. Fêmea 0,52-0,59 mm; macho 0,54-0,61 $\mathrm{mm}$. Ver Lind̄ berg $(1954 \mathrm{~b})$.

4a. (2) Cerdas apicais do ramo caudal grossas; 29 ao 49 segmentos do urossomo com 1 a 2 series de espínulos pequenissimos no lado ventral (Fig. 21).... . ...... . Oithona bjornbergae Ferrari \& Bowman, $19 \ddot{g} 0$ Brasil (Pará); limitada à América do Sul. Rios; àgua doce. Fêmea $0,44-0,51 \mathrm{~mm}$; macho 0,41-0,48 $\mathrm{mm}$.

4b. Cerdas apicais do ramo caudal normais 3 ? ao 5 : seg mentos do urossomo com 1 série de espínulos pequenís simos na margem ventro-posterior (Figs. 22,23) .... . $\cdots$. Oithona gessneri Kiefer, 1954 Brasili (Pară); Venezuela; limitada à América do Sul Rios; àgua doce. Fêmea 0,5 mm; macho desconhecido Ver Brandorff et al. (1982), Kiefer (1956)

5a.(1) Ramo caudal 1,5-2 vezes mais longo que largo ..6 $5 \mathrm{~b}$. Ramo caudal 3 vezes mais longo que largo. . .7 6a.(5) Segundo basipodo da mandíbula com 2 cerdas grossas e digitiformes, fortemente curvadas em forma de gan chos; região anterior da cabeça arredondada em vista dorsal e quadrada em vista lateral (Figs. 24,25).... ............ Oithona ovalis Herbst, 1955 Brasiï (Bahia, Espírito Santo, Pará, Parană, Sáo Pau lo): Iimitada à América do Sul. Manguezais e estuá = rios; águas salobras de salinidades entre 12,7 $35,8 \%$ (Fonseca, 1976; Fonseca \& Bjonrberg, 1976*; e Fonseca \& Prado, $1979 \mathrm{a}$ ). Fêmea 0,54-0,60 mm; macho $0,50-0,56 \mathrm{~mm}$. Ver Bj8rnberg $(1963,1968 *, 1972 *$ 1981), Fanta (1972, 1976), Fonseca \& Prado (1979b*), Herbst (1967*), Mat sumura-Tundisi (1972), Milsteín (1979), Santos (1970), Teixeira et al. (1965, 1969), Tundisi (1963, 1970), Tundisi \& Matsumura-Tundisi (1968).

6b. As 2 cerdas grossas do segundo basípodo da mandíbula pouco curvadas; região anterior da cabeça com uma protuberáncia arredondada no vértice superior (Fig. 26 ........... . Oithona hebes Giesbrecht, 1891 Brasil (Cearà, Pernambuco); Equador, Venezuela; Mar das Caraibas, Oceanos Pacífico e Atiantico Sul. Es tuấrios e lagoas costeiras de salinidades entre 3$60 \%$ (Zoppi de Roa, 1974) Fêmea 0,53-0,67 mm; macho 0,48-0,58 mm. Notar que na opinião de $C$. E. F Rocha (comunicação pessoal à autora), 0 . ovalis è provavel mente sinonimo desta espécie. Ver Bacon (1971), Bjorñ berg (1971), Bowman (1975*), Calef \& Grice (1967), Farran (1913*), Ferrari (1977*), Ferrari \& Bowman $(1980 *)$, Fonseca \& Bjornberg $(1976 *)$, Fonseca \& Prado (1979b), Gonzälez \& Bowman (1965*), Kiefer (1929b* $\left.1936 c^{*}\right)$ Lind berg (1954a, b*), Lyffler (1963). Schu bart (1938), Wellershaus'(1970), Zacarias \& Zoppi de 
7a. (5) Roa (1981*), Zoppi de Roa (1974).

7a. (5) Endópodo da mandíbula com 5 cerdas (Fig. 27); compri mento do segmento anal do macho igual ou maior que

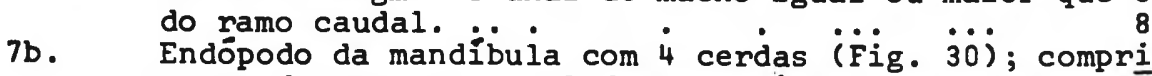
mento do segmento anal do macho igual ou menor que $\overline{0}$ do ramo caudal. . .. Oithona neotropica Herbst,1967 Venezuela; costa de Honduras. Estuários e lagoas cos teiras. Fểmea $0,56-0,64 \mathrm{~mm}$; macho $0,51 \mathrm{~mm}$. 0 local 은 riginal, Lago Mucubaji nas montanhas andinas da Venezuela, repetido por Gessner \& Hammer (1967), $\bar{e}$ provavelmente errôneo (Ferrari \& Bowman, 1980*) Ver também Fonseca \& Bjornberg (1976*)

8a.(7) Parte anterior da cabeça arredondada em vista dorsal e lateral (Figs. 28, 29). . . . . - Oithona fonsecae Ferrari \& Bowman, 1980 Suriname; Mar das Caraíbas. Estuários e lagoas costeiras. Fêmea $0,49-0,60 \mathrm{~mm}$; macho $0,49-0,51 \mathrm{~mm}$.

8b. Parte anterior da cabeça pontuda em vistal dorsal e quadrada em vista lateral (Figs. 31, 32). . .... - ...oithona oligohalina Fonseca \& Bjornberg, 1976 Brasil (Bahia, São Paulo); limitada à América do Sul. Estuários e lagoas costeiras de salinidades entre 3,1-22,3\% (Fonseca \& Prado, 1979a) Fêmea 0,58$0,64 \mathrm{~mm}$; macho $0,58-0,60 \mathrm{~mm}$. O registro de " 0 . he bes" feito por Santos (1970) em Cananéia é na realidade 0 . oligohalina (Fonseca \& Prado, 1979b*). Ver também Bjornberg $(1981 *)$, Ferrari \& Bowman (1980*), Fonseca $\left(1976^{*}\right)$.

III. Chave para as subfamílias da família Cyclopidae:

1a. Artículo terminal da quinta pata com 4 ou 5 cerdas e lou espinhos; patas natatórias triarticuladas. ..... .. . subfamilia Halicyclopinae (ïi). Ver as chaves e discussões dos gêneros desta subfamí lia em Monchenko (1977), Plesa (1961, 1963, 1973 , 1981) e Vervoort (1964)?

1b. Artículo terminal da quinta pata com 3 cerdas e/ou espinhos; patas natatorias triarticuladas. . ...

1c. Artículo terminai da quinta pata com 1 ou 2 cerdas e lou espínulos; patas natatórias bi- ou triarticula das. - subfamilia Cyclopinae (VI)

IV. Chave para a subfamília Halicyclopinae:

1a. Quinta pata biarticulada, com o artículo proximal fundido ao segmento torácico correspondente; antênula com 6 artículos.. Halicyclops (3) As espécies deste gềnero nomalmente habitam àgua sa lobra; $B$. aberrans tem sido registrado em àgua doce. Ver as chaves mundiais de Kiefer (1936a) e Lindberg (1957a), e a de C.E.F Rocha (1981) para as espécies brasileiras. A chave seguinte foi adaptada desta ültima.

1b. Quinta pata triarticulada, com o artículo proximal 
fundido ao segmento torácico correspondente (Figs. 35,37 ); antênula com 8 a 12 artículos. . 2

2a.(1) Antênula com 12 artículos; palpo mandibular com 2 cerdas (Figs. 34, 35) : : .. Paraeuryte vicina Herbst, i955 Sinônimo: Neocyclops remanei vicinus de Plesa (1963, 1983).

Brasil (São Paulo); limitada à América do Sul, com registro duvidoso no Mar Negro (Plesa, 1963, 1964\%) Praias arenosas. Águas marinha ou salobra. Fémea $0,75 \mathrm{~mm}$; macho desconhecido. Ver Plesa (1961, 1983)

2b. Antênula com 12 artículos (outras espécies deste gênero, não encontradas na América do Sul, possuem antênulas com 8 artículos); mandíbula sem palpo mandibular e cerdas (Figs. 36,37 ). -........ . Neocyciops medius Herbst, $1955^{\circ}$ Brasil (Bahia, São Paulo); limitada à América do Sul. Praias arenosas. Aguas marinha ou salobra. Fêmea 0,59 mm; macho 0,50 mm. Ver Plesa (1961).

3a.(1) Fórmula de espinhos dos artículos terminais dos exópodos das primeira à quarta patas natatórias 3.4 .4 .3 (Fig. 42) : : : : $:^{4}$ 3b. Förmula de espinhos dos artículos terminais dos exöpodos das primeira à quarta patas natatórias 23.3 .2 (Figs. 38-40)..

... Haitcyciops aberrans C. E. F. Rocha, $i \dot{9} 84$ Brasil (Pará): limitada à Anérica do Sul. Rios; àgua doce cristalina. Fêmea $0,58-0,68 \mathrm{~mm}$; macho $0,50-0,53$ $\mathrm{mm}$.

4a. (3) Margens posteriores dos segmentos do metassomo com membrana hialina dorsal lisa. 5

4b. Margens posteriores dos segmentos do metassomo com membrana hialina dorsal denteada (Figs. 41, 42) . Balicyclops paradenticulatus C. E. F Rocha, no preio Brasil (Sergipe); limitada à América do Sul. Fēmea $0,415 \mathrm{~mm}$; macho desconhecido. Ver C. E. F. Rocha (1981*).

5a. (4) Porção terminal das cerdas apicais medianas intennas do ramo caudal com ornamentação (espínulos ou cérdulas) homônoma (Fig. 46). : : . 6

5b. Porção terminal das cerdas apicais medianas internas do ramo caudal com ornamentação heterōnoma (Fig. 53)

6a. (5) Artículo terminal do endópodo da quarta pata natatö-

6b. Artículo terminal do endópodo da quarta pata natatória da fêmea sem cerdas internas (Figs. 43, 44) .... : $\because$ Halicyciops glaber C. E. F Rocha, ig̈j Brasii (Sergipe); limitada à Anérica do Sul. Estuärios de salinidades entre $1,0-7,4 \varepsilon_{0}$ Fêmea $0,52-0,61$ $\mathrm{mm}$; macho 0,43-0,49 mm: Ver C. E. F. Rocha (1981*).

7a. (6) Cerdas internas do artículo terminal do endöpodo da quarta pata natatória mais longas que o artículo; ra mo caudal täo longo quanto largo (Figs. 45-47)
.Halicyclops pilosus C. E. F Rocha, no prelo 
Brasil (Sergipe); limitada à América do Sul. Fēmea $0,56-0,61 \mathrm{~mm}$; macho 0,42-0,46 mm. Ver C. E. F Rocha (1981*).

7b. Cerdas internas do artículo terminal do endópodo da quarta pata natatória mais curtas que o artículo; ra mo caudal ligeiramente mais curto que largo (Figs $48,49)$... . Halicyclops crassicornis Herbst, 1955 Brasil (Rio de Janeiro, São Paulo, Sergipe); limitada à América do Sul. Lagunas e manguezais. Fémea 0,60 $\mathrm{mm}$; macho 0,56 $\mathrm{mm}$. Ver Herbst (1982), Plesa (1961), C. E. F Rocha (1981*,1983, no prelo), M. S. Wilson (1958b).

8a.(5) Ramos caudais mais longos que largos .. .9

8b. Ramos caudais tão longos quanto largos ${ }^{*}$. . i

$9 a .(8)$ Segmento genital da fêmea mais longo que largo e com uma dilatação pontiaguda voltada para trás em cada lado (Fig. 50) .. . . ... . . . ... ... ...Haicyciops thermophizus Kiefer, $1929 \mathrm{e}$ Brasil (Sergipe); Golfo Pérsico, Oceanos Indico e Pa cífico. Águas marinha e salobra. Fêmea 0,48-0,52 $\mathrm{mm}$; macho 0,35-0,38 mm. Ver Dussart (1982a*) Heberer \& Kiefer $\left(1932^{*}\right)$, Kiefer $(1933 \mathrm{c}, 1936 \mathrm{a})$, Lindberg(1950, 1952*), C. E. F Rocha (1981*, no prelo), M. S. Wilson (1958).

9b. Segmento genital da fêmea tão longo quanto largo e com uma pequena protuberância no terço anterior, em cada lado (Fig. 51 ).

- ....Halicyclops oraeeburnensis Lindberg, 1957a Brasil (Sergipe); Costa do Marfim. Fêmea 0,54-0,63 $\mathrm{mm}$; macho 0,42-0,48 mm. Ver Dussart \& Gras (1966), Herbst (1982), C.E. F Rocha (1981*, no prelo), $M$. S. Wilson (1958)

10a. (8) Cerdas ou espinhos internos do artículo terminal do endópodo da quarta pata natatória semelhantes em com primento, a cerda ou espinho distal atingindo ou ul= trapassando um pouco o apice do espinho apical inter no .. ... . ... . .... . . . . . II

10b. Cerdas internas do artículo terminal do endốpodo da quarta pata natatória desiguais em comprimento, a distal ultrapassando consideravelmente o ápice do es pinho apical interno (Figs. 52-54)......

- M Halioyclops ovatus C. E. F. Rocha, no prelo Brasil (Sergipe); limitada à América do Sul. Fêmea 0,39-0,49 $\mathrm{mm}$; macho 0,39-0,43 $\mathrm{mm}$. Ver C. E. F Rocha $(1981 *)$.

11a. (10)Margem interna do artículo terminal do endópodo da quarta pata natatória com 2 cerdas; segmento genital da fêmea mais Iongo que largo........ .12

11b. Margem interna do artículo terminal do endópodo da quarta pata natatória com 2 espinhos; segmento genital da fêmea tão longo quanto largo (Figs. 55, 56). ... Halicyclope verae C. E. F Rocha, no prelo Sinồnimo: H. souzaorusae de C. E. F Rocha (1981*) Brasil (Sergipe); limitada à América do Sul. Estuá rios. Fêmea 0,64-0,67 $\mathrm{mm}$; macho desconhecido.

12a.(11) Segmento genital da fêmea com uma pequena protuberân cia dorso-lateral no terço anterior, em cada lado ; 
membrana hialina das margens posteriores dos segmen tos abdominais denteada apenas ventralmente (Fig. 57)... .. . . . Halicyclops exiguus Kiefer, 1934b Brasil (Sergipe); Costa Rica, Haiti. Lagunas e es tuârios. Fémea $0,40-0,48 \mathrm{~mm}$; macho cerca de 0,40 $\mathrm{mm}$. Ver Collado et al. (no prelo*), Herbst (1982), Kiefer (1936a*), Lindberg $(1954 b), C$. E. F Rocha (1981*, no prelo), M. S. Wilson (1958).

12b. Segmento genital da fémea com uma dilatação lateromediana, em cada lado; membrana hialina das margens posteriores dos segmentos abdominais denteada em to da a sua extensão (Fig. 58). .

.... - .. .Halicyclops veneauelaeneis Lindberg, $1954 a$ Venezuela; limitada à América do Sul. Agua doce ou possivelmente água salobra a beira-mar; possivelmen te bentônica. Fêmea 0,60-0,72 $\mathrm{mm}$; macho desconhecido. Ver C. E. F Rocha (1981*, no prelo); M. S. Wil son (1958)

V Chave para a subfamília Eucyclopinae:

1a. Quinta pata biarticulada; artículo distal com 2 espinhos e 1 cerda (Figs. 64, 67)....Macrooyclops (5) Ver a chave mundial de Kiefer (1929b), e as de Dussart (1969), Kiefer (1960) e Monchenko'(1974) para as espécies européias.

1b. Quinta pata uniarticulada, com um conjunto de cerdas e espinhos arranjado de outra maneira (Figs. 61,73, $82,90,97$ ). . . ... . . 2

2a. (1) Artículo da quinta pata nã் fundido ao segmento torácico, com 1 espinho e 2 cerdas de comprimentos de siguais, uma apical e outra marginal (Figs. 61, 90, 97); antênula com 12 ou 17 artículos. ...3

2b. Artículo da quinta pata não fundido ao segmento torácico, com 2 cerdas apicais de comprimentos iguais, e 1 espinho apical (Fig. 73); antênula com 8 artícu los (outras espécies deste gênero, não encontradas na Anérica do Sul, possuem antênulas com 6,11 ou 12 artículos. ... .......Paracyclops (7) Ver as chaves mundiais de Kiefer (1929b) e de Lindberg (1958), e as de Dussart (1969), Kiefer (1960), e Monchenko (1974) para as espécies européias.

2c. Artículo da quinta pata parcialmente fundido ao seg mento torácico, com 3 cerdas e/ou cerdas espiniformes, de comprimentos mais ou menos desiguais (Fig. $82)$; antênula com 8 a 11 artículos... ..... ... $\quad$. : - Ectocyciops (ii) Ver as chaves mundiais de Fryer (1955), Kiefer (1929b) e Lindberg (1957a), e as discussões de Dussart (1982a) e de Loffler (1968)

3a. (2) Antênula con 12 artículos...: ... . 3b.

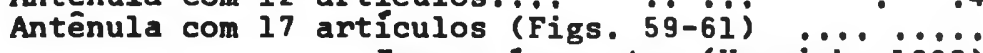
- $\because .$. . Homocyolops ater (Herrick, i882) Brasil (Anazonas); Antilhas, América Central e do 
Norte. Zona litorânea de lagoas e lagos. Fêmea 1,38 $-2,90 \mathrm{~mm}$; macho desconhecido. Gênero uniespecífico. Ver Dodds (1926), Ewers (1930*), Harris (1978) Herbst (1962), Herrick (1884*, 1887*), Juday (1915), Kiefer (1929b*, 1931b, 1933a*), Lindberg (1954a,b), Marsh $(1910 *)$, Pennak $(1963 *$, 1978*), Smith \& Fer nando (1978, 1980*), Yeatman (1959), Zo (1982*)

4a.(3) Receptáculo seminal com 2 projeçōes corniformes anteriores (Fig. 89); ramo caudal da fêmea sem espínu los na margem externa. .... . Tropocyclops (15) Ver as chaves mundiais de Kiefer (1931) e de Lind berg (1954b, 1955a)

4b. Receptäculo seminal sem projeçōes corniformes (Fig. 104); ramo caudal da fémea com espínulos na margem externa (Figs. 96, 99, 100). . ...Eucyclops (18) Ver as chaves mundiais de Kiefer (1929b) e Lindberg (1954b, 1957a), a de Kiefer (1960) para as espécies européias, e a de Ringuelet (1958a) para as espé cies argentinas.

5a.(1) Margem interna do ramo caudal lisa. ... . ..6

5b. Margem interna do ramo caudal hirsuta ( : . Macrocyclops fuscus (Jurine, 1820) Possivelmente Paraguai; fora da América do Sul, cos mopolita. Euritópica em lagos,äguas correntes e aguas subterrâneas. Fêmea $1,8-4,0 \mathrm{~mm}$; macho $1,19-2,5$ $\mathrm{mm}$. Ver Chappuis (1927), Daday (1905), Dukina(1956), Dussart (1969*), Ewers (1930), Gurney (1933*), Harding \& Smith (1974*), Harris (1978), Juday (1915), Kiefer (1929b*, 1960), Lindberg (1954a,b, 1956b*) , Marsh (1910*), Monchenko (1974*), Pennak (1963*, $1978 *)$, Rylov (1948*), Yeatman (i959*)

6a. (5) Artículo terminal do éndópodo da quarta pata natató ria com 2 cerdas internas, sendo a distal rudimen tar, não ultrapassando o äpice do artículo (Figs.66 -69).. Macrocyclops albidus albidus (Jurine, 1820) Brasil (Amazonas; possivelmente Santa Catarina); Ar gentina, Chile, Colómbia, Equador, Paraguai, Uru guai, Venezuela; cosmopolita. Eurítópica em lagos, ăguas correntes e àguas subterrâneas. Fêmea 1,10 2,50 mm; macho 0,96-1,30 mm. Ver Amelina (1927k), Ar mengol $\left(1978^{*}\right)$, Brehm (1935), Brian (1926), Chappuis (1927), Cole (1976), Collado et al. (no prelo), Comita (1951), Daday (1905*), Dodds (1926), Dukina $\left(1956^{*}\right)$, Dussart $\left(1969,1982 a^{*}\right.$, no prelo), Ewers (1930*), Gurney $\left(1933^{*}\right)$, Harding \& Smith (1974*), Harris (1978), Herbst (1960, 1962), Juday (1915), Kiefer (1928b, 1929b*, 1936a, 1952b*, 1956, 1960*', 1973*, 1978b), Lindberg (1954a,b, 1956b*), LUffler (1961, 1963), Manfredi (1925*), Marsh (1910*, 1913, 1919, 1931), Martínez de Ferrato (1967), Monchenko (1974*), Mrázek (1901), Osorio-Tafall (1943, 1944), Pearse (1938b), Pennak (1963*, 1978*), Plesa(1981*), Reddell (1965), Richard (1897), Ringuelet (1958a,b, $1962,1968)$, Ringuelet et al. (1965), Rioja (1940a, b), Rylov (1948*), Smith \& Fernando (1978, 1980*), 
Thiêbaud (1914), C. B. Wilson (1936), Yeatman (1959), Zuñiga \& Domínguez (1977).

$6 \mathrm{~b}$.

Cerda interna distal do artículo terminal do endópo do da quarta pata natatória desenvolvida normalmen= te, ultrapassando o ápice do artículo (Fig. 70)... - Macrooyclops albidus f. principalis Herbst, 1962 Brasil (Amazonas); Venezuela; limitada à América do Sul. Rios e lagos; possivelmente prefere águas ácidas. Comprimentos dos sexos não dados. Ver Dussart (no prelo*), Gessner \& Hammer (1967), Herbst(1967).

7a.(2) Série de espínulos na face dorsal do ramo caudal arranjada transversal ou diagonalmente na direção da margem interna do ramo (Fig. 72).

7b. Série de espinulos na face dorsal do ramo caudal se estendendo quase verticalmente na direçäo da base do ramo (Fig. 71)... . . . .... .... - .Paracyclops fimbriatus poppei (Rehberg, 1880) Brasil (Rio de Janeiro); Paraguai; Africa, América do Norte e Europa. Agua rasa com detrito, e äguas subterrâneas. Fêmea 0,62-0,95 $\mathrm{mm}$; macho 0,70-0,85 $\mathrm{mm}$. Ver Dussart (1969*), Gurney $\left(1933^{*}\right)$, Harding \& Smith $\left(1974^{*}\right)$, Kiefer (1929b*, 1931b, 1960*), Lindberg (1954a, 1958), Monchenko (1974*), Pennak (1963*, 1978*), Reddell (1965), Rylov (1948*), Van Douwe (1912), Yeatman (1959*).

8a.(7) Ramos caudais próximos na base (separados por uma distância menor que a largura do ramo), paralelos ou divergentes, 3,5 - 4 vezes mais longos que lar gos (Fig. 74) ... . . . 9

8b. Ramos caudais pröximos na base e paralelos; 2,4-2,9 vezes mais longos que largos (Fig. 76) $\ldots . .10$

8c. Ramos caudais separados na base por uma distầncia maior que a largura do ramo, paralelos ou divergentes, e quase sempre mais de 3 vezes (normalmente 4,6 vezes) mais longos que largos (Figs. 72, 73) .. ..Paracyclops fimbriatus fimbriatus (Fischer, 1853) Brasil (Distrito Federal, Rio Grande do Sul, São Paulo); Argentina, Chile, Paraguai, Uruguai, Vene zuela, e possivelmente Colómbia e Peru; cosmopoli ta. Zona litorânea de lagos; brejos, ảguas subter râneas. Fêmea $0,70-1,5 \mathrm{~mm}$; macho 0,70-1,0 mm. Notar que os caracteres das sub-espécies do grupo fimbria tus sensu lato frequientemente se sobrepōem um a outro. No entanto, formas morfometricamente idênticas podem ser isoladas na reprodução (Frenzel, 1976

1977). Ver Armengol (1978*), Brehm (1935), Briañ (1926), Chappuis (1927), Cicchino (1974*), Cole (1976), Daday (1902b, 1905), Delachaux (1928), Duki na $(1956 *)$, Dussart (1969*, 1982a*), Ewers (1930*), Gurney $(1933 *)$, Harding \& Smith (1974*), Herbst (1959*, 1960*), Infante et al. (1979*), Juday(1915), Kiefer (1926b*, $1929 a^{*}, b^{*}, 1931 b, 1943,1952 a$

$1960 *)$, Lindberg (1954a*,b, 1958), Marsh (1910*), Matsumura-Tundisi \& 0 . Rocha (1983*), Monchenkó (1974*), Mrázek (1901), Olivier (1955), Osorio Ta - 
$9 a .(8)$

$9 b$. 10a.(8) Ramo caudal cerca de 2,4 vezes mais longo que lar

fall (1943), Reddell (1965), Reid (no prelo), Ri chard (1897), Ringuelet (1958a,b, 1962, 1968), Rioja $(1940 a, b), 0$. Rocha \& Matsumura-Tundisi (1976*), Rylov (1948), Thiébaud (1914), C. B. Wilson (1936), Yeatman (1959), Zuñiga \& Domínguez (1977)

Comprimento da cerda lateral do ramo caudal 2 vezes ou mais a largura do ramo caudal (Fig. 74) ..... - Paracyclops fimbriatus andinus Lindberg, 1957b Equador, Peru; limitada à América do Sul. Lagos. Fê mea 0,93-1,18 $\mathrm{mm}$; macho $1,10 \mathrm{~mm}$. Ver Lindber $\bar{g}$ $\left(1958^{*}\right)$, Loffler $\left(1963^{*}\right)$.

Comprimento da cerda lateral do ramo caudal menos de 2 vezes a largura do ramo caudal (Fig. 75)..... - Paracyclops fimbriatus chiltoni (Thomson, 1882) Sinônimos: $P$. chiltoni, $P$. finitimus, $P$. fimbriatus forma finitima.

Brasil (Rio Grande do Sul); Chile, Equador, Para guai, Peru, Uruguai, Venezuela; cosmopolita. Águas lênticas e subterrâneas. Fêmea $0,60-1,0 \mathrm{~mm}$; macho 0,50-0,86 mm. Ver Brehn (1936a), Dussart (1982a*) Frenzel (1976, 1977), Gurney (1933*), Harding(1955), Kiefer (1928a, 1929a,b*, 1931d), Lindberg (1954a, $\left.1955 a^{*}, 1957 b^{*}, 1958\right)$, Loffler $\left(1961 a^{*}, b, 1963^{*}\right)$, Monchenko (1974*), Plesa (1981), Ringuelet (1958a, go; tegumento do metassomo e urossomo liso (Fig.76) go; : Paracyclops andinus Kiefer, igs7 Lago Titicaca; limitada a América do Sul. Zona lito rânea. Fêmea $0,73 \mathrm{~mm}$; macho $0,65 \mathrm{~mm}$.

10b. Ramo caudal 2,9 vezes mais longo que largo; exoesqueleto do terceiro, quarto e quinto segmento torácico e de todos os segmentos abdominais ornamentado com linhas de micro-ondulações (Fig. 77). .. -Paracyclops pilosus Dussart, no prelo Venezuela; limitada à América do Sul. Rios. Fêmea e macho $0,59 \mathrm{~mm}$.

11a.(2) Margem interna do ramo caudal com séries dorsoven trais de cérdulas piliformes (Fig. 79). .12 12a. (11) Somente a cerda espiniforme interna ou nenhuma cer12a. (11) Somente a cerda espiniforme interna ou nenhuma cer-
da da quinta pata da fêmea atingindo a margem poste rior do segmento genital; cerda espiniforme interna da sexta pata do macho 1,5 vezes mais longa que as cerdas mediana e externa... . . ...13

12b. As cerdas da quinta pata da fềmea, todas espiniformes, atingindo ou ultrapassando a margem posterior do segmento genital; cerdas da sexta pata do macho de comprimentos quase iguais (Figs. 78-80).

$\because: \quad$ Ectocyclops herbsti Dussart, no prelo Sinônimo: $E$. hirsutus de Herbst (1959). Brasil (São Paulo); Venezuela; limitada à América do Sul. Lagoas e brejos. Fêmea $0,82 \mathrm{~mm}$; comprimento do macho não dado.

13a.(12) Cerda espiniforme interna da quinta pata da fêmea 
quase igual às cerdas mediana e externa; antênula do macho com 17 artículos (Figs. 81-83). . ... - .. ...Ectocyclops phaleratus (Koch, 1838) Argentina, Colômbia, Paraguai, Suriname, Venezuela; registros duvidosos no Brasil (Santa Catarina e Rio Grande do Sul); cosmopolita. Primariamente bentônica, na zona litorânea de lagos e brejos, e bromé lias. Fêmea 0,82-1,26 mm; macho 0,70-1,0 mm. Ver $\underline{A}$ melina $(1927 *)$, Brian (1926), Chappuis (1917), Cicchino (1974), Comita (1951*), Daday (1905*), Dodds (1926), Dukina (1956*), Dussart (1969*, 1982a*), Ewers $\left(1930^{*}\right)$, Fryer $\left(1955^{*}\right)$, Gurney (1933*), Har ding \& Smith (1974*), Juday (1915), Kiefer (1927b , $\left.1929 b^{*}, 1930 a^{*}, 1960^{*}\right)$, Lindberg (1954a,b, 1957a*), Lucks (1929*), Marsh (1910*, 1913), Monchenko (1974*), Pearse (1922), Pennak (1963*, 1978*), Pesta (1927), Picado (1913), Richard (1897), Ringuelet (1958a,b, 1962, 1968), Rylov (1948*), Smith \& Fernando (1978, $\left.1980^{*}\right)$, Thiébaud (1914), Van Douwe (1912), Yeatman (1959*)

13b. Cerda espiniforme interna da quinta pata da fêmea mais longa que as cerdas mediana e externa; antênula do macho com 14 artículos (em formas neotropi cais) (Fig. 84). Ectocyclops rubescens Brady, 1904 Vários autores consideram esta como sub-espécie de $E$. phaleratus.

Brasil (Amazonas, Distrito Federal, Pará, São Pau10); Colômbia, Paraguai, Venezuela; circum-tropical. Primariamente bentônica, nas margens de lagos, brejos e àguas efêmeras. Fêmea 0,72-0,90 mm; macho 0,60-0,62 mm. Ver M. A. J. Carvalho (1971*), Cipol1 i \&. A. J. Carvalho (1973), Dussart (1969*,1974, $1982 a^{*}$, b), Fryer $\left(1955^{*}\right)$, Gurney $\left(1933^{*}\right)$, Herbst $\left(1962^{*}\right)$, Kiefer $\left(1927 \mathrm{~b}, 1929 \mathrm{~b}^{*}, 1952 \mathrm{~b}^{*}, 1956^{*}\right)$, Lind berg (1951*, 1954a, 1957a*), Lowndes (1930*, 1934), Matsumura-Tundisi \& 0 . Rocha $(1983 *)$, Montiel \& Zoppi de Roa (1979), Rylov (1948), 0. Rocha \& Matsú mura-Tundisi (1976*).

14a. (11) Ramo caudal do macho, curto e tão longo quanto largo; comprimentos das cerdas apicais interna e exter na do ramo caudal mais ou menos iguais (Fig. 85)... $\because$. Ectocyclops bromelicola Kiefer, 1935b Brasil (Pernambuco); limitada à América do Sul. Bro mélias. Macho 0,60 mm; fêmea desconhecida.Ver Fryer (1955*), Lindberg (1954a, 1957a*), Schubart (1938)

14b. Ramo caudal 1,6 vezes mais longo que largo em ambos os sexos; cerda apical externa do ramo caudal cerca de 2 vezes o comprimento da cerda apical interna ; antênula da fêmea com 8 artículos (Fig. 86). . . .

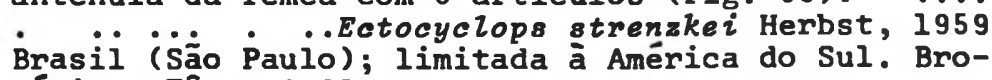
mélias. Fêmea $0,62 \mathrm{~mm}$; macho $0,56 \mathrm{~mm}$.

15a.(4) Ramo caudal $1,8-3$ vezes mais longo que largo. ...16 15b. Ramo caudal somente $1,5-1,7$ vezes mais longo que 
16a. (15) Espinho apical interno do articulo terminal do endố podo da quarta pata natatória $2,2-3,1$ vezes o com primento do próprio artículo; ramo caudal $1,7-2,0$ vezes mais longo que largo (Figs. 87,88 ).

- Tropocyclops prasinus meridionalis (Kiefer, 193ia) Sinônimo: T. prasinus forma peruviana lindberg, 1955a,b. Brasil (São Paulo, Rio de Janeiro; regis tros duvidosos no Rio Grande do Sul e Santa Catarina); Argentina, Bolívia, Chile, Peru, Uruguai, Vene zuela; possivelmente Ilhas Malvinas, Paraguai e Te $\bar{r}$ ra do Fogo; limitada à América do Sul. Planctốnicà em lagos. Fèmea 0,55-0,78 mm; macho 0,56-0,60 mm Ver Bonetto \& Martínez de Ferrato,(1966), Brehm (1928, 1935), Brian (1926), Cicchino (1974*), Daday (1902a,b, 1905*), Harding (1955*), Kiefer (1927a , $1929 b, 1956^{*}, 1957 *$, 1959*), Lindberg (1954a* 1955a*,b, 1957b), Lơffler (1958, 196i), Mrázeḱk (1901), Pennak (1963), Pesta (1927), Richard(1897), Ringuelet (1955b, 1958a,b, 1959b, 1962, 1968), T Scott (1914), Sendacz \& Kubo (1982*), Thomasson (1955), Van Douwe (1912)

16b. Espinho apical interno do artículo terminal do endó podo da quarta pata natatória 1,5 - 2,0 vezes mais longo que o próprio artículo; ramo caudal 2-2,6 ve zes mais longo que largo (Figs. 89-9l). . ..... Tropocyolops prasinus prasinue (Fischer, 1860) Brasil (Distrito Federal, Minas Gerais); Colómbia ; registros de outros países sulamericanos são provavelmente confundidos com $T$. $p$. moridionalis (ver discussão de Kiefer, 1959); fora da América do Sul, cosmopolita. Euritópica em lagos, àguas correntes e ăguas subterrâneas; âguas doce e salobra: Fêmea 0,48-0,95 $\mathrm{mm}$; macho 0,47-0,70 mm. Ver Amelina (1927*), Armengol (1978*), Brehm (1928), Brian (1926), Chappuis (1927), Collado et al. (no prelo), Daday (1902a,b*, 1905*), Dodds (1926), Domínguez \& Zuñiga (1979), Dussart (1969*, 1982b*), Ewers (1930*), Gurney (1933*), Harding \& Smith (1974*), Harris (1978), Herrick (1887*), Juday (1915), Kie fer $\left(1929 b^{*}, 1956 *, 1960^{*}, 1978 b\right)$, Lindberg (1954b, $\left.1955 a^{*}, 1956 b^{*}\right)$, L8ffler (1958), Manfredi (1923), Marsh (1910, 1913, 1919), Monchenko (1974*), Mrázeḱ (1901), Okano (1980), Osorio Tafall (1943, i944)

Pearse (1938), Pennak (1963*, 1978*), Pesta (1927), Plesa (1981*), Richard (1897), Rioja (1940a,b,1942), Rylov (1948*), T. Scott (1914*), Torres et al (1980), Uéno (1939), Van Douwe (1912), Yeatman (1959*), Zuñiga \& Domínguez (1978).

17a.(15) Cerda apical interna do ramo caudal cerca de 1,62,0 vezes mais longa que a cerda apical externa; ar tículo terminal do endópodo da quarta pata natató ria cerca de 2,6 vezes mais longo que largo (Figs. $92,93)$. . . . .... . . . . - Tropocyciops schubarti schubarti Kiefer, $1935 \dot{b}$ 
Brasil (Pernambuco, São Paulo); limitada à Anérica do Sul. Bromélias. Fêmea $0,54-0,60 \mathrm{~mm}$; macho 0,44 $-0,46 \mathrm{~mm}$. Ver Herbst $(1959 *)$, Lindberg (1954a, 1955a*), Schubart (1938)

17b. Cerda apical interna do ramo caudal cerca de 1,4 ve zes mais longa que a cerda apical externa; artículo terminal do endopodo da quarta pata natatoria 2 vezes mais longo que largo (Figs. 94, 95). .... . . Tropocyclops schubarti dispar Herbst, 1962 Brasil (Pará); limitada à América do Sul. Na àgua a cumulada em cascas de Castanhas-do-Pará. Fémea 0,5市 $\mathrm{mm}$; macho 0,50 $\mathrm{mm}$.

18a. (4) Ramo caudal da fêmea com una série de espínulos ("serra") que se estende somente até a metade de sua margem externa; esta série é, às vezes, rudimen tar, sendo composta de somente $3-4$ espínulos... . $1 \overline{9}$ 18b. Serra do ramo caudal da fêmea estendendo-se alèm da metade de sua margem externa. .. .25

19a. (18) Margem interna do ramo caudal lisa. . . 20 19b. Parte anterior da margem interna do ramo caudal hir suta (Figs. 96-98) . ... .... … .Eucyciops neotropicus Kiefer, $19 \dot{9} \dot{\mathrm{bb}}$ Brasil (Pernambuco); limitada à América do Sul. Açu des. Fêmea $0,94 \mathrm{~mm}$; macho $0,74 \mathrm{~mm}$. Ver Lindberg (1954a,b*, 1957a*), Ringuelet (1958a*), Schubart (1938).

20a.(19) Serra estendendo-se sobre a metade da margem exter na do ramo caudal. . . 2 I

20b. Serra mais curta, não alcançando a metade da margem externa do ramo caudal. . .22

2la. (20) Ramo caudal 4 vezes mais longo que largo; serra variável, composta de 4-10 ou as vezes 17 espínulos, alcançando ou não a metade da margem externa do ra-

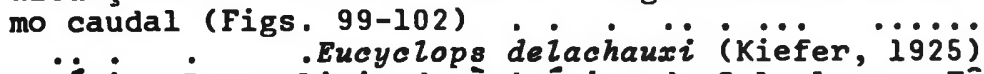
Bolivia, Peru; limitada à América do Sul. Lagos. Fế mea 0,95-1,0 $\mathrm{mm}$; comprimento do macho não dado. Ver Delachaux (1928), Harding (1955), Kiefer (1926b*, $\left.1929 b^{*}, 1943,1952 a\right)$, Lindberg (1954a, b*, 1955a, $\left.1957 a, b^{*}\right)$

21b. Ramo caudal 5 vezes mais longo que largo; serra estendendo-se sobre a metade ou até toda a margem externa do ramo caudal (Figs. 103, 104).. . ..... .. Eucyclops sersulatus (Fischer, 1851) Sinồnimo: $\dot{E}$. agilis (Koch, 1838) o nome serrulatus, embora seja preferido pela grande maioria de pesqui sadores, é confuso; o nome agilis $\bar{e}$ favorecido por alguns (ver discussōes de Gurney, 1933, e de Yeat man, 1959)

Brasil (São Paulo; registros duvidosos no Rio Grande do Sul e em Santa Catarina); Argentina, Bolívia, Chile, Equador, registros duvidosos na Colómbia, Pa raguai, Terra do Fogo, Venezuela; fora da Américá do Sul, cosmopolita. Espécie muito comum e euritópi ca em lagos, àguas efêmeras, rios e águas subter râneas; àguas doce e salobra. Fémea $0,65-1,50 \mathrm{~mm}$; 
macho 0,65-0,81 $\mathrm{mm}$. Ver Amelina (1927*), Armengol $(1978 *)$, Auvray \& Dussart $(1966 *)$, Bonetto \& Martinez de Ferrato (1966), Brian (1926), Chappuis(1927), Cicchino (1974*), Comita (1951), Daday (1902b 1905), Deevey \& Deevey (1980), Dodds (1926), Dukiná (1956*), Dussart (1982a), Ekman (1905), $\left(1930^{*}\right)$, Gurney $\left(1933^{*}\right)$, Harding (1955), Harding \& Smith (1974*), Harris (1978), Infante et al. (1978), Juday (1915), Kiefer (1929b*, 1960*, 1973*,1978b), Lindberg (1954a,b*, 1957a*,b), Loffier (1961b

1963*), Manfredi (1923), Marsh (1910, 1913, 1919), Martínez de Ferrato (1967), Monchenko (1974*), Mrázek (1901), Osorio Tafall (1943), Pearse (1922 1938b), Pennak (1963*, 1978*), Pesta (1927), Ri chard (1897), Ringuelet (1958a*, 1962, 1968), Rylov (1948), Sendacz \& Kubo $(1982 *)$, Smith \& Fernando (1978, 1980*), Steinitz-Kannan (1979), Steinitz-Kan nan et al. (1983), Thiêbaud (1914), C. B. Wilson (1936), Yeatman (1959*), Zuñiga \& Domínguez (1977, 1978)

22a. (20) Ramos caudais da fêmea e do macho cerca de 4 vezes mais longos que largos. . . . . 23

22b. Ramo caudal da fêmea 4,4-8,6 vezes, geralmente mais de 5,5 vezes mais longo que largo (ramo caudal do macho mais curto) . ... . . . . 24

23a. (22) Artículo terminal do endópodo da quarta pata natató ria 1,6 vezes mais longo que largo; serra do ramo caudal muito curta, se estendendo até $1 / 8$ da margem externa; cerda lateral do ramo caudal mais curta que a largura do ramo (Figs. 105-107)...... .... - ... .Eucyclops alticola Kiefer, 1957 Lago Titicaca; limitada à Anérica do Sul. Fêmea $1,16 \mathrm{~mm}$; comprimento do macho não dado.

23b. Artículo terminal do endópodo da quarta pata natató ria 2,0 vezes mais longo que largo; serra do ramó caudal se estendendo de $1 / 3$ até $1 / 2$ da margem exter na do ramo; cerda lateral do ramo caudal igual ou mais longo que a largura do ramo.

24a. (22) Comprimento do espinho interno da sexta pata do macho cerca de $0,06 \mathrm{~mm}$; artículo terminal do endópodo da quarta pata natatória 2 vezes mais longo que lar go; ramo caudal da fêmea cerca de 8 vezes mais lon= go que largo (Figs. 108-111)..

.. ... Eucyclops neumani neumani (Pesta,igi7) Brasil (Amazonas); Argentina, Bolívia, Paraguai, Pe ru, Uruguai e possivelmente Chile. Vários registros sulamericanos de $E$. macrurus são provavelmente $E$. neumani (Lindberg, 1954a). Aguas correntes e zona litorânea de lagos. Fêmea $1,04-1,53 \mathrm{~mm}$; macho 0,88$1,22 \mathrm{~mm}$. Ver Brehm (1935a), Brian (1927), Cicchino (1972*, 1974*), Daday (1905), Gurney (1933*), Herbst (1962*), Kiefer (1929b*, 1936b, 1960), Lindberg (1954a, b*, 1955a*, 1957a*, b), Richard (1897), Rin guelet (1958a*,b, i959b, 1962, 1968), Ringuelet $\frac{\bar{t}}{\bar{t}}$ 
al. (1965), Thiébaud (1914), Wierzejski (1892), Yeat $\operatorname{man}(1959 *)$

24b. Comprimento do espinho interno da sexta pata do macho cerca de $0,085 \mathrm{~mm}$; artículo terminal do endópodo da quarta pata natatória 1,66 vezes mais longo que largo; ramo caudal da fémea muito variável, 4,4 $-8,6$ vezes mais longo que largo (Figs. 112-114) .... . ... Eucyclops neumani titicacae Kiefer, 1957 Lago Titicaca e Venezuela; limitada à América do Sul. Planctốnica em lagos; água doce e possivelmen te àgua salobra oligo-halina. Fêmea 1,0-1,27 m ; macho 0,85-1,16 mm. Ver Harding (1955*), Infante $\left(1978^{*}\right)$, Infante et al. (1979*), Pearse (1922)

25a.(18) Cerda externa da quinta pata inserida a um nível consideravelmente mais distal que o espinho interno (Fig. 116) . . . . . . 26

25b. Cerda externa da quinta pata inserida mais ou menos no mesmo nível que o espinho interno (Fig. 122)..29

26a. (25) Cerda externa e cerda mediana da quinta pata não in seridas no mesmo nível no artículo (Fig. 116). .27

26b. Cerda externa e cerda mediana da quinta pata inseri das no mesmo nível do artículo (Fig. 119) . .28

27a. (26) Ramo caudal cerca de 5 vezes mais longo que largo; espinho interno da quinta pata muito forte, 5 vezes ou mais a largura das cerdas externa e mediana... 27b. $\quad$ Ramo caudal $\dot{3}, \dot{6}-4$ vezes mais longo que largo; espinho interno da quinta pata fino, sendo somente 2 ve zes a largura das cerdas externa e mediana (Figs. 115-117). .. .Eucyclops leptacanthus Kiefer, 1956 Macho descrito por Collado et al. (no prelo) Venezuela; Costa Rica. Lagoas. Fêmea 0,70-0,76 mm; comprimento do macho não dado.

28a. (26) Espinho interno da quinta pata mais curto que a cer da externa; serra do ramo caudal composta de mais de 20 espínulos; ramo caudal da fêmea 3,2-4,6 vezes mais longo que largo (Figs. 118-120). ... . . ... . . Eucyciops ensifer Kiefer,ig36e Brasil (Rio Grande do Sul, São Paulo); Argentina, Chile, Peru, Terra do Fogo; Cuba, Nicarágua. Lagos. Fêmea 0,92-1,25 mm; macho 0,85-0,95 mm. Ver Bonetto \& Martínez de Ferrato (1966), Cole (1976), Herbst (1960*), Lindberg (1954a*, b*, 1955a*, 1957a*), Mat sumura-Tundisi \& 0 . Rocha $\left(1983^{*}\right)$, Plesa (1981*), Ringuelet (1958a*,b, 1968), 0.Rocha \& Matsumura-Tun disi (1976*), Thomasson (1955).

28b. Espinho interno da quinta pata mais comprido que a cerda externa; serra do ramo caudal composta normal mente de 4-6, às vezes de 10 ou 17 espínulos; ramō caudal da fémea 4,0 vezes mais longo que largo. . . . .. Eucyclops delachauxi (ver 2la)

29a. (25) Ramo caudai da fềmea 6,5 vezes mais longo que lar go; cerda mediana da quinta pata muito longa, sendo 2,65 vezes mais longa que o espinho interno e 4 vezes mais longa que a cerda externa (Figs. 121-123). 
$\because$ :.: ..Eucyclops solitarius Herbst, 1959 Brasil (Rio Grande do Sul, são Paulo); limitada à América do Sul. Lagoas. Comprimento da fêmea não dạ do; macho desconhecido.

29b. Ramo caudal da fêmea 3,5-5,7 vezes mais longo que largo; cerda mediana da quinta pata da fềmea 2 ve zes ou menos o comprimento da cerda externa. . . 30

29c. Ramo caudal da fêmea curto, 2-3 vezes mais longo que largo; cerda mediana da quinta pata da fêmea cerca de 2 vezes o comprimento da cerda externa..36

30a. (29) Espinhos apicais do articulo terminal do endópodo da quarta pata natatória com flanges largas e serrilhadas; cerda apical externa do ramo caudal 2 vezes mais longa que a largura do ramo caudal; ramo caudal 4,5 vezes mais longo que largo (Figs. 124 126).... . . . . EucycZops sp., Herbst, 1959 Brasil (São Paulo); limitada à América do Sul. Margem arenosa de rios. Comprimento da fêmea não dado; macho desconhecido.

30b. Um ou ambos espinhos apicais do articulo terminal do endópodo da quarta pata natatória com espinulos (Fig. 132); cerda apical externa do ramo caudal mais de 2 vezes mais longa que a largura do ramo

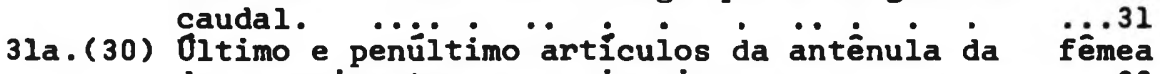
de comprimentos quase iguais. ... $\quad . .32$

31b. Oltimo artículo da antênula da fềmea consideravel mente mais longo (acima de 1,5 vezes) que o penúltí mo artículo (Figs. 127-129) .. ... .. . .... - .. Eucyclops silvestrii (Brian, i9ij) Argentina, Uruguai, Venezuela; limitada à América do Sul. Rios e águas subterrâneas. Fêmea 0,68-1,00 $\mathrm{mm}$; macho, 0,76-0,84 mm. Ver Brehm (1935), Kiefer (1929b*, 1936e*), Lindberg (1954a*, $\left.b^{*}, 1957 a^{*}\right)$, Ringuelet (1958a*, b, 1959b, 1968).

32a. (31) Cerda externa da quinta pata mais curta que a cerda mediana (Fig. 134).. . .. .33

32b. Cerda externa da quinta pata sempre un pouco mais longa que a cerda mediana e cerca de 2 vezes mais longa que o espinho interno; ramo caudal $3,6-4,1$ vezes mais longo que largo (Figs. 130-132).. .... .Eucyclops serrulatus var. chilensis Loffler, 196la Chile; limitada à América do Sul. Lagos. Fêmea 0,96 $\mathrm{mm}$; macho desconhecido.

33a. (32) Antênula não alcançando a margem posterior do seg mento cefálico; ramo caudal cerca de 4 vezes mais longo que largo. . . . . . 34

33b. Antênula ultrapassando a margem posterior do seg mento cefálico, e atingindo até a margem posterior do segundo segmento torácico; ramo caudal 5-5,7 vezes mais longo que largo. . . . . . . 35

34a. (33) Espinho interno da quinta pata da fểmea inserido un pouco mais distalmente que a cerda externa; espinho apical interno do artículo terminal do endópodo da quarta pata natatória ligeiramente mais longo $(1,1$ vezes) que o prôprio articulo; membrana hialina, fí 
namente denteada nos ültimos 3 artículos da antênula; comprimentos das 2 cerdas externas da sexta pata do macho quase iguais ao do espinho interno(Figs. 133-136)..Eucyclops pseudoensifer Dussart, no prelo Venezuela; limitada a Anérica do Sul. Lagos. Fêmea $0,77 \mathrm{~mm}$; macho $0,76 \mathrm{~mm}$.

34b. Espinho interno da quinta pata da fêmea inserido ao mesmo nível que a cerda externa; espinho apical interno do artículo terminal do endópodo da quarta pa ta natatória distintamente ( 1,3 vezes) mais longō que o próprio artículo; membrana hialina nos últi mos 3 articulos da antênula lisa; comprimento das 2 cerdas externas da sexta pata do macho cerca da metade daquele do espinho interno (Figs. 137-140). - . Eucyclops prionophorus Kiefer, 1931b,c Registros duvidosos no Paraguai e Uruguai; América do Norte. Lagoas e riachos. Fêmea 0,70-0,94 mm; ma cho $0,80 \mathrm{~mm}$. Ver Harris (1978), Kiefer (1936 *), Lindberg (1954a, $\left.b^{*}, 1957 a^{*}\right)$, Pennak (1963*, 1978*), Yeatman (1959*)

35a. (33) Espínulos da serra do ramo caudal da fêmea dispos tos em dois grupos, às vezes separados por um peque no espaço, os 7-11 espínulos proximais sendo mais curtos que os 7-8 distais; ramo caudal 5-5,7 vezes (média 5,4 vezes) mais longo que largo (Figs. 141 143) ...... Euoyclops demacedoi Lindberg, $1957 \mathrm{~b}$ Peru; limitada à América do Sul. Lagos. Fêmea 1,091,25 mm; macho 0,95-1,05 mm.

35b. Espínulos da serra do ramo caudal da fêmea dispos tos numa série contínua, o tamanho dos espínulos au mentando ligeiramente na parte distal; ramo caudal cerca de 5 vezes mais longo que largo.

36a. (29) Espinho interno da quinta pata da fêmea mais curto que o próprio artículo, fino e mais estreito na base que as cerdas; artículo terminal do endópodo da quarta pata natatória cerca de 2,5 vezes mais longo que largo (Figs 144-146) . $\ldots \ldots$. . . . que largo (Figs 144-146) Brasil (Parä); limitada a América do Sul. Igarapés. Comprimento da fêmea não dado; macho desconhecido

36b. Espinho interno da quinta pata da fêmea 1,5 vezes mais longo que o proprio artículo, forte e mais lar go na base que as cerdas; artículo terminal do endō podo da quarta pata natatória somente 1,5 vezes mais longo que largo (Figs. 147-149)...... .... - . Eucyclops breviramatus Loffler, 1963 Equador (montanhas andinas e bacia do rio Amazo nas); limitada à América do Sul. Lagos. Fêmea 1,16 $\mathrm{mm}$; macho 0,98 $\mathrm{mm}$ : Ver Steinitz-Kannan (1979), Stei nitz-Kannan et al. (1983). 
VI. Chave para a subfamilia Cyclopinae:

la.

$1 \mathrm{~b}$.

$2 a \cdot(1)$

$2 \mathrm{~b}$.

3a. (1)

3b.

$4 a \cdot(3)$

$4 \mathrm{~b}$.

5 a. (4)

$5 \mathrm{~b}$.
Todas as patas natatórias biarticuladas.. . ...2 Todas ou algumas patas natatörias triarticuladas. .. . .. . . . . . . . .3 Quinta pata biarticulada, o artículo proximal fun dido ao segmento torácico, restando dele apenass uma cerda situada ântero-lateralmente à inserção do artículo distal; antênula com 10-13 ou 17 artí culos. . ... ... . .24 Quinta pata inteiramente fundida ao segmento torá cico, restando dela uma cerda anterior e duas cer das inseridas numa protuberância pequena posteri= or; antênula con 11 artículos (Figs. 150-152). .

. Allocyclops neotropicalis Dussart, no prelo Venezuela; limitada à America do Sul. Zona litorâ nea de rios. Macho $0,59 \mathrm{~mm}$; fémea desconhecida. Artículo distal da quinta pata com 1 cerda e 1 es pinho de comprimentos desiguais (Figs. 154, 157, 167); antênula com 11,12 ou 17 artículos. . .4 Artículo distal da quinta pata com 2 cerdas ion -

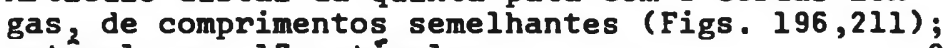
antênula com 17 artículos. .. . . . 9 Espinho da quinta pata inserido terminal ou sub terminalmente na margem interna da mesma, prolongando-se além do artículo (Fig. 157)... .5 Espinho da quinta pata inserido na margem interna da mesma e não alcançando o ápice do artículo

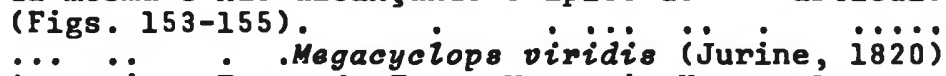
Argentina, Terra do Fogo, Uruguai, Venezuela; cos mopolita. Zona litorânea de lagos, e águas subter râneas; ăguas doce e salobra oligo-halina. Fêmeà 1,30-3,00 mm; macho 1,25-1,6 mm. Ver Amelina (1927*), Ammengol (1978*), Brian (1926), Chappuis (1927), Dukina (1956*), Dussart (1969*), Gurney $\left(1933^{*}\right)$, Harding \& Smith $(1974 *)$, Juday (1915), Kiefer (1928b, 1929b*, 1960*, 1973*, 1978b), Lind berg (1954a,b, 1956*), Marsh (1910*), Monchenkō $(1974 *)$, Pearse (1922), Ringuelet (1958a, 1962 , 1968), Rylov (1948), Thomasson (1955), Yeatman (1944*,1959)

Espinho interno da quinta pata mais longo que o artículo; cérdulas piliformes do ramo caudal dispostas em vârias séries laterais sobre as margens interna e externa do ramo (Figs. 156-158)..... - $\quad$ - Diacyclops uruguayensis (Kiefer, 1935a) Uruguai; limitada a América do Sul. Lagoas. Fêmea $1,30-1,40 \mathrm{~mm}$; macho 1,04 $\mathrm{mm}$. Ver Brehm (1935)

Lindberg ( $1954 \mathrm{a})$; a diagnose do gênero de Yeatmań (1944), e a chave de Dussart (1969) para espécies européias

Espinho interno da quinta pata mais curto que o artículo (Fig. 167); margem interna do ramo cau dal lisa ou hirsuta, se hirsuta, as cérdulas pili formes dispostas somente ao longo da margem in 
terna do ramo. . ... .....Acanthocyclops (6) Ver a diagnose de Yeatman ( 1944$)$, a chave mundial de Kiefer (1929b), as chaves de Dussart (1969), Kiefer (1960), e Monchenko (1974) para espécies européias, e a de Ringuelet (1958a) para espécies argentinas. Diacyclops, Megacyclops Acanthocy clops sensu stricto säo considerados por alguns autores como subgéneros do gênero Acanthocyclopo sensu lato

6a. (5) Margem interna do ramo caudal lisa. . . ...7 $6 \mathrm{~b}$.

$7 a \cdot(6)$

$7 \mathrm{~b}$.

Margem interna do ramo caudal hirsuta (Figs. 159161) ..Acanthocyclops skottsbergi Lindberg, 1949 Chile (estuário do rio Pera); limitada à Ánérica do Sul. Macho 1,03 mm; fêmea desconhecida. Ver Lindberg (1954a, 1961).

Antênula com 17 artículos. . ... .....8 Antênula com 11 ou 12 artículos (Figs. 162-164).. .. .Acanthocyclops michaelseni (Mrázek, 1901) Argentina, Chile, Terra do Fogo, Ilhas Malvinas; limitada à América do Sul. Euritópica em lagos

Fêmea 0,93-1,42 mm; macho 0,75-1,20 mm. Ver Bo netto \& Martínez de Ferrato (1966), Ekman (1905*), Kiefer $\left(1929 b^{*}\right)$, Lindberg $(1949 *$, 1954a, 1961), livier (1955), T. Scott (1914*), Ringuelet (1955b, $1958 a, b, 1962,1968,1972)$, Ringuelet et $a l$. (1955, 1965)

8a.(7) Expansão anterior do segmento genital da fêmea pouco desenvolvida e arredondada; artículo terminal do endópodo da quarta pata natatória 2,34 vezes mais longo que largo (Figs. 165-168) ..... ....Acanthocyclops robustus (G. O. Sars, 1863) Sinốnimo: A, vernalis forma robusta te Monchenko (1974). Argentina, Bolívia, Equador, Peru, Uru guai; cosmopolita. Lagos, àguas efêmeras e águas subterrâneas. Fêmea $1,03-1,98 \mathrm{~mm}$; macho $0,79-1,5$ mm. Ver Armengol $(1978 *)$, Bonetto \& Martínez de Ferrato (1966), Brehm (1935), Cicchino (1974*), Daday (1902b), Dussart (1969*), Ewers $(1930 *)$, Gur ney $\left(1933^{*}\right)$, Kiefer $\left(1929 b *, 1943,1952 a, 1960^{*}\right.$, $\left.1973^{*}, 1976^{*}, 1978 b\right)$, Lindberg (1954a,b, 1955a 1957b), LUffier (1963*), Marsh (1910*), Martí nez de Ferrato (1968), Mastrantuono \& Stella (1974*), Monchenko (1974*), Mrázek (1901), 01i vier (1955), Orellana (1967), Paggi \& Paggi(1974), Price (1958), Ringuelet (1958a,b, 1959b, 1962 , $1968,1972)$, Rylov (1948*), G. O. Sars (1913), Yeatman (1959).

8b. Expansão anterior do segmento genital da fêmea bem desenvolvida e aguda; artículo terminal do en dópodo da quarta pata natatória 2,06 vezes mais longo que largo (Figs. 169-172). . . . -Acanthocyclops vernalis (Fischer, 1853) Bolivia, Peru, possivelmente Argentina; cosmopoli ta. Lagos, águas efêmeras, e águas subterrâneas ; àguas doce e salobra. Fêmea $0,99-1,80 \mathrm{~mm}$; machó 
96.

10a. (9) Expansão interna do segundo artículo do basípodo

$10 \mathrm{~b}$.

$11 a \cdot(10)$

0,80-1,50 mm. Ver Amelina (1927*), Armengol(1978), Chappuis (1927), Comita (1951), Cuzon du Rest (1963), Daday (1902b), Delachaux (1928), Dukina (1956), Dussart (1969*), Gurney (1933*), Harding (1955), Harding \& Smith $(1974 *)$, Harris (1978), Kiefer (1926b, 1927b, 1952a, 1960*, 1976*,1978b*), Lindberg (1957b), Manfredi (1925*), Marsh (1910), Mastrantuono \& Stella (1974*), Monchenko (1974*), Mrázek ( $1901 *)$, Osorio Tafall (1944), Pennak (1963*), Price (1958*), Reddell (1965), Rylov $\left(1948^{*}\right)$, G. 0. Sars (1913), Smith \& Fernando

(1978*, $1980 *)$, Yeatman (1944*, 1959*).
Cerda interna do artículo distal da quinta pata inserida próximo à metade da margem interna do artículo (Fig. 196); ültimo artículo da antênula da fêmea $3-5$ vezes mais longo que largo.. .... . .. .............Mesocyclops (i0) Ver a diagnose de Kiefer $(1929 a)$, as discussōes e chaves de Coker $(1943,1945)$, a revisão de Van de Velde (1984) para as espécies africanas, as chaves mundiais de Kiefer (1930b) e de Lindberg (1956), e a de Ringuelet (1958a) para as espécies argentinas.

Cerda interna do artículo distal da quinta pata inserida teminal ou subterminalmente (Fig.211) ; último artículo da antênula da fêmea cerca de 2 vezes mais longo que largo..... Thermocyclops (19) Ver a diagnose de Kiefer (1929a), as chaves mun diais do mesmo autor $(1929 b, 1930 \mathrm{~b})$, a revisāo do gênero por Sewell (1957/1964), a chave de Einsle (1970) para espécies africanas, e a de Ringuelet (1958a) para espécies argentinas. Alguns autores consideram Thermocyclops como un subgênero de Mesooyclops sensu lato. da primeira pata natatória sem cerda (Fig.174).11 Expansão interna do segundo artículo do basípodo da primeira pata natatoria com cerda (Figs. 181, $185)$.

Oltimo segmento do metassomo (anterior ao segmento genital) e margem interna do ramo caudal $1 i$ sos; segmento genital e artículos da antênula sem depressoes circulares (Figs. 173-177).

- ... … Mesocyclops leuckar ti ( Claus, $i \ddot{8 j} j$ ) sensu stricto Kiefer (1981). $M$. Zeuckarti sensu stricto está confinada à Europa e ao oeste da Ásia (Kiefer, 1981). A maioria dos registros sulamericanos de "M. leuckarti" é provavelmente $M$. meridianus, $M$. brasilianus ou ou tras espécies ainda não descritas (Kiefer, 1981). Registros duvidosos no Brasil (Amazonas, Rio de Janeiro, Santa Catarina), Argentina, Colômbią, Pa raguai, Venezuela. Euritópica em lagos e ăguas subterrâneas; águas doce e salobra. Fêmea $0,9-1,3$ $\mathrm{mm}$; macho 0,75-1,0 mm. Ver Amelina (1927*), Brian $(1926 *)$, Brandorff (1978), Candelas \& Candelas (1963), Coker (1943), Comita (1951), Daday (1905), 
Deevey \& Deevey (1980), Dodds (1926), Dussart (1969*, 1982a*), Ewers $(1930 *)$, Gurney (1933*), Harding \& Smith $(1974 *)$, Hardy $(1978,1980)$, Kie fer $\left(1928 b, 1929 a^{*}, b^{*}, 1930 b^{*}, 1960^{*}, 1973^{*}\right.$, $\left.1978 b^{*}, 1981^{*}\right)$, Lindberg (1954a,b, 1956*), Marsh (1910*, 1913*, 1919, 1931), Monchenko (1974*), Pearse (1911, 1938), Pennak (1963*, 1978*), Plesa (1981*), Richard (1897), Rylov (1948*), Saunders \& Infante $(1981 *)$, Smith \& Fernando $(1978,1980 *)$, Straškraba (1969), Strałkraba et al. (1969), Thiëbaud (1914), Thomasson (1959), Van Douwe (1912*), Van de Velde $(1984 *)$, Yeatman (1959*)

11b. Oltimo segmento do metassomo e margem interna do ramo caudal com pelos finos; artículos da antênula $e$, em algumas fémeas, segmento genital com séries de pequenas depressões circulares (Figs. 204-206). - .. .Mesooyclops aspericornis (Daday, 1906) Colómbia, Venezuela; Antilhas, Africa, Âsia e i Ihas do Oceano Pacífico. Euritópica em corpos pe quenos de água, brejos e lagos. Fêmea 1,18-1,50mm; macho 0,76-0,83 mm. Ver Dussart (1982b*, no pre 10), Gurney $\left(1933^{*}\right)$, Infante (1978), Infante et al. $\left(1979^{*}\right)$, Kiefer $\left(1929 b, 1981^{*}\right)$, Saunders \& Infante $(1981 *)$, Van de Velde $(1984 *)$.

12a. (10) Margem livre da placa basal da quarta pata natatória sem ornamentos (Fig. 180); ramo caudal $2,7-4$ vezes (normalmente $3-3,5$ vezes) mais longo que lar go. . . . ... .. . . . $1 \overline{3}$ 12b. Placa basal da quarta pata natatöria com um dente ou espinho que se prolonga alem da margem livre da placa (Fig. 189); ramo caudal $3-5$ vezes mais longo que largo.... $: \dot{j}_{0} \quad \ldots \ldots 14$ 13a. (12) Ramo caudal $2,7-3,5$ vezes mais longo que largo, com margem interna hirsuta; margem livre da placa ba sal da quarta pata natatória sempre sem ornamentos; receptáculo seminal com expansōes laterais estreitas mas não filiformes, e ligeiramente recurvadas posteriormente (Figs. 178-182) ... .... . . . É possivei que $M$. brasilianus seja um sinônimo de $M$. meridianus; comparar as discussões de Dussart (no prelo), Harding (1955) e Loffler (1963)

Brasil (Anazonas, Pará); Colómbia, Venezuela, possivelmente Peru e Nicaragua. Planctônica em lagos e äguas efêmeras; águas doce ou salobra oligo-hali na. Fêmea $0,85-1,15 \mathrm{~mm}$; macho 0,62-0,74 mn. Ver Cipölli \& M.A.J.Carvalho (1973), Coker $\left(1943^{*}\right)$, Co le (1976), Epp \& Lewis (1980), Gessner (1968), Herbst $\left(1960^{*}\right)$, Harding $\left(1955^{*}\right)$, Infante (1978), Infante et al. (1979*), Kiefer (1956*), Lindberg (1954a, 1956*), Loffler (1963*), Montiel \& Zoppi de Roa (1979), Zoppi de Roa (1972)

13b. Ramo caudal 3,0-4 vezes mais longo que largo, com margem interna lisa ou finamente hirsuta; fêmeas de populaçōes diferentes possuem ou não 1 espinho 

14a. (12) Receptáculo seminal com expansões laterais muito

estreitas, quase filiformes e mais ou menos hori -
zontais (Fig. 183); fêmeas de populaçóes diferen -
tes possuem ou não l espinho na margem livre da
placa basal da quarta pata natatória.
.

estreitas, quase filiformes e mais ou menos hori -
zontais (Fig. 183); fêmeas de populaçóes diferen -
tes possuem ou não l espinho na margem livre da
placa basal da quarta pata natatória.
.

estreitas, quase filiformes e mais ou menos hori -
zontais (Fig. 183); fêmeas de populaçöes diferen -
tes possuem ou não l espinho na margem livre da
placa basal da quarta pata natatória.
-

estreitas, quase filiformes e mais ou menos hori -
zontais (Fig. 183); fêmeas de populaçóes diferen -
tes possuem ou não l espinho na margem livre da
placa basal da quarta pata natatória.
.

na margem livre da placa basal da quarta pata nata tória; receptáculo seminal com expansões laterais filiformes e mais ou menos horizontais (Figs. 183186). .Mecocyclops meridianus (Kiefer, 1926a) Ver comentärio sobre sinonimia, $13 \mathrm{a}$.

Brasil (Amazonas): Argentina, Bolivia, Equador, Pa raguai, Uruguai, Ilha de Bonaire, e possivelmenté Venezuela. Planctônica em lagos; äguas doce e salo bra oligo-halina. Fêmea 0,80-1,5 mm; macho $0,85 \mathrm{~mm}$. Ver Bonetto \& Martínez de Ferrato (1966), Brandorff et al. (1982), Brehm (1935), Coker (1943*), Daday $\left(1905^{*}\right)$, Dussart (no prelo*), Harding $\left(1955^{*}\right)$, Kie fer $\left(1929 a^{*}, b^{*}, 1930 b^{*}, 1933 b\right)$, Lindberg (1954a,b, $1956 *, 1957 \mathrm{~b})$, Loffler $(1963 *)$, Lowndes (1934), Margalef (196i*), Pesta (1927*), Ringuelet (1958a,

14b. Receptä́culo seminal com expansōes laterais muito largas, recurvadas posteriormente e arredondadas nas extremidades (Fig. 187) ... ... .15

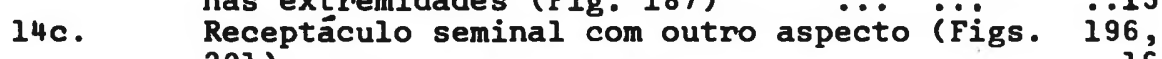
15a.(14) Ramo caudai cerca de $\dot{3}, \dot{2}$ vezes mais iongo que iargo; artículo terminal do endópodo da quarta pata natatória cerca de 2,5 vezes mais longo que largo (Figs. 187-190).: : Mesocyclops longisetus iongisetus (Thiébaud, igiu) Brasil (Amazonas, Distrito Federal, Minas Gerais, Parā, Rio de Janeiro, Rio Grande do Sul, São Pau10); Argentina, Bolívia, Chile, Colómbia, Paraguai, Venezuela; Antilhas e Anérica do Norte até o sul dos Estados Unidos. Euritópica em lagos e äguas subterrâneas; âguas doce e salobra oligo-halina Fêmea $1,26-2,8 \mathrm{~mm}$; macho 0,82-0,91 $\mathrm{mm}$. Ver Bonetto \& Martínez de Ferrato (1966), Brandorff (1977) Brandorff et al. (1982), M.A.J Carvalho (1975), Cí pôlli \& M.A.J. Carvalho (1973), Coker (1943*), Daday $(1905 *)$, Domínguez \& Zuñiga (1979), Dussart

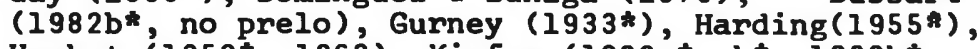
Herbst (1959*, 1962), Kiefer (1929a*, $b *, 1930 b^{*}$, $\left.1936 a^{*}\right)$, Lindberg (1954a*, b, 1956*, 1957b), LUf fler (1958), Lowndes (1934*), Matsumura-Tundisi \& 0 . Rocha (1983*), Matsumura-Tundisi et a 2 . (1981), Okano (1980), Oliveira (1954*, Plesa (1981*), Reddell (1965), Richard (1897), Ringuelet (1958a, b, 1962 , 1968), Ringuelet et ai. (1965), o Rocha \& Matsumura-Tundisi $(1976 *)$, Saunders \& Infante (1981), Sendacz \& Kubo $\left(1982^{*}\right)$, Smith \& Fernando $\left(1978 *, 1980^{*}\right)$, Thomasson $(1957 *, 1959)$, Torres et al. (1980), Wierzejski (1892*), Yeatman (1944*), Zuñiga \& Dómínguez (1977, 1978) 
15b. Ramo caudal 3,6-4,4 vezes mais longo que largo; ar tículo terminal do endópodo da quarta pata natatória cerca de 4 vezes mais longo que largo (Figs. 191,192 ). ..............

Mesocyclops iongisetus var.araucanus Lüfiler, ig6la Chile, Terra do Fogo; limitada à América do Sul Planctônica em lagos grandes. Fêmea 1,13-1,62 mm; macho 0,95-1,10 mm. Ver Campos et al. (1974), Lind berg (1954a*), LUffler (1961b), Thomasson (1955).

16a.(14) Ramo caudal 4,5-5,2 vezes mais longo que largo; ca da segmento abdominal com séries laterais de espínulos (Fig. 193). . . ... .. .17

16b. Ramo caudal $2,1-3,5$ vezes mais iongo que largo;seg 17a. (16) Articulo terminal do endópodo da quarta pata natatória cerca de 2,6 vezes mais longo que pata natapinho apical interno deste articulo mais curto $(0,9: 1)$ que o espinho apical externo (Figs. 193 195 ).

Mesocyciops annuiatus annuiatus (Wierzejski, $\ddot{1} \ddot{8} \ddot{2}$ ) Argentina, Bolivia, Chile, Paraguai, Peru, Uru guai; limitada à América do Sul. Zona litorânea de lagos. Fêmea 1,3-2,0 mm; macho 1,0-1,19 mm. Ver Brian (1926, 1927*), Brehm (1935), Coker (1943*), Daday (1902b*, 1905*), Harding (1955), Kiefer (1926a, 1929a*, $\left.\mathrm{b}^{*}, 1930 \mathrm{~b}^{*}, 1957^{*}\right)$, Lindberg(1954a, 1955a*, 1956*, 1957b), Mräzek (1901), Richard (1897b*), Ringuelet (1958a, b, 1962, 1968), Saun ders \& Infante (1981), Thomasson (1956, 1959,1963)

17b. Artículo terminal do endópodo da quarta pata natatória cerca de 2,1 vezes mais longo que largo; espinho apical interno deste artículo 1,3 vezes mais longo que o espinho apical externo (Figs. 196-198) ......Mesocyclops annulatus diversus Herbst, 1962 Brasil (Anazonas; limitada à América do Sul. Rios. Fêmea 1,05 mm; macho desconhecido.

18a.(16) Espinho apical interno do artículo terminal do en- dópodo da quarta pata natatória pouco maior do que a metade do comprimento do espinho apical externo (Figs. 199, 200).. . . . . . . ....... - ... Mesocyclops edax (S.A. Forbes, 1890) Antilhas, América Central e do Norte; registros du vidosos na Colômbia e Venezuela. Brejos e zona li= torânea de lagos. Fêmea 0,95-1,5 mm; macho 0,75 $0,90 \mathrm{~mm}$. Ver Coker (1943), Cole (1976), Comita (1951), Deevey \& Deevey (1980), Gurney (1933), Har ris (1978), Herrick (1887*), Infante et al. (1979), Kiefer (1929a, b*, 1930b, 1981), Lindberg (1954a), b, 1956), Marsh (1910), Osorio Tafall (1944), Pearse $(1916,1922)$, Pennak (1963*, 1978*), Smith \& Fernando $\left(1978,1980^{*}\right)$, Wyngaard \& Chinnappa $(1982 *)$, Yeatman $(1959 *)$

18b. Espinho apical interno do artículo terminal do endópodo da quarta pata natatória quase igual ou pou co mais longo $(0,9-1,2: 1)$ que o espinho apical ex- 
$19 a \cdot(9)$

$19 \mathrm{~b}$.

20a.(19)

$20 \mathrm{~b}$.

2la.(19) Espinho apical interno do artículo terminal do endópodo da quarta pata natatória 2-5 vezes mais lon

go que o espinho apical externo.

$21 b$.

Ramo caudal $3,5-4,5$ vezes mais longo que largo..20 Ramo caudal $2,1-3,0$ vezes mais longo que largo..21 Espinho apical interno do artículo terminal do endópodo da quarta pata natatória $2,0-2,3$ vezes mais longo que o espinho apical externo (Figs. 207-209) - . Thermocyclops tenuis (Marsh, 1910) Macho descrito por Reed \& McQuaid (1966)

Brasil (Pernambuco); Argentina, Paraguai; América Central e do Norte até o sul dos Estados Unidos Euritópica em lagos e águas subterrâneas. $0,80-1,10 \mathrm{~mm}$; macho 0,65 mm. Ver Coker (1943*) Collado et al. (no prelo), Dodds (1926), Harris (1978), Kiefer (1929a, $\left.b^{*}, 1930 b, 1931 b, 1936 d^{*}\right)$ Lindberg (1954a,b), Lowndes (1934*), Marsh (1913*, 1931), Pearse (1938), Pennak (1963*, 1978*), Rin guelet (1958a,b, 1959, 1968), Rioja (1942), Schu bart (1938), Sewell (1957/1964*), Smith \& Fernando (1978*, 1980*), Wierzejski (1892), C. B. Wilson (1936), Yeatman $(1959 *)$.

Espinhos apicais do artículo terminal do endópodo da quarta pata natatória iguais em comprimento (Figs. 210-213).. .... Thermocyclops brehmi (Kiefer, ig27) Argentina, Uruguai; registro duvidoso na Venezue la; limitada à América do Sul. Planctônica em rios e lagos. Fêmea 1,0 mm; macho desconhecido. Ver Brehm (1928), Coker (1943*), Kiefer (1929b* $\left.1930 b^{*}\right)$, Lindberg (1954a), Margalef (1961), Ringué let $(1958 \mathrm{a}, \mathrm{b}, 1959)$, Sewell $(1957 *)$, Van de Veldè (1978). terno (Figs. 201-203).

... . Mesocyclops eilipticus Kiefer, 1936d Brasil (Amazonas, Pernambuco); Venezuela; registro duvidoso em Cuba. Euritópica em lagos, riachos e águas efêmeras; àguas doce e salobra oligo-hali na. Fêmea 0,92-1,21 $\mathrm{mm}$; macho 0,68-0,77 $\mathrm{mm}$. Ver Coker $\left(194^{*}\right)$, Dussart (no prelo*), Gessner(1956), Herbst $\left(1962^{*}\right)$, Kiefer $(1956 *)$, Lindberg (1954a, 1956), Montiel \& Zoppi de Roa (1979), Saunders \& Infante (1981), Schubart (1938), Smith \& Fernando $(1978 *, 1980 *)$. dópodo da quarta pata natatória muito mais curto $(0,6: 1)$ que o espinho apical externo (Figs. 214 216).: . Thermocyclops inversus Kiefer, 1936b Brasil (Pernambuco); Cuba, América Central e México. Euritópica em lagos, rios, açudes e ăguas subterrâneas. Fêmea 0,60-0,70 mm; comprimento do ma cho não dado. Ver Coker (1943*), Cole (1976), Collado et al. (no prelo*), Deevey \& Deevey (1980)

Kiefer (1938a*), Lindberg (1954a,b), Marsh(1913*), Osorio Tafall (1941, 1943, 1944), Rioja (1940a,b), 
Schubart (1938), Sewell (1957/1964*), Smith \& Fernando $(1978 *, 1980 *)$, Straškraba et al. (1969), Uéno (1939), Yeatman (1959*)

22a. (21) Espinho apical interno do artículo terminal do endópodo da quarta pata natatória cerca de 2 vezes mais longo que o espinho apical externo. . .23

22b. Espinho apical interno do artículo terminal do endópodo da quarta pata natatónia cerca de 5 vezes mais longo que o espinho apical externo (Figs. 217 -219). .. .Thermocyclops minutus (Lowndes, 1934) Brasil (Amazonas, Bahia, Minas Gerais, Pará, Per nambuco, Sāo Paulo); Argentina, Paraguai; limitada à Anérica do Sul. Euritôpica em lagos e riachos Fêmea 0,5-0,65 $\mathrm{mm}$; macho 0,49-0,54 $\mathrm{mm}$. Ver Bran dorff (1977, 1978), Brandorff \& Andrade (1978), Brandorff et $a z$. (1982), Coker $\left(1943^{*}\right)$, Gouvêa $(1978 *)$, Hardy $(1978 *, 1980)$, Herbst $(1967 *)$, Kiefer $\left(1936 d^{*}\right)$, Lindberg $(1954 a)$, Matsumura-Tundisi \& 0 . Rocha (1983*), Matsumura-Tundisi \& Tundisi (1976), Matsumura-Tundisi et al. (1981), Okano (1980), Ringuelet (1958a, 1959, 1968), 0. Rocha \& Matsumura-Tundisi $(1976 *)$, Schubart (1938), Sen dacz \& Kubo $(1982 *)$, Sewell (1957/1964*).

23a. (22) Expansões laterais do receptáculo seminal relativa mente largas, comprimento total lateral sendo cerca de 4 vezes a largura das expansōes; ramo caudal $2,1-2,4$ vezes mais longo que largo (Figs. 220-223) ... . Thermocyclops crassus (Fischer, 1853) Sinônimo possịvel: T- hyalinus (Rehberg, 1880).

Esta espécie è facilmente confundida com $T$. deci piens; então, a maioria dos registros neotropicais de $T$. crassus ou de $T$. hyalinus é duvidosa.

Costa Rica; registros duvidosos no Brasil (São Pau 10), Argentina, Venezuela, América Central e AntiIhas; fora da regiāo neotropical, cosmopolita em regiốes tropicais e subtropicais. Planctónica em lagos e lagoas efémeras; aguas doce e salobra oligo-halina. Fêmea 0,62-1,02 $\mathrm{mm}$; macho 0,56-0,70 mm. Ver Bonetto \& Martínez de Ferrato (1966), Coker $\left(1943^{*}\right)$, Collado et al. (no prelo*), Deevey \& Deevey $(1980)$, Dussart (1969*, 1982a*), Einsle (1970), Epp \& Lewis $(1980)$, Gurney $\left(1933^{*}\right)$, Harding \& Sinith $(1974 *)$, Kiefer (1929b, 1930b*, 1938b*, , $1952 b^{*}, 1960^{*}$, 1973*, 1978b), Lindberg (1954b), Mat́ sumura-Tundisi et al. (1981), Monchenko (1974*), Richard (1895), Ringuelet (1972), Rylov (1948*), G. 0. Sars (19i4), Sewell (1957/1964*), Smith \& Fernando $(1978$, 1980*), Wierzejski (1892), Yeatman $(1959)$, Zoppi de Roa (1972)

23b. Expansồes laterais do receptáculo seminal relativa mente estreitas, comprimento total lateral sendo cerca de 5,5 vezes a largura das expansōes; ramo caudal 2,5-2,8 vezes mais longo que largo (Figs. 224-227). Thermocyclops decipiens (Kiefer, 1929c) 

espinho e 1 cerda curtos, de comprimentos quase iguais (Figs. 230, 233); se a cerda externa fốr mais de 2 vezes o comprimento do espinho apical, a cerda está inserida longe do espinho (Fig. 234) ; antênula com 10 ou 11 artículos.. .. . . . 25

24b. Artículo distal da quinta pata com $i$ cerda ionga e 1 espinho apical curto, inseridos proximamente (Fig. 243); antênula com 11-13 ou 17 artículos....

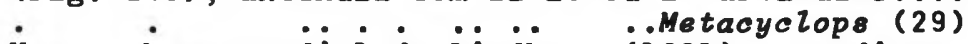
Ver a chave mundial de Lindberg (1961) e as discus söes de Plesa (1981) e de Yeatman (1944).

24c. Artículo distal da quinta pata com 1 cerda apical longa e pode ou não apresentar 1 espínulo ou cérdu la, inserido subapicalmente ou na sua margem inter na (Figs. 274, 279, 286); antênula com 10-12 artí-

25a. (24) Articulo distal da quinta pata pequeno, mais iargo que longo (Figs. 233, 234); antênula com 10 ou il artículos.... . . . . . . . . . 26

25b. Artículo distal da quinta pata mais longo que largo; antênula com 11 artículos (Figs. 228-230).... : : Menzeliella staheli (Chappuis, i 1917 ) Sinốnimo: Graeterielia surinamensis de Brehm (1926)

Suriname; limitada à América do Sul. Musgos. Fêmea 0,5-0,6 mm; macho desconhecido. Ver Kiefer (1928b*, $\left.1929 b^{*}\right)$, Lindberg (1954a, $\left.d *\right)$.

26a. (25) Artículo distal da quinta pata com 1 espinho api cal curto, e 1 cerda externa inserida longe do espinho e 2 vezes ou mais longa que este (Fig. 234); ramo caudal $3-5$ vezes mais longo que largo; antênu la com 11 artículos. : Apocyclope (27) Ver diagnose e discussõ̉es de Lindberg (1942, 1961) e a chave mundial do mesmo autor (1954c).

26b. Artículo distal da quinta pata com 2 cerdas cur tas, de comprimentos iguais; ramo caudal curto e tão longo quanto largo; antenula com 10 ou 11 artí culos (Figs. 231-233) .... ... .... … ...Mrcocyclops operculatus (Chappuis, $19 i 7$ ) Sinônimo: Graeterielza operculata de Brehm (1926) 
$27 \mathrm{a} \cdot(26)$
$27 \mathrm{~b}$.

$28 a \cdot(27)$

$28 \mathrm{~b}$.

$29 a$

29c.

$30 a \cdot(29)$

$30 \mathrm{~b}$.

$31 \mathrm{a} \cdot(30)$
Brasil (Pernambuco); Suriname; limitada à América do Sul. Musgos, bromélias. Fêmea 0,27-0,36 mm; macho 0,44-0,46 mn. Ver Brehm (1927), Chappuis (1927), Gurney (1933), Kiefer (1927b, 1928b*, 1929b*, $\left.1935 b^{*}\right)$, Lindberg (1954a, $\left.d^{*}\right)$, Schubart (1938)

Antênula atingindo o fim do cefalotórax .28 Antênula atingindo o bordo posterior do segundo segmento torácico (Figs. 234-236).. ... . ..... .. - . Apocyclops panamensis (Marsh, 1913) Sinōnimo: A. panamensie var. tannica Davis (1948). Ilha de Aruba e outras Antilhas; América Central e do Norte. Euritópica em lagos e rios; águas doce e salobra. Fêmea 0,53-0,73 $\mathrm{mm}$; macho 0,51-0,71 mm. Ver Bjornberg (1971), Comita (1951), Cuzon du Rest (1963), Davis (1950), Dodds (1926), Kiefer (1929b*, $\left.1933 b^{*}, 1936 a^{*}\right)$, Lindberg (1942, 1954b, $\left.c^{*}, 1961\right)$, Marsh (1919), Pennak (1963*), Smith \& Fernando (1978*, 1980*), Straßkraba et al. (1969), Yeatman (1959*, 1963*).

Ramos caudais da fêmea separados na base por uma distância igual à largura do ramo; margem e face anterior da placa basal da quarta pata natatória ornamentadas com 3 séries de espínulos de cada lado (Figs. 237-239). . ... ... . .... - ...Apocyclops distans (Kiefer, 1956) Venezuela; Antilhas. Lagos; àgua salobra: Fêmea 0,55 $\mathrm{mm}$; macho 0,47-0,54 mm. Ver Dussart (1982 $\left.\mathrm{b}^{*}\right)$, Gessner (1956), Lindberg (1961)

Ramos caudais da fêmea próximos na base, separados por uma distância menor que $1 / 3$ da largura do ramo; margen da placa basal da quarta pata natatória ornamentada somente com 2-5 dentes pequenos de cada lado (Figs. 240-242)

- ... - . Apocyclops procerus (Herbst, $i \ddot{95}$ ) Brasil (Rio de Janeiro); Peru; limitada à América do Sul. Lagoas; águas doce e salobra. Fêmea 0,60 $\mathrm{mm}$; macho 0,56 mm. Ver Herbst (1960*), Luffier (1963).

Antênula com 11 ou 12 artículos. ....... .30 Antênula com 13 artículos (Figs. 243-245). .... - .. .Metacyclops tredecimus (Lowndes, 1934) Argentina, Paraguai, Venezuela; limitada à Ámérica do Sul. Lagoas pequenas. Fémea 0,71-0,86 mm; macho $0,66 \mathrm{~mm}$. Ver Dussart (no prelo), Lindberg (1954a), 1961*), Ringuelet (1958a*, 1968).

Antênula com 17 artículos (Figs. 246-248). . $\ddot{3}$; - : : : Metacyolopo grandis (Kiefer, 1935a) Uruguai; limitada à América do Sul. Lagoas. Fêmea 1,50-1,60 mm; macho desconhecido. Ver Brehm(1935), Lindberg (1954a, 1961*)

Antênula com ll artículos.. . . . .

Antênula com 12 artículos. . $\quad .32$ Articulo terminal do endópodo da quarta pata natatória com 1 espinho apical, mais curto $(0,8: 1)$ que o articulo terminal (Figs. 249-251). 
$31 \mathrm{~b}$.

- Metacyclops curtispinosus Dussart, no prelo Venezuela; limitada à América do Sul. Fêmea 0,60 $\mathrm{mm}$; macho desconhecido.

$32 a \cdot(30)$
$32 b$.
$33 a \cdot(32)$

Articulo terminal do endópodo da quarta pata natatória com 2 espinhos apicais, ambos de comprimento quase igual ao do articulo terminal (Figs. 252 254). ..Metacyclops subaequalis Dussart, no prelo Venezuela; limitada a América do Sul. Rios. Fêmea $0,56 \mathrm{~mm}$; macho desconhecido.

Ramo caudal 2-3 vezes mais longo que largo. . 33

Ramo caudal 4-5 vezes mais longo que largo. .34 Cerda apical interna do ramo caudal 1,5 vezes mais longa que a cerda apical externa; cerda apical da quinta pata longa, atingindo o terço posterior do segmento genital (Figs. 255-258). . . . ... -... . Metacyclops brauni Herbst, 1962 Brasil (Anazonas); limitada a América do Sul. Igarapés; àguas pretas. Fêmea $0,88-1,09 \mathrm{~mm}$; macho des conhecido.

33b. Cerda apical interna do ramo caudal menor que o comprimento da cerda apical externa $(0,7: 1)$; cerda apical da quinta pata curta, atingindo o terço anterior do segmento genital (Figs. 259-261) ..... - Metacyclops Laticornis (Lowndes, i934) Paraguai; limitada à América do Sul. Brejos. Fêmea $1,1 \mathrm{~mm}$; macho desconhecido. Ver Lindberg (1954a, $1961 *)$.

34a.(32) Artículo distal da quinta pata tão longo quanto largo; cerda apical interna do ramo caudal menor que a cerda apical externa $(0,7: 1)$; cerda apical mediana interna do ramo caudal 2 vezes ou menos 0 comprimento do ramo (Figs. 262-264).

...Metacyclops mendocinus (Wierzejski, is $\ddot{9} \ddot{\text { j }}$ Brasil (são Paulo); Argentina, Bolivia, Chile, Colómbia, Equador, Paraguai, Peru, Uruguai, Venezuela; America Central e Antilhas. Euritópica em la gos e rios; água doce e salobra. Fêmea 0,75- 1,17 $\mathrm{mm}$; macho 0,66-0,90 mm. Ver Bonetto \& Martínez de Ferrato (1966), Brehm (1928), M. A. J. Carvalho (1975), Cicchino $(1974 *)$, Daday $(1905 *)$, Delachaux (1928), Dussart (1979*), Harding (1955), Herbst $\left(1960^{*}\right)$, Kiefer $\left(1926 b^{*}, 1927 a, 1929 a^{*}, b^{*}\right)$, Lindberg ( $1954 \mathrm{a}, \mathrm{b}, 1957 \mathrm{~b}, 1961 *)$, Loffler (1961* $\left.1963^{*}\right)$, Lowndes $\left(1934^{*}\right)$, Margalef $\left(1961^{*}\right)$, Marsh $(1906 *)$, Mrázek (1901*), Olivier (1955), Petkovski $\left(1963^{*}\right)$, Richard (1895*, 1897a), Ringuelet (1958a, b, 1959b, 1962, 1972), Ringuelet et al. (1965), Sendacz (1978, no prelo), Sendacz \& Kubo (1982*), Sendacz et al. (no prelo), Smith \& Fernando(1978*, 1980*), Steinitz-Kannan (1979), Steinitz-Kannan et ą. (1983), Thiébaud (1914), Zuñiga \& Domínguez (1977).

34b. Artículo distal da quinta pata cerca de 1,5 vezes mais longo que largo; cerda apical interna e cerda apical externa do ramo caudal semelhantes em com - 
primento; cerda apical mediana interna do ramo cau dal $2,6-3,3$ vezes mais longa que o ramo . . ..35

35a.(34) Cerda apical externa do artículo distal da quinta pata $3-4$ vezes mais longa que o artículo (Figs 265-267) . . . ... . .... -Metacyclope leptopus leptopus (Kiefer, 1927a) Bolívia, Peru, possivelmente Venezuela; limitada à América do Sul. Planctônica em lagos andinos. Fê mea 1,00-1,33 $\mathrm{mm}$; macho 0,66-0,97 $\mathrm{mm}$. Ver Brehm (1951), Gessner \& Hammer (1967), Harding (1955), Kiefer (1929a*, b*, 1943, 1952a, 1957), Lindberg (1954a, 1955a*, 1957b*, 1961*), Loffler (1958, $1963^{*}, 1972$ ), Thomasson (1956).

35b. Cerda apical externa do artículo distal da quinta pata $1,5-2$ vezes mais longa que o artículo. .36

36a.(35) Espinho apical interno da quinta pata forte, mais largo que a cerda externa; margem livre da placa basal da primeira pata natatóría da fémea lisa (Figs. 268-270). ... ........ - Metacyclops leptopus mucubajiensis Kiefer, 1956 Venezuela; limitada a América do Sul. Planctônica em lagos. Fêmea 0,89-0,96 mm;macho 0,75 mm. Ver Dussart (no prelo*), Gessner \& Hammer (1967), Lind berg (1961*)

36b. Espinho apical interno da quinta pata mais fino que a cerda externa; margem livre da placa basal da primeira pata natatória da feemea com 4 dentes pequenos (Figs. 271-273)... .. . ... . Metacyolops leptopus venezolanus Kiefer, i 956 Venezuela; limitada à América do Sul. Planctônica em lagos. Fêmea $0,80 \mathrm{~mm}$; macho desconhecido. Ver Lindberg ( $\left.1961^{*}\right)$, Dussart (no prelo*)

37a. (24) Artículo distal da quinta pata mais longo que largo, com l cerda apical longa e 1 cérdula ou espínu lo inserido subterminalmente ou na margem interna, ou sem cérdula ou espínulo (Figs. 279,286, 289); antênula com 11 ou 12 artículos.. Microcyclops (38) Ver as diagnoses de Kiefer $(1929 a, b)$ e de Yeatman (1944), a chave mundial de Lindberg (1957a), e a de Ringuelet(1958a) para as espécies argentinas.

37b. Artículo distal da quinta pata reduzido a uma pe quena protuberância com 1 cerda; antênula com 10 ou 11 artículos (o quarto artículo às vezes somen te parcialmente dividido) (Figs. 274-277) ..... .Neutrocyclops brevifurca (Lowndes, 1934) Macho descrito por Dussart (1982b)

Brasil (Pernambuco, Säo Paulo); Colômbia,Paraguai, Venezuela; Antilhas. Zona litorânea de lagos. Fêmea 0,66-0,75 $\mathrm{mm}$; macho 0,48 mu. Ver Dussart (1982b*, no prelo*), Kiefer (1936 b*, 1956*), Lindberg (1954a), Matsumura-Tundisi \& 0 . Rocha(1983*), Montiel \& Zoppi de Roa (1979), 0. Rocha \& Matsumura-Tundisi (1976*), Schubart (1938)

38a.(37) Antênula com 11 artículos.

$38 \mathrm{~b}$.

Antênula com 12 artículos.

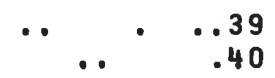


39a. (38) Artículo distal da quinta pata com 1 espínulo forte inserido subterminalmente na margem interna; ra mo caudal cerca de 2,7 vezes mais longo que largō e com 1 espínulo diminuto inserido no terço ante rior da margem externa (Figs, 278-281). . .

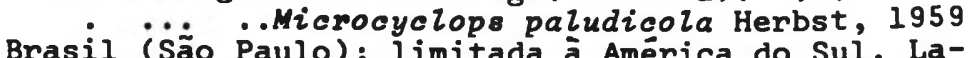
gos. Fémea 0,65 mn; macho desconhecido.

39b. Margem interna do artículo distal da quinta pata lisa; ramo caudal cerca de 3,0 vezes mais longo que largo e sem espínulo no terço anterior da margem externa (Figs. 282-286) .. .... . $\ldots$

Bolivia $\dot{0}$. Microcyclops alius (Kiefer, 1935a) Lagos. Fémea 0,56-0,70 mm; macho 0,47 mm. Central. Brehm (1935), Harding $\left(1955^{*}\right)$, Herbst $\left(1960^{*}\right)$, Lind berg (1954a, 1957a,b), Loffler (1961*, 1963) , Steinitz-Kannan (1979), Steinitz-Kannan et al. (1983), Zuñiga \& Domínguez (1977)

40a.(38) Margem interna do artículo distal da quinta pata com 1 espinho forte, inserido subterminalmente ou na margem interna (Fig. 289); ângulo interno do segundo artículo do basípodo da primeira pata nata tória sem cerda (Fig. II) .. . . . .4I 40b. Margem interna da quinta pata lisa ou com i cérdula piliforme ou 1 espínulo (Figs. 294, 303, 306) ; ângulo interno do segundo artículo do basípodo dá primeira pata natatória geralmente com cerda forte (Fig. 304) . .. ... . .. . .43

4la.(40) Cerda da quinta pata inserida no inicio da metade distal do artículo terminal (Figs. 287-289)

- Microcyclops finitimus Dussart, no prelo Venezuela; limitada a América do Sul. Lagos. Fêmea $0,89 \mathrm{~mm}$; macho desconhecido.

41b. Cerda da quinta pata inserida terminalmente no artículo terminal (Figs. 15, 290) 42

42a.(41) Ramo caudal 3-5 vezes mais longo que largo; artícu lo terminal do endópodo da quarta pata natatória 2,5-3 vezes mais longo que largo (Figs. 4-16). $\dot{ }$ ...Microcyclops anceps anceps (Richard, 1897a) Brasil (Distrito Federal, Rio de Janeiro, Rio Gran de do Sul, São Paulo); Argentina, Bolívia, Chile, Equador, Paraguai, Peru, Uruguai, Venezuela; Amérí ca Central e México. Plancton e zona litorânea dé lagos; brejos, äguas efêmeras. Fêmea 0,74-1,40 mm; macho 0,54-0,84 mm. Ver Brehm (1927, 1935), Brian (1926), Cicchino (1974b), Comita (1951*), Daday (1902a, 1905*), Dodds (1926), Harding (1955)

Herbst (1959*), Infante et ai. (1979*), Kiefer (1926a, 1928b, 1929b*, 1956*, 1957*), Lindberg (1954a,b, 1955a*, 1957a*,b), Loffler (1961a*, b, $1963 *)$, Lowndes $(1934 *)$, Marsh (1913*), Martínez de Ferrato (1967), Matsumura-Tundisi \& 0 . Rocha (1983*), Montiel \& Zoppi de Roa (1984), Mrázek (1901), Olivier (1955), Pesta (1927), Ringuelet 
42b. Ramo caudal 2,6 vezes mais longo que largo; artícu

(1958a,b, 1959b, 1962, 1968), Ringuelet (1955, 1965), Sendacz \& Kubo (1982*), Thiébaud et $a$. (1914), Thomasson $\left(1959^{*}\right)$, Zuñiga \& Domínguez (1977) lo terminal do endópodo da quarta pata natatória não mais que 2 vezes mais longo que largo (Figs 290-292) . - Microcyclops anceps pauxensis Herbst, 1962 Sinônimo: Microcyclopo anceps var. minor Dussart (no prelo).

Brasil (Amazonas); Venezuela; limitada à América do Sul. Lagos. Fêmea $0,63 \mathrm{~mm}$; macho desconhecido.

43a. (40) Placa basal da quarta pata natatória com 2 séries transversais de espínulos na face anterior; ramo caudal 2,8-5 vezes mais longo que largo e com 5-6 espínulos inseridos anteriormente à cerda lateral (Figs. 293-295)

... Microcyciope ceibaensis (Marsh, 1919) Sinônimo provävel: Microcyclops diversus Kiefer, $1935 a$.

Brasil (São Paulo); Bolívia, Peru, Uruguai, Vene zuela; América Central, México e Antilhas. Zona li torânea de lagos. Fêmea 0,60-1,16 mm; macho desconhecido. Ver Brehm (1935), Collado et al. (no prelo*), Comita (1951), Dussart (no prelo*), Gurney (1933), Harding (1955*), Herbst (1959*), Kiefer (1929a*,b, 1935a*, 1936a*), Lindberg (1954a, b, 1957a*, b), Lbffler (1958, 1963), Osorio Tafali (1941), Smith \& Fernando (1978*, 1980*)

43b. Placa basal da quarta pata natatória lisa; ramo caudal sem espínulos anteriores à cerda lateral , cerda lateral e estendendo-se até o meio dorsal e ventral do ramo. . . .. ... .44 44a. (43) Ramo caudal $2,25-4$ vezes mais iongo que iargo. .45 44b. Ramo caudal 5-6 vezes mais longo que largo. 47 45a.(44) Ramo caudal 2,25-2,5 vezes mais longo que largo; cerdas apicais medianas do ramo caudal com espínulos proximalmente, e cérdulas distalmente; artículo distal da quinta pata sem cérdula nem espínulo na margem interna (Figs. 296, 297) . : : . Microcyclops dubitabilis Kiefer, 1934 Possivelmente sinônimo de Microcyclops varicans (Sars, 1863)

Colômbia, Venezuela; América Central e Antilhas.Zo na litoránea de lagos. Fêmea $0,44-0,60 \mathrm{~mm}$; machō $0,38 \mathrm{~mm}$. Ver Collado et al. (no prelo*), Dussart (1982b*), Harding (1955), Herbst (1960*), Kiefer (1936a*, 1956*), Lindberg (1954b).

45b. Ramo caudal 3,2-4,4 vezes mais longo que largo; cer das apicais medianas do ramo caudal com ornamentação (cérdulas) homônoma ; artículo distal da quin ta pata geralmente com cérdula fina inserida nō terço distal da margem interna (Fig. 298) 
46a.(45) Artículo terminal do endópodo da quarta pata natatória $2-2,5$ vezes mais longo que largo; espinho apical interno deste artículo cerca da metade do comprimento do próprio artículo (Figs. 298-300)...; - Microcyclope varicans varicans (G.0.Sars, 1863) Brasil (Amazonas, Distrito Federal, Rio de Janei ro, São Paulo); Argentina, Paraguai, Peru, pos sivelmente Venezuela; fora da América do Sul, cosmopolita. Zona litoránea de lagos; águas doce e sa lobra oligo-halina. Fêmea 0,5-1,0 mm; macho 0,5 = $0,6 \mathrm{~mm}$. Ver Cipólli \& M.A.J Carvalho (1973), Cole (1976), Collado et al. (no prelo), Daday (1902b), Dussart $\left(1969,1982 a^{*}\right)$, Gurney $\left(1933^{*}\right)$, Harding (1955), Harding \& Smith $\left(1974^{\star}\right)$, Herbst (1959*, $1962)$, Kiefer (1928b, 1929b*, 1931b, 1956, 1960*), Lindberg ( $1954 \mathrm{a}, \mathrm{b}, 1957 \mathrm{a}, \mathrm{b})$, Lowndes (1934), Marsh (1910*,1913, 1919), Monchenko (1974*), Montiel \& Zoppi de Roa (1984), Richard (1895), Ringuelet (1958a*, 1968), Rylov (1948*), Smith \& Fernando $(1978$, 1980*), Van Douwe (1912), Yeatman (1944*)

46b. Artículo terminal do endópodo da quarta pata natatória 2,3-2,9 vezes mais longo que largo; espinho apical interno deste artículo mais curto que o pró prio artículo $(0,75: 1)$ (Fig. 301)... . . ... . Microcyclops varicans subaequalis (Kiefer, 1928c) Brasil (Amazonas); Venezuela; Africa, Ásia. Zona litorânea de lagos. Fêmea 0,71-0,90 mm; macho $0,61 \mathrm{~mm}$. Ver Gurney (1933), Herbst (1962), Kiefer (1929a*,b*, 1933c*, 1952b*, 1956), Lindberg(1939*).

47a.(44) Ramo caudal 5-6 vezes mais longo que largo, com 1 série de espínulos anterior à cerda lateral, esten dendo-se até 0 meio dorsal e ventral do ramo; arti culo distal da quinta pata com l cérdula na metade da margem interna; faces anteriores dos artículos terminais dos endópodos da segunda, terceira e quarta patas natatórias com grupo de espínulos inseridos numa escama (Figs. 302-305) . ... - :Microcyclops elongatus (Lowndes, 1934 ) Paraguai; limitada à América do Sul. Brejos. Fémea 1,0 mm; macho desconhecido. Ver Lindberg (1954a, $1957 a *)$

47b. Ramo caudal 6 vezes mais longo que largo, sem série de espínulos anterior à cerda lateral; margem interna do artículo distal da quinta pata lisa; es pínulos nas faces anteriores da segunda, terceirá e quarta patas natatórias, se presentes, não inseridos numa escama (Figs. 306, 307). ... .... - ....Microcyclops furcatus (Daday, i $\ddot{9} 0 \dot{5}$ ) Paraguai; limitada à América do Sul. Fêmea 0,75$0,80 \mathrm{~mm}$; macho desconhecido. Ver Kiefer(1929a,b*), Lindberg ( $\left.1954 a, 1957 a^{*}\right)$ 
AGRADECIMENTOS - Pelo auxílio e críticas extensivas e intensivas do manuscrito em värias fases de preparação, estendo os mais sinceros agradecimentos ao $\mathrm{Dr}$. Carlos Eduardo $F$ da Rocha. O Mestre Kiniti Kitayama também ajudou em questões gramaticais. Pelo interesse, sugestōes e empréstimo de espécimes, agradeço os Drs. Thomas E. Bowman, Bernard $H$. Dussart, Frank D. Ferrari e James F Saunders, III, e a Mestre Suzana Sendacz. Pelas muitas atos de auxílio e encorajamento, permaneço grata aos ex-colegas e alunos dos Departa mentos de Biologia Animal e de Biologia Vegetal da Universidade de Brasilia. A colaboração e boa vontade do pessoal da Biblioteca Central da Universidade de Brasília e das Smith sonian Institution Libraries foram de valor inestimável. As investigações e coletas no Brasil foram realizadas sob a licença do Conselho Nacional de Desenvolvimento Científico e Tecnológico ( CNPq) Agradeço os seguintes autores, socieda des e editoras, as quais graciosamente concederam licença para utilizar figuras: os Drs. Thomas E. Bowman, Bernard H. Dussart, C.H. Fernando, Frank D. Ferrari, Hans V. Herbst, Aí da de Infante, Friedrich Kiefer, Heinz Löffler, Carlos Eduar do $F$ da Rocha, e James $F$ Saunders, III; a Academia Brasi leira de Ciências (Anais); Akademische Verlagsgesellschaft Geest \& Portig K.-G. (Zeitschrift fulr wissenschaftliche Zoologie); Biological Society of Washington (Proceedings); Gustav Fischer Verlag (Beitrage zur neotropischen Fauna); Insti tut fur Meereskunde an der Universityt Kiel (Kieler Meeres = forschungen); Landessammlungen fur Naturkunde Karlsruhe (Bei trag der Naturkundliche Forschung von Sudwestdeutschland); Museum fur Naturkunde der Humboldt-Universityt zu

Berlin (Zoologischer Anzeiger), Rijksmuseum van Natuurlijke Histo rie, Leiden (Crustaceana), E. Schweitzerbart'sche Verlags buchhandlung (Nagele u. Obermiller (Archiv fllr Hydrobiologie e Zoologica); Smithsonian Institution Press (Smithsonian Contributions to Zoology, figuras $4 d, 6 a, b, f$ do artigo de Ferrari \& Bowman, 1980); The Crustacean Society (Journal of Crustacean Biology); The Linnaean Society of London (Tran sactions, Journal); e The Royal Swedish Academy of Sciences (Archiv for Zoologi).

\section{REFERENCIAS}

AMELINA, L. 1927. Die Susswasser Cyclopidenlarven. Arb.bioz. Stn Kosiino, 5:31-39 + 2 pranchas.

ARMENGOL, J. 1978. Los crustáceos del plancton de los embalses españoles. Oecol.aquat., 3:3-96.

AUVRAY, C. \& B. DUSSART 1966. Rōle de quelques facteurs du milieu sur le développement post-embryonnaire des Cyclopi des (Crustacés Copépodes). I. Généralités. Cas des Eucy = clops.Bull.Soc. zool. Brance, 91:477-491.

BACON, P.R. 1971. Plankton studies in a Caribbean estuarine environment. Caribb.J.Sc., 11:81-89.

BAIRD, W. 1843. Note on the luminous appearance of the sea, with descriptions of some of the entomostracous insects 
by which it is occasioned. Zoologist, 1:55-61.

BJÓRNBERG, T.K.S. 1959. Copepods as indicators of water masses off the Brazilian coast. $P$. 137-138 In International Oceanographic Congress Preprints. M.S. Sears, ed. 1022 p. American Association for the Advancement of Science, Nova York.

BJÖRNBERG, T.K.S. 1963. On the marine free-living copepods of Brazil. Bolm Inst.oceanogr., S Paulo, 13:3-142.

BJÖRNBERG, T.K.S. 1964. Copépodos. P. 207-222 In História Na tural de Organismos Aquäticos do Brasil. P. E. Vanzolini, ed. 452p. Fundação de Amparo à Pesquisa do Estado de São Paulo, São Paulo.

BJÖRNBERG, T.K.S. 1968 . Estägios de desenvolvimento de al guns copépodos marinhos planctónicos tropicais e subtropí cais. Faculdade de Filosofia de Ciências e Letras, Univ. São Paulo. 175p. Tese de doutoramento (mimeografado)

BJÓRNBERG,T.K.S. 1971. Distribution of plankton relative to the general circulation system in the area of the Carib bean Sea and adjacent regions. $\mathrm{P}, 343-356$ In UNESCO-FAO Symposium on Investigations and Resources of the Carib bean Sea and Adjacent Regions, Curacao, 1968. 545. UNES Co, Paris.

BJÖRNBERG, T.K.S. 1972. Developmental stages of some tropi cal and subtropical planktonic marine copepods. Stud. Fauna Curacao, 40:1-185.

BJÖRNBERG, T.K.S. 1981. Copepoda. P. 587-679 In Atlas del Zooplancton del Atläntico Sudoccidental y Métodos de Trabajo con Zooplancton Marino. D. Boltovskoy, ed. $\mathbf{x x x +}$ 936p. Instituto Nacional de Investigación y Desarrollo Pesquero, Ministerio de Comercio y Intereses Marítimos, Rep. Argentina.

BOLTOVSKOY, D. 1978 (1979) Características biogeográficas del Atlăntico Sudoeste: plancton. Physis, B.Aires, Ser.A, $38: 67-90$.

BONETTO, A.A. \& A. MART INEZ DE FERRATO 1966. Introducción al estudio del zooplancton de las cuencas isleñas del Parana medio. Physis, B.Aires, Ser.A, 26:385-396.

BOWMAN, T.E. 1975. Oithona colcarva n. sp., an American cope pod incorrectly known as 0 . brevicornis (Cyclopoida: $0 i=$ thonidae). Chesapeake Sci., 16:134-137

BRADY, G.S. 1904. On Entomostraca collected in Natal by Mr. James Gibson. Proc.zool.Soc.London, 2:121-128 + 3 pran chas.

BRANDORFF, G.-0.1976. The geographic distribution of the Diaptomidae in South America (Crustacea, Copepoda) Revta bras.Biol., 36:613-627.

BRANDORFF, G.-0. 1977 Untersuchungen zur Populationsdynamik des Crustaceenplanktons im tropischen Lago Castanho (Ama zonas, Brasilien). Christian-Albrechts-Univ., Kiel. 108pDissertation zur Erlangung des Doktorgrades (mimeografa do).

BRANDORFF, G.-0. 1978. Preliminary comparison of the crustacean plankton of a white water and a black water lake in Central Amazonia. Verh.int.Verein.theor.angew, Limnol. $20: 1198-1202$ 
BRANDORFF, G.-0. \& E.R. ANDRADE 1978. The relationship between the water level of the Amazon River and the fate of the zooplankton population in Lago Jacaretinga, a Várzea lake in the central Amazon. Stud. neotrop. Fauna Envi ron., $13: 63-70$.

BRANDORFF, G.-O.; W. KOSTE \& N.N. SMIRNOV 1982. The composition and structure of rotiferan and crustacean communi ties of the lower Rio Nhamundá, Amazonas, Brazil. Stud. neotrop. Fauna Environ., 17:69-121.

BREHM, V. 1926. Zoologische Ergebnisse der von Prof Dr. F Klute nach Nordpatagonien unternommenen Forschungsreise I. Die Entomostraken. Arch.Hydrobiol., 16:302-328.

BREHM, V 1927 Copepoda. Handb.200l., 3:435-496.

BREHM, V 1928. Hydrobiologische Untersuchungen aus Uruguay. Arch. Hydrobiol., $19: 719-722$

BREHM, V. 1935 . Uber die Süsswasserfauna von Uruguay. Arch. Hydrobiol., 28:295-309.

BREHM, V 1936a. Mitteilungen von den Forschungsreisen Prof Rahms. Mitteilung VI. Uber die Cladocerenfauna des Titica ca und tber einige neue Fundstellen bereits bekannter Copepoden. 200Z.Anz., 114:157-159.

BREHM, V 1936b. Mitteilungen von den Forschungsreisen Prof Rahms. Mitteilung V Zur Variabilitat der Pseudoboeckella gibbosa Brehm. - Zur Thermalfauna der Anden. Zool.Anz., $114: 107-108$.

BREHM, V 1951. Sobre la microfauna de las aguas dulces de diversos paises extraeuropeos. Publs.Inst.Biol.apl., 5: 83-100.

BREHM, V 1958. Bemerkungen zu einigen Kopepoden Suldameri kas. Sber.öst.Akad.Wiss.,Abt.I, 167:139-171.

BRIAN, A. 1926. Di alcuni Copepodi d'acqua dolce dell'Argentina raccolti dal Prof $F$ Silvestri. Memorie Soc. ent ital., $4: 177-200$.

BRIAN, A. 1927. Aggiunte e note sui Copepodi d'acqua dolce raccolti dal Prof F. Silvestri nell'Argentina. Boll. Soc.ent.ital., 59:126-132.

BURCKHARDT, G. I912 Ein zweites Cyclopidengenus im süssen Wasser. Zool.Anz., 39:725-727.

BURCKHARDT, G. 1913. Wissenschaftliche Ergebnisse einer Reise un die Erde von M. Pernod und C. Schröter. III. Zoo plancton aus ost- und süd-asiatischen Binnengewässern Zool.Jb.,Abt.Syst., 34:341-472 + pranchas 9-17

CALEF, G.W. \& G.D. GRICE 1967. Influence of the Amazon River outflow on the ecology of the western tropical Atlantic II. Zooplankton abundance, copepod distribution, with remarks on the fauna of low-salinity areas. J.mar.Res., 25 : 84-94.

CAMPOS, H.; E. BUCAREY \& J N. ARENAS 1974. Estudos limnológicos del lago Riñihue y río Valdivia (Chile) Boln Soc. Biol. Concepción, 46:47-67

CANDELAS, G. \& G.C. CANDELAS 1963. The West Indies. P. 435450 In Limnology in North America. D.G. Frey, ed. $734 \mathrm{p}$ Univ - Wisconsin Press, Madison, Wisconsin.

CARVALHO, J.P - 1945. Copépodos de Caiobá e Baía de Guanaba ra. Archos Mus.parana., 4:83-116 + 7 pranchas. 
CARVALHO, J.P. 1952. Sôbre uma coleção de copépodos, não parasiticos, da baía de Santos e suas adjacências. Bolm Inst.oceanogr., s Paulo, 3:131-188.

CARVALHO, M.A.J. 1971. Desenvolvimento de Ectocyclops rubescens (Brady 1904) (Copepoda, Crustacea) Bolm Fac. Filos. Ciēnc.Univ. S Pauzo (Zool.Bioz.mar.), N.S., 28:343-388.

CARVALHO, M.A.J 1975. A Represa de Americana: Aspectos físi co-químicos e a variação das populações de Copepoda, $C y=$ clopoida de vida livre. Instituto de Biociências, Univ Sāo Paulo. 157 p. Tese de doutoramento (mimeografado).

CERVIGÓN, F 1962 Contribución al conocimiento de los copépodos pelágicos de las costas de Venezuela.Mems Soc.Cienc. nat. "La Sazle", 22:181-188.

CERVIGÓN, $F$ \& P. MARCANO 1965. Estudios sobre el ecosistema pelägico del N.E. de Venezuela. 2l. Zooplancton. Mems Soc.Cienc.nat. "La SalZe", 25:261-356.

CHAPPUIS, P.A. 1917 Zur Kenntnis der Copepodenfauna von Surinam. Zool.Anz., 49:221-225.

CHAPPUIS, P.A. 1927 Die Tierwelt der unterirdischen Gewäs ser. Binnengewässer. $3: 1-175$.

CICCHINO, G. 1972 Desarrollo post-embrionario de Notodiapto mus coniferoides (Wright, 1927) y Eucyclops neumanni (Pes ta, 1927) (Crustacea, Copepoda). Physis, B.Aires, Ser. B, $31: 585-596$.

CICCHINO, G. 1974. La larva nauplius de copépodos ciclopoi deos dulceacuícolas. Physis, B.Aires, Ser. $B, 33: 19-44$.

CIPÓLLI, M.N. \& M.A.J CARVALHO 1973. Levantamento de Cala noida e Cyclopoida (Copepoda, Crustacea) das ăguas da região do Guamä, Capim e Tocantins, com nota sobre a fauna acompanhante. Papéis Avulsos Zool. S.Paulo, 27:95-110.

CLAUS, C. 1857 Weitere Mitteilungen über die einheimischen Cyclopiden.Arch.Naturgesch., 23:205-2ll + l prancha.

CLAUS, C. 1863. Die frei-lebenden Copepoden mit besonderer Berulcksichtigung der Fauna Deutschlands, der Nordsee und des Mittelmeeres. $230 \mathrm{p}$. + 37 pranchas. Leipzig.

CLAUS, C. 1866. Die Copepoden-Fauna von Nizza. Schr.Ges. Beförd.ges.Naturw.Marburg, Supp Z. 1:1-34+5 pranchas.

COELHO, R.M.P. 1983 Efeitos do zooplâncton na composição qualitativa e quantitativa do fitoplâncton no lago Para noá, Brasília, DF, Brasil. Departamento de Biologia Vegetal, Univ. Brasília. 163p. Tese de mestrado (mimeografa do)

COKER, R.E. 1943. Mesocyclops edax (S.A. Forbes), M. Zeuckar $t i$ (Claus) and related species in America. J.Elisha Mit = chell scient.Soc., 59:181-200.

COKER, R.E. 1945. Copepods of the genus Mesocyclops Sars Revta chil. Hist.nat., 48:107-109.

COKER, R.E. \& J.G. GONZĂLEZ 1960. Limnetic copepod popula tions of Bahia Fosforescente and adjacent waters, Puerto Rico.J.Elisha Mitchell scient.Soc., 76:8-28.

COLE, G.A. 1976. Limnology of the great lakes of Nicaragua p. 9-15 In Investigations of the Ichthyology of Nicara guan Lakes. T.B. Thorson, ed. $663 \mathrm{p}$. School of Life Sciences, Univ. Nebraska, Lincoln, Nebraska.

COLLADO, C.; D. DEFAYE; B.H. DUSSART \& C.H. FERNANDO No pre 
10. The freshwater Copepoda (Crustacea) of Costa Rica with notes on some species. Hydrobiologia.

COMITA, G.W. 1951. Studies on Mexican copepods. Trans.Am. microsc.soc., 70:367-379.

COULL, B.C. 1977 Marine flora and fauna of the northeastern United States. Copepoda: Harpacticoida. ii $i+48 \mathrm{p}$. National Oceanographic and Atmospheric Administration Technical Report: NMFS Circular 399. 003-020-00125-4, U.S. Govern ment Printing Office, Washington, D.C. 20402.

CUZON DU REST, R.P. 1963. Distribution of the zooplankton in the salt marshes of southeastern Louisiana. Publs Inst. mar.Sci.Univ.Texas, 9:132-155.

DADAY, E. VON. 1902a. Beiträge zur Kenntniss der SüsswasserMikrofauna von Chile. Természetr. Füz., 25:436-447

DADAY, E. VON. 1902b. Mikrroskopische süsswassertiere aus Patagonien. Természetr.Fuz., 25:201-310.

DADAY, E. VON. 1905. Untersuchungen über die Süsswasser-Mi krofauna Paraguays. Zoologica, Stuttg., 18:1-374 + 23 pranchas.

DADAY, E. VON. 1906. Untersuchungen über die Copepodenfauna von Hinterindien, Sumatra und Java nebst ein Beitrag zur Copepodenkenntnis der Hawaii-Inseln. Zool.Jb., Abt.Syst., 24:175-206.

DANA, J.D. 1848. Conspectus Crustaceorum, in orbis terrarum circumnavigatione, C. Wilkes e classe Reipublicae Faedera tae duce, collectorum auctore. Pars I. Crustacea Copepo = da. Proc.Am.Acad.Arts Sci., $1: 150-154$.

DANA, J.D. 1853. Crustacea. United States Exploring Expedi tion during the Years 1838, 1839, 1840, 1841, 1842 under the Command of Charles Wilkes, 14:693-1618.

DAVIS, C.C. 1948. Notes on the plankton of Long Lake, Dade County, Florida, with descriptions of two new copepods.Q. Jl Florida Acad.Sci., 10:79-88,

DAVIS, C.C. 1950 (1949) Observations of plankton taken in marine waters of Florida in 1947 and 1948.Q. Jl Florida Acad.Sci., 12:67-103.

DEEVEY, E.S. \& G.B. DEEVEY 1980. Structure of zooplankton communities in the Petén Lake District, Guatemala. P. 669 -678 In Evolution and Ecology of Zooplankton Communities. C.W. Kerfoot, ed. 793p. Univ. New England Press, Hanover, New Hampshire.

DELACHAUX, T. 1928. Faune invertebrée d'eau douce des hautes plateaux du Pérou (région de Huancavelica, Département de Junin). Bull.Soc.neuchatel.Sci.nat., N.S., 1:45-77.

DODDS, G.S. 1926. Entomostraca from the Panama Canal Zone with description of one new species. Occ.Pap.Mus.Zool. Univ. Michigan, $8: 1-27$.

DOMINGUEZ, T.P. \& L.R. ZUÑIGA 1979. Perspectiva temporal de la entomostracafauna limnética de lago Ranco (Valdivia, Chile) An.Mus.Hist.nat.Valparaiso, 12:53-58.

DUKINA, V V 1956. Diferenças entre espécies nas larvas de Cyclops. 200Z. 2h., 35:680-690. (Na língua russa, com resu mo no inglês).

DUSSART, B.H. 1969. Les Copépodes des Eaux Continentales 
d'Europe Occidentale. Vol. 2. Cyclopdides et Biologie. 292 p. Boubée et Cie., Paris.

DUSSART, B.H. 1974. Contribution à I'étude des copépodes des eaux douces d'Ethiopie. Bull. Inst.fond-Afr.noire, Sér. $A$, $1: 92-116$

DUSSART, B.H. 1979. Algunos copēpodos de América del Sur. Publnes ocas.Mus.nac. Hist.nat.Santiago, 30:1-13.

DUSSART, B.H. $1982 \mathrm{a}$. Crustacés copépodes des eaux intérieu res. Faune Madagascar, 58:1-146.

DUSSART, B.H. 1982b. Copépodes des Antilles françaises.Revue Hydrobiol.trop., $15: 313-324$.

DUSSART, B.H. No prelo. Some Crustacea Copepoda from Venezue la. Devs . Hydrobiol.

DUSSART, B.H. \& R. GRAS 1966. Faune planctonique du lac Tchad. I. Crustacés copépodes. Cah.ORSTOM Sér.Oceánogr., 4:77-9l.

EINSLE, U. 1970. Etudes morphologiques sur des espècies de Thermocyclops (Crust. Cop.) d'Afrique et d'Europe. Cah. ORSTOM Sér. Hydrobiol., 4:13-38.

EKMAN, S. 1905. Cladoceren und Copepoden aus antarktischen und subantarktischen Binnengewässern, gesammelt von der schwedischen antarktischen Expedition 1901-1903. Wiss. Ergebn.schwed.Südpolarexped. 1901-1903, Zool., 5:1-40+3 pranchas.

EPP, R.W. \& W.M. LEWIS, JR. 1980. The nature and ecological significance of metabolic changes during the life history of copepods. Ecology, 61:259-264.

EWERS, L.A. 1930. The larval development of freshwater Copepoda. Contr.Franz Theodore stone Lab., 3:1-43.

FANTA, E.S. 1972. Anatomy of the nauplii of Euterpina acutifrons (Dana) (Copepoda, Harpacticoida). Crustaceana, 23 : 165-181.

FANTA, E.S. 1976. Anatomy of the nauplii of oithona ovalis Herbst (Copepoda, Cyclopoida) Bolm Zool.Univ. S Paulo, 1: 205-238.

FARRAN, G.P. 1908. Note on the copepod genus Oithona. Ann. Mag.nat.Hist., Ser.8, 2:498-503.

FARRAN, G.P. 1913. Plankton from Christmas Island, Indian Ocean. II. On Copepoda of the Genera Oithona and Paroitho na. Proc.sool.Soc.London, 1913:181-193 + 15 pranchas.

FARRAN, G.P. 1929. Crustacea. X. Copepoda. Nat.Hist.Rep.British Antarct. Terra Nova Exped. 1910, 8:203-306

FERNANDO, C.H. \& K.E. SMITH 1982. Copepoda. P. 192-195 In Aquatic Biota of Mexico, Central America and the West Indies. S.H. Hurlbert \& A. Villalobos-Figueroa, eds. 529 . San Diego State Univ., San Diego, California.

FERRARI, F.D. 1977. A redescription of Oithona dissimizis Lindberg 1940 with a comparison to Oithona hebes Gies brecht 1981 (Crustacea: Copepoda: Cyclopoida). Proc.biol. Soc. Washington, 90:400-411.

FERRARI, F.D. \& T.E. BOWMAN 1980. Pelagic copepods of the Family Oithonidae (Cyclopoida) from the east coasts of Central and South America. Smithson.Contr.Zool., 312:1-27

FISCHER, S. 1851. Beiträge zur Kenntniss der in der Umgegend von St. Petersburg sich findenden Cyclopiden. Bull.Soc. 
imp. Moscow, 24:409-438+2 pranchas.

FISCHER, S. 1853. Beiträge zur Kenntniss der in der Umgegend von St. Petersburg sich findenden Cyclopiden. Bull. Soc.imp. Moscow, 26:74-100+2 pranchas.

FISCHER, S. 1860. Beiträge zur Kenntniss der Entomostraceen. Abh.Akad. Wiss.München, 8:645-680.

FONSECA, V.L. 1976. Copépodos do gênero Oithona da região de Cananéia (Lat.25007's., Long. $47^{\circ} 56^{\prime} \mathrm{W}$. ) Instituto Oceano gráfico, Univ. São Paulo. 68p. Tese de mestrado (mimeogrâ fado)

FONSECA, V \& T. BJORNBERG 1976. Oithona oligohalina, sp. n. de Cananéia (Est. de São Paulo) e consideraçōes sobre oithona ovalis Herbst (Copepoda, Cyclopoida) Anais Acad. bras.Ciên., 47:127-131.

FONSECA, V.L. \& M.S.A. PRADO 1979a. Copepods of the Genus $O_{i}$ thona from Cananeia region (Lat. $25^{0} 07^{\prime} \mathrm{S}$, Long. $47^{\circ} 56^{\prime} \mathrm{W}$ ) Bolm Inst.oceanogr., S Paulo, 28:1-15.

FONSECA, V.L. \& M.S.A. PRADO 1979b. The naupliar development of Oithona oligohalina, Fonseca \& Björnberg, 1976 Bolm Inst.oceanogr., S Paulo, 28:17-22

FORBES, S.A. 1890. On some Lake Superior Entomostraca. A. Rep.U.S. Comissioner Fish Fisheries, 1887:701-718+4 pran chas.

FREITAS, J.S. 1983. Variação sazonal e distribuiçāo vertical de micro-crustáceos planctônicos no lago Paranoá, DF Departamento de Biologia Vegetal, Univ. Brasília. 1lop. Tese de mestrado (mimeografado)

FRENZEL, P. 1976. Beitrag zur Kenntniss der Fimbriatus-Gruppe des Genus Paracyclops. Beitr.naturk.Forsch.südwDt 2 . , $35: 119-124$.

FRENZEL, P 1977 Fortpflanzungsisolate bei Paracyclops fimbriatus s. 1. (Fischer, 1853) (Crustacea: Copepoda).Beitr. naturk. Forsch. SuldwDtl., 36:109-112.

FRYER, G. 1955. A critical review of the Genus Eotocyclops (Crustacea: Copepoda) Ann.Mag.nat.Hist., Ser. 12, 8:938950 .

GAY, C. 1849. Zoologia. P. 81-96 In Historia Fisica y Politi ca de Chile. Vol. 4. Madrid.

GAY, C. 1854. Atlas de la Historia, Fisioa y Politica de Chile. Vol. 2. Zoologia. Madrid.

GESSNER, F 1956. Das Plankton des Lago Maracaibo. Ergebn. deutsch.Limnol. Venezuela-Exped., 1:67-92.

GESSNER, F 1968. Ei plancton del Lago de Valencia. El Lago, Valencia, $2: 98-100$.

GESSNER, F \& L. HAMMER 1967 Limnologische Untersuchungen an Seen der venezolanischen Hochanden. Int.Revue ges. Hydrobiol. Hydrogr., 52:301-320.

GIANI, A. 1984. Distribuição horizontal do fitoplâncton e zooplấncton no lago Paranoá, Brasilia, DF, Brasil. Departamento de Biologia Vegetal, Univ- Brasilia. 148p. Tese de mestrado (mimeografado)

GIESBRECHT, W. 1891. Elenco dei copepodi pelagici raccolte dal Tenente di Vascello Gaetano Chierchia durante el viag gio della R. Corvetta "Vettor Pisani" negli anni 1882 1885 e dal Tenente di Vascello Francesco Orsini nel Mar 
Rosso, nel 1884. Re.R.Accad.Lincei, 7:474-481.

GIESBRECHT, W. 1892. Systematik und Faunistik der pelagischen Copepoden des Golfs von Neapel und der angrenzenden Meeresabschnitte. Fauna Flora Golf. Neapel, 19: 1-831 +54 pranchas.

GIESBRECHT, $W .1895$. Reports on the dredging operations of the west coast of central America. Die pelagischen Copepo den. Bull. Mus.comp.Zool.Harvard, 25:243-263 + 4 pranchas.

GIESBRECHT, W. 1902. Résultats du Voyage du S. Y. Belgica en 1898-1899. Copepoden. Rapp.scient.Govt.belge, Zool., An vers, $1902: 1-49+13$ pranchas.

GONZALEZ, J.G. \& T.E. BOWMAN 1965. Planktonic copepods from Bahía Fosforescente, Puerto Rico, and adjacent waters Proc.U.S.natn.Mus., 117:241-303.

GOUVEA, E.P. 1978. Estágios de desenvolvimento pós-embrionário de Thermocyclops minutus (Lowndes) e de Notodiaptomus conifer (Sars) (Crustacea, Copepoda) da lagoa do Abaeté (Salvador-BA). Instituto de Biociências, Univ. São Paulo. 13lp. Tese de doutoramento (mimeografado).

GRICE, G.D. 1956. A qualitative and quantitative seasonal study of the Copepoda of Alligator Harbor. Pap.oceanogr. Inst. Florida st. Univ., 2:37-76.

GRICE, G.D. 1960a. Copepods of the Genus Oithona from the Gulf of Mexico. Bulz.mar.Sci.Gulf Caribb., 10:485-490.

GRICF. G.D. 1960b. Calanoid and cyclopoid copepods collected from the Florida Gulf Coast and Florida Keys in 1954 and 1955. Bull.mar.Soi.Gulf Caribb., 10:217-226.

GURNEY, R. 1933. British Freshwater Copepoda. Vol. III. 384 P. Ray Society, Londres.

HARDING, J.P - 1955. The Percy Sladen Trust Expedition to Lake Titicaca in 1937. XV. Crustacea: Copepoda. Trans.Linn. Soc.London, Ser. 3, 1:219-247.

HARDING, J.P. \& W.A. SMITH 1974. A key to the British fresh water cyclopoid and calanoid copepods. Freshwat.biol. A88., $18: 1-56$.

HARDY, E.R. 1978. Composiçāo do zooplâncton em cinco lagos da Amazônia Central. Instituto de Biociências e da Saúde, Univ. São Carlos. 149p. Tese de mestrado (mimeografado)

HARDY, E.R. 1980. Composição do zooplâncton em cinco lagos da Amazônia Central. Acta Amazonica, 10:577-609.

HARRIS, M.J. 1978. Copepoda of northern Mississippi with a description of a new species. Tulane stud.200Z.Bot., 20: 27-34.

HEBERER, G. \& F. KIEFER 1932. Zur Kenntnis der Copepodenfauna der Sunda-Inseln. Arch. Naturgesch, Z.wis8.zool., Abt. $B, 1: 225-274$.

HENSEN, V. 1911. Das Leben im Ozean nach Zählungen seiner Bewohner. Ergebn.Plankton-Exped. Humboldt Stiftung, $5: 1$ 406 .

HERBST, H.V, 1955. Cyclopoida Gnathostoma (Crustacea Copepoda) von der brasilianischen Atlantikkllste. Kieler Meeresforsch., 11:214-229.

HERBST, H.V 1959. Brasilianische süsswassercyclopoiden(Crus tacea Copepoda). Gewts8.Abw $188 ., 24: 49-73$. 
HERBST, H.V 1960. Copepoden (Crustacea Entomostraca) aus Nicaragua und Suldperu. Gewăss.Abwäss., 27:27-54.

HERBST, H.V. 1962. Crustacea aus dem Amazonasgebiet, gesam melt von Professor Dr. H. Sioli und Dr. R. Braun. I. Lito rale und substratgebundene Cyclopoida Gnathostoma (Copepō da) Crustaceana, 3:259-278.

HERBST H.V. 1967 Copepoda und Cladocera aus südamerika. Gewäss. Abwäs8., 44/45:96-108.

HERBST, H.V 1982. Drei neue marine Cyclopoida Gnathostoma (Crustacea: Copepoda) aus dem nordamerikanischen KUstenbe reich. Gewäss.Abwäss., 68/69:107-124.

HERRICK, C.L. 1882. Papers on the Crustacea of the fresh waters of Minnesota. I. Cyclopidae of Minnesota with notes on other Copepoda. Rep.geol.nat.Hist.Surv.Minnesota, 10: 219-233 + 7 pranchas.

HERRICK, C.L. 1884. A Final Report on the Crustacea of Minne sota Included in the orders Cladocera and Copepoda. 19lp. +22 pranchas. The Geological and Natural History Survey of Minnesota; Johnson, Smith \& Harrison, Minneapolis.

HERRICK, C.L. 1887. Contributions to the fauna of the Gulf of Mexico and the South. List of the fresh-water and mari ne Crustacea of Alabama, with descriptions of new species and synoptical keys for identification. Mem. Denison scient.Ass., 1:1-56 + 9 F:zr. ?has.

HOPKINS, T.L. 1966. The plankton of the St. Andrews Bay system, Florida. Publs Inst.mar.Sci., 11:12-64.

HOPKINS, T.L. 1977 Zooplankton distribution in surface wa ters of Tampa Bay, Florida. Bull.mar.Sci., 27:467-478.

INFANTE, A. 1978. The zooplankton of Lake Valencia (Venezue1a). I. Species composition and abundance. Verh.int.Ve rein.theor.angew.Limnol., 20:1186-1191.

INFANTE, A. 1981. Natural food of copepod larvae from Lake Valencia, Venezuela. Verh.int.Verein.theor.angew.Limnol., 21:709-714.

INFANTE, A.; W. RIEHL \& J.D. SAUNDERS 1979. Los copepódos del Lago de Valencia, Venezuela. Acta cient.venez., 30 : 224-23-3.

JAKOBI, H. 1969a. Forficatocaris nondti n.gen., n.sp. (Copepoda Harpacticoidea) aus brasilianischem Limnopsamnal Crustaceana, 17:231-238.

JAKOBI, H. 1963b. O significado ecológico da associação Ba thynellacea - Parastenocaris (Crustacea) Bolm Univ.Paraná, 20ol., 3:167-191.

JAKOBI, H. 1972. Zur Kenntnis der Forficatocaris - Zoenose des Nhundiaquara (Paraná - Brasilien). Stud.neotrop. Fauna, $7::, y-251$.

JUDAY, C. 1915. Limnologi jul studies on some lakes in Cen tral America. Trans.Wrsconsin Acad.Sci. Arts Lett., 18: 214-250.

JURINE, L. 1820. Histoire des Monocles qui se trouvent aux environs de Genève. Genebra e Paris.

KANAEVA, I.P. 1960. A distribuição do plâncton no meridiano $30 \%$ W. no Oceano Atlántico, abril-maio 1959. P. 173-183 In Sovietskie Rybokhoziaistvennye Issledovanniia $v$ Moriakh 
Europelskogo Severa. Institut Murskogo Rybnogo Khoziastva i Okeanografii, Moscow. (Na lingua russa.)

KIDD, R. \& F. SANDER 1979. Influence of Amazon River dischar ge on the marine production system off Barbados, West Indies. J.mar.Res., 37:669-68I.

KIEFER, F - 1925. Ein neuer Süsswasser - Copepode aus südamerika: Cyclops delachauxi n.sp. Zool. Ans., 63:46-47.

KIEFER, $F$ 1926a. Beitrăge zur Copepodenkunde. IV. Zool. Anz., 69:21-26.

KIEFER, F. 1926b. Uber einige Süsswasser - Cyclopiden aus Peru. Arch. Bydrobiof., 16:494-507.

KIEFER, F 1927 a. Beitrăge zur Copepodenkunde. VI. Zool. Ans., 74:116-122.

KIEFER, F, $1927 \mathrm{~b}$. Versuch eines Systems der Cyclopiden.zooz. Anz., 73:302-308.

KIEFER, F 1928a. Beitrag zur Kenntnis der freilebenden Cope poden Marokkos. BuZZ.Soc.Sci.nat.Maroc, 8:87-108.

KIEFER, F. $1928 \mathrm{~b}$. Uber Morphologie und Systematik der sulswas ser - Cyclopiden. 200Z.Jb., Abt.syst., 54:495-556.

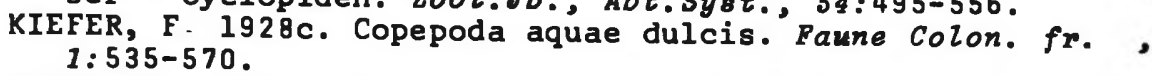

KIEFER, F 1929a. Zur Kenntnis einiger Artengruppen der suls swasser - Cyclopiden. 2.wis8.Z0ol., 133:1-56.

KIEFER, F 1929b. Crustacea Copepoda. 2. Cyclopoida Gnathostoma. Tierreich, 53:1-102.

KIEFER, F, $1929 \mathrm{c}$. Neue und wenig bekannte süsswasser - Copepoden aus südafrika. Zool. Anz., 80:309-316.

KIEFER, F. 1929d. Neue Ruderfusskrebse von den Sunda - In seln. 200l. Anz., 84:46-49.

KIEFER, F. 1930a. Beitrăge zur Copepodenkunde. XV. Zool. Anz., 87:315-318.

KIEFER, F. 1930b. 3. Mitteilung uber die Cyclopiden der Deutschen Limnologischen Sunda - Expedition. Ein Neuer Me socyclops aus Java. Mit einem Bestimmungschilussel furr alle bekannten Mesocyclopo - Arten. Zool. Anz., 90:86-92.

KIEFER, F 1931a. Der Untergattung Tropocyciops der Gattung Eucyclops (Copepoda Cyclopoida) Z.wiss.Zool., 138:487
514 .

KIEFER, F - 1931b. Zur Kenntnis der freilebenden Stlsswasserco pepoden, insbesondere der Cyclopiden Nordamerikas. Zool. Jb., Abt.syst., 61:579-620.

KIEFER, F - 1931c. Kurze Diagnosen neuer SUlsswasser - Copepoden. Zool.Anz., 94:219-224.

KIEFER, F 1931d. Report on a collection of fresh-water Cy clopidae from New Zealand. 5p. New Zealand Institute.

KIEFER, F. 1933a. Stlsswassercopepoden aus Brasilien. Zool. Ans., 105:38-43.

KIEFER, F 1933b. Zoologische Ergebnisse einer Reise nach Bonaire, Curaçao und Aruba im Jahre 1930. Suss - nach Brackwasser - Copepoden von Bonaire, Curaçao und Aruba.

KIEFER, F. 1933c. Die freilebenden Copepoden der Binnenge whsser von Insulinde. Arch.Hydrobiol., Suppl., 12:519 -
621 . 
KIEFER, F 1934. Neue Ruderfusskrebse von der Insel Haiti.I. Cyclopoida. II. Harpacticoida. Zool. Anz., 108:227-233.

KIEFER, F. 1935a. Neue Stlsswassercyclopiden (Crustacea Copepoda) aus Uruguay. Zool.Anz., 109:181-188.

KIEFER, F. 1935b. Ober drei Cyclopiden (Crustacea Copepoda) aus Brasilien. Zool. Anz., 112:23-31.

KIEFER, F . 1936a. Freilebenden Suss - und Salzwassercopepo den von der Insel Haiti. Arch. Hydrobiol., 30:263-317.

KIEFER, F. 1936b. Brasilianische Ruderfusskrebse (Crustacea Copepoda), gesammelt von Herrn Dr. Otto Schubart. II. Mit teilung. Zool. Anz., 114:129-133.

KIEFER, F. 1936c. Brasilianische Ruderfusskrebse (Crustacea Copepoda), gesammelt von Herrn Dr. Otto Schubart. III. Mitteilung. Zool. Anz., 114:320-322.

KIEFER, F. 1936d. Brasilianische Ruderfusskrebse (Crustacea Copepoda), gesammelt von Herrn Dr. Otto Schubart. V. Mitteilung. Zool.Anz., 116:31-35.

KIEFER, F. 1936e. Mitteilungen von den Forschungsreisen Prof Rahms. Mitteilung VIII. Cyclopiden. 2002.Anz., 115: 244-249.

KIEFER, F 1938a. Ruderfusskrebse (Crust. Copep.) aus Méxi Co. Zool. Anz., 123:274-280.

KIEFER, F 1938b. Die von Wallacea-Expedition gesammelten Ar ten der Gattung Thermocyclops Kiefer. Int. Revue ges. Hy= drobiol. Hydrogr., 38:54-74.

KIEFER, F 1943. Freilebende Copepoda (Crust.) Beitr. Fauna Perus, 2:213-215.

KIEFER, F - $1952 \mathrm{a}$. Freilebende Copepoda (Crust.).Beitr. Fauna Perus, 3:197-199.

KIEFER, F 1952b. Copepoda Calanoida und Cyclopoida. Explor. Pare natn. Albert Miss.H.Damas 1935-1936, 21:1-136+21 ta belas + 5 pranchas.

KIEFER, F 1954. Drei neue Ruderfusskrebse (Crust.Cop.) aus Venezuela. Zool. Anz., 153:170-174.

KIEFER, F 1956. Freilebende Ruderfusskrebse (Crustacea Cope poda). I. Calanoida und Cyclopoida. Ergebn. deutsch. Limnot. VenezueZa-Exped., 1:233-268+2 tabelas.

KIEFER, F - 1957 Freilebende Ruderfusskrebse des Titicaca sees. Verbff.zool.StSamm Z., Mllnchen, 4:127-150.

KIEFER, F 1959. Uber einige Ruderfusskrebse aus Sudchile Beitr.naturk. Forsch. SlldwDt 2 ., 18:53-58.

KIEFER, F 1960. Notizen zur Copepodenfauna Nordwestdeutschlands. Abh.naturw.Ver.Bremen, 35:438-449.

KIEFER, F. 1973. Vergleichende Studien an Nauplien verschiedener Cyclopiden (Crustacea Copepoda) Memorie Ist.ital. Idrobiol. "Dott. Marco de Marchi", 30:45-60.

KIEFER, F. 1976. Revision der robustus - vernalis Gruppe der Gattung Acanthocyclops Kiefer (Crustacea, Copepoda) (Mit eingehender Beurteilung des "Cyclops, americanus Marsh, 1892") Beitr.naturk.Forsch. Slldwtl., 35:95-110.

KIEFER, F 1978a. Zur Kenntnis der Copepodenfauna ygyp tischer Binnengew lsser. Arch. Bydrobiol., 84:480-499.

KIEFER, F 1978b. Freilebende Copepoda. Binnengéwdeser, 26 : $1-343$.

KIEFER, F 1981. Beitrag zur Kenntnis von Morphologie, Taxo- 
nomie und geographischer Verbreitung von Mesocyclops leuckarti auctorum. Arch. Hydrobiol., Suppl. 62 (Monogr Beitr.), 1:148-190.

KING, J.E. 1950. A preliminary report on the plankton of the west coast of Florida. Q.Jl Florida Acad.Sci., 12:109-137

$\mathrm{KOCH}, \mathrm{C.L.} \mathrm{1838.} \mathrm{Deutschlands} \mathrm{Crustaceen,} \mathrm{Myriapoden} \mathrm{und}$ Arachniden: Ein Beitrag zur deutschen Fauna, 1/40. Regens burg.

KOLESNIKOV, A.N. \& A. ALFONSO 1973. Preliminary data on zooplankton of the eastern part of the Gulf of Mexico and the Florida Strait. P - 141-151 In Investigations of the Central American Seas. Translated from Russian, Publ. Indian National Scientific Documentation Centre, New Delhi. U. S. Dept. Comnerce, National Technical Information Service TT 70-57762.

LANG, K. 1948. Monographie der Harpacticiden. Vols. I a II $1683 \mathrm{p}$. Nordiska Bokhandeln, Stockholm.

LEGARE, J.E.H. 1961. Estudios preliminares del zooplancton en la región de Cariaco. Boln Inst.oceanogr., Univ. Orien te, $1: 191-218$.

LEGARE, J.E.H. 1964. The pelagic Copepoda of eastern Venezue la. 1. The Cariaco Trench. Boln Inst.oceanogr., Univ Oriente, 3:15-81.

LINDBERG, K. 1935. Notes sur des cyclopides d'eau douce de l'Inde, avec description d'une espece nouvelle et de deux variétés nouvelles. Rec. Indian Mus., 37:405-419+1 pran cha.

LINDBERG, K. 1939. Cyclopides (Crustacēs Copépodes) de I'Inde. II. Une revision des répresentants indiens du sousgenre Microcyclops Claus, du genre Cyclops MUller. Rec. Indian Mus., 41:235-262.

LINDBERG, K. 1942. Cyclopides (Crustacés Copépodes) de I'Inde. XIV-XVII. XIV. Notes sur quelques membres du sous-gen re Metacyclops Kiefer. XV. Contribution à la connaissance de Mesocyclops leuckarti Claus. XVI. Notes sur Mesocy clops rylovi Smirnov et Mesocyclops vermifer Lindberg XVII. Description d'un Thermocyclops nouveau. Rec. Indian Mus., $44: 139-190$.

LINDBERG, K: 1949. Contributions à l'étude des Cyclopides (Crustacés - Copépodes) K. fysiogr.salzsk.Lund FArh., 19: 98-121.

LINDBERG, K. 1950. Liste des Cyclopoldes gnathostomes (Crustacés copépodes) des illes Britanniques et de l'Irlande Hydrobiologia, 2:301-312.

LINDBERG, K. 1951. Mission hydrobiologique belge au Lac Tanganika, 1946-1947 Cyclopides (Crustacés Copépodes) Ré sult.scient. Explor.hydrobiol. Lac Tanganika, 3:45-91 + 5 tabelas, 2 pranchas.

LINDBERG, K. 1952 . Cyclopides (Crustacēs Copépodes) de Madagascar. Troisième note. Mém. Inst.scient.Madagascar, Sér A, 7:53-67.

LINDBERG, K. 1953: La sous-famille des Cyclopininae Kiefer (Crustacés Copépodes). Ark.Zool., Ser. 2, 4:311-325.

LINDBERG, K. 1954a. Cyclopides (Crustacés copépodes) de I'Amérique du Sud. Ark. Zool., 7:193-222. 
LINDBERG, K. 1954b. Cyclopoïdes (Crustacés copépodes) du Mexique. Ark. Zooz., 7:459-489.

LINDBERG, K. 1954c. Cyclopides (Crustacés copépodes) d'îles du Pacific Sud (Mélanésie et Micronésie) et de Bornēo. $K$. fysiogr.sulzok. Lund FBrh., 24:161-174.

LINDBERG, K. 1954d. Un Cyclopide (Crustacé copépode) troglobie de Madagascar. Bydrobiologia, 6:97-119.

LINDBERG, K: 1955a. Cyclopides (Crustacés Copèpodes) récol tés au Pérou par le Dr. Hernando de Macedo. Folia biol. andina, $I I, 2002$., $1: 1-18$.

LINDBERG, K. 1955b. Cyclopides (Crustacés copépodes) nou veaux de l'ile de Crète et du Pérou. K. fysiogr.sulzsk. Lund FBrh., 25:82-88.

LINDBERG, K. 1956a. Cyclopides (Crustacés copépodes) de l'Ou ganda (Afrique orientale britannique). K. fysiogr.sallsk. Lund Forh., 26:1-14.

LINDBERG, K. 1956b. Monoculus quadricornis rubens L. Jurine 1820 , synonyme Cyclops strenuus S. Fischer 1851. BuZZ. Soc.zool. France, 81:115-120.

LINDBERG, K. 1957a. Cyclopoides de la Côte de'Ivoire. Bull. Inst.fr.Afr.noire, 19:139-179.

LINDBERG, K. 1957b. Cyclopides (Crustacés Copépodes) récol tés au Pềrou par le Dr. Hernando de. Macedo (Deuxième partie). Bolia biol. andina, II. Zool., 1:39-52.

LINDBERG, K. 1958. Un Cyclopide récolté par Monsieur Patrice Paulian dans l'ile Amsterdam. Revue de la synonymie et de la repartition géographique des espècies du genre Paracyclops (C. Claus 1893). Ark. Zool., 11:355-377:

LINDBERG, K. 1961. Remarques sur le genre Metacyclops (Kie fer 1927) et description d'un Metacyclops nouveau du Portugal. K. fysiogr.sulisk. Lund F\&rh., 31:133-145.

LOFFLER, H. 1958. Die Klimatypen des holomiktischen Sees und ihre Bedeutung flir zoogeographische Fragen. Sber.bst.Akad. Wiss., Abt. I, 167:1-33.

LÜFFLER, H. 196la. Zur Systematik und Okologie der chile nischen susswasserentomostraken. Beitr.neotrop.Fauna, 2 : 143-222.

LÖFFLER, H. 1961b. Beitrag zur Copepoden - und Ostracodenfau na Chiles. Anz.8st.Akad. Wiss., $98: 111-116$.

LOFFLER, H. 1963. Zur Ostrakoden - und Copepodenfauna Ekua dors. Arch. Hydrobioz., 59:196-234.

LOHFFLER, H. 1968. Die Crustaceenfauna der Binnengewăsser ostafrikanischer Hochberge. Hochgebirgsforschung, 1:107-169.

LOFFLER, H. 1972 Contribution to the limnology of high moun tain lakes in Central America. Int. Revue ges. Hydrobiol. Bydrogr., 57:397-408.

LOFFLER, H. 1981. Copepoda. P. 14-19 In Aquatic Biota of Tro pical South America. Part 1. Arthropoda. S.H. Hurlbert ; G. Rodriguez \& N.D. dos Santos, eds. 323p. San Diego State Univ., San Diego, California.

LOWNDES, A.G. 1930. Freshwater Copepoda from Abysinia collected by Mr. J Omer-Cooper. Proc.sool.Soc.London, Pt. 1, 11:161-180 + 4 pranchas.

LOWNDES, A.G. 1934. Reports of an Expedition to Brazil and Paraguay in 1926-7 supported by the Trustees of the Percy 
Sladen Memorial Fund and the Executive Committee of the Carnegie Trust for Scotland. Copepoda. J.Linn.Soc., Zool., $39: 83-131$.

LUCKS, R. 1929. Cyclops phaleratus Koch. Ein Beitrag zu ei ner Entwicklungsgeschichte. Ber.westpreuss.bot.-zool. Ver., $51: 9-31$.

MANFREDI, P. 1923. Etude sur le développement larvaire de quelques espèces du genre Cyclops. Annls Biol. lacustre, 12:273-303 + 2 pranchas.

MANFREDI, P - 1925. Etude sur le développement larvaire de quelques espéces du genre Cyclops. Annls Biol. lacustre, $14: 111-129$.

MARGALEF, R. 1961. La vida en los charcos de agua dulce en Nueva Esparta (Venezuela). Mem Soc.Cienc.nat. "La Salle", 21:75-110.

MARSH, C.D. 1893. On the Cyclopidae and Calanidae of central Wisconsin. Trans. Wisconsin Acad. Sci.Arts Lett., 9:189-224 +4 pranchas.

MARSH, C.D. 1906. Copépodes. P. 175-188 In Les Lacs des Hauts Plateaux de l'Amérique du Sud, Miss.Scient.G. de Créqui Montfort et $E$. Sénéchal de la Grange. M. Néveau-Lemaire, ed. 197p. Soudier, Paris.

MARSH, C.D. 1910. A revision of North American species of $C y$ clops. Trans. Wisconsin Acad.Sci.Arts Lett., 26:1067-1135.

MARSH, C.D. 1923. Report on the freshwater copepods from $\mathrm{Pa}-$ nama, with descriptions of new species. Smithson. misc. Colln $8,61: 1-31$.

MARSH, C.D. 1919. Report on a collection of Copepoda made in Honduras by F.J Dyer. Proc.U.S.natn.Mus., 55:545-548.

MARSH, C.D. 1931. On a collection of Copepoda made in El Sal vador by Samuel F. Hildebrand and Fred $J$ Foster of the U.S. Bureau of Fisheries. J.Washington Acad.Sci., 21:207209.

MARTINEZ DE FERRATO, A. 1967 Notas preliminares sobre migra ciones del zooplancton en cuencas isleñas del Parana medio. Acta zool. lilloana, 23:173-188.

MART INEZ DE FERRATO, A. 1968. Zooplancton. (Apêndice 3 de : J.A. Orellana, Estudo limnológico de la laguna Paiva, pro vincia de Santa Fe, Argentina). Physis, B. Aires, 27:185186.

MASTRANTUONO, L. \& E. STELLA 1974. Morfologia e posizione sistematica di Acanthocyclops robustus Sars (Crustacea Co pepoda) di uno stagno del lazio. Riv. Idrobiol., Univ. Perugia, $13: 211-224$.

MATSUMURA-TUNDISI, T. 1972. Aspectos ecológicos do zooplâncton da região lagunar de Cananéia com especial referência aos Copepoda (Crustacea) Instituto de Biociências, Univ. São Paulo. 191p. Tese de doutoramento (mimeografado).

MATSUMURA-TUNDISI, T.; K. HINO \& S.M. CLARO 1981. Limnological studies at 23 reservoirs in southern Brazil. Verh. int.Verein.theor. angew. Limnol., 21:1040-1047

MATSUMURA-TUNDISI, T., \& O. ROCHA 1983. Occurrence of Cope pod (Calanoida Cyclopoida and Harpacticoida) from "Broa" Reservoir (São Carlos, São Paulo, Brazil). Revta bras. Biol., $43: 1-17$ 
MATSUMURA-TUNDISI, T. \& J.G. TUNDISI 1976. Plankton studies in a lacustrine environment. I. Preliminary data on zoo plankton ecology of Broa Reservoir. Oecologia (Berl.), 25: 265-270.

MICHEL, H.B. \& M. FOYO 1976. Caribbean zooplankton. Part I Siphonophora, Heteropoda, Copepoda, Euphausiacea, Chae tognatha and Salpidae. 549p. Office of Naval Research, Dept. of the Navy. 008-051-00066-6, U.S. Government Printing office, Washington, D.C. 20402.

MILSTEIN, A. 1979. Vertical distribution of Paracalanus cras sirostris (Copepoda, Calanoidea): analysis by the general linear model. Bolm Inst.oceanogr., S Paulo, 28:65-78.

MONCHENKO, V.I. 1974. Cyclopidae. Fauna Ukrainii, 27:1-452 (Na lingua russa.)

MONCHENKO, V.I. 1977 Sobre um copépodo novo e muito modificado Colpocyclops dulcis gen. et sp. n. (Crustacea, Cyclo pidae) Vêst. Zoologii, 6:25-32. (Na língua russa, com rê sumo no inglès.)

MONTIEL, E. \& E. ZOPPI DE ROA 1979. Notas sobre la disposi ción horizontal de copepodos en un cuerpo de agua tempo ral en el Alto Apure, Venezuela. Acta biol.venez., 10:109 -128 .

MOORE, E. \& F SANDER 1979. A comparative study of zooplankton from oceanic, shelf, and harbor waters of Jamaica Biotropica, 11:196-206.

MORYAKOVA, V.K. \& A. CAMPOS 1973. Qualitative and quantitati ve characteristics of zooplankton of the Cuban bench. P. 128-140 in Investigations of the Central American Seas

Translated from Russian, Publ. Indian National Scientific Documentation Centre, New Delhi. U.S. Dept. Commerce, National Technical Information Service TT 70-57762.

MRĀZEK, A. 1901. Süsswasser - Copepoden. Ergebn.Hamburger Ma galhaensische Sammelreise, 6:1-29 + 4 pranchas.

NILSSEN, J.P. 1979. Problems of subspecies recognition in freshwater cyclopoid copepods.2.Zool.Syst.Evolut. Borsch., 17:285-295.

NOODT, W. 1972a. Brasilianische Grundwasser - Crustacea, 1. Studien an den Gattungen Parastenocaris Kessler und Forfi catocaris Jakobi aus der Serra do Mar von São Paulo (Copê poda Harpacticoidea). Crustaceana, 23:76-99.

NOODT, W. 1972b. Drei neue Parastenocaris aus Kolombien(Crus tacea Copepoda) 1. Mitteilung Uber kolumbianische Grundwas ser - Crustaceen. Stud. neotrop. Bauna, 7:101-112.

NOODT, W. 1973. Artenreichtum und Monardsches Prinzip bei Crustacea des Limnopsammons der Neotropis. Amazoniana, 4: 255-261.

OKANO, W.Y. 1980. Padrão de migração vertical e flutuação sa zonal das principais espécies de Copepoda (Crustacea) dō Lago Dom Helvécio, Parque Florestal do Rio Doce - MG. Ins tituto de Biociências e da Saúde, Univ. São Carlos. 168p. Tese de mestrado (mimeografado).

OLIVEIRA, L.P.H. $1945 \mathrm{a}$. Contribuição ao conhecimento dos Crustăceos do Rio de Janeiro: Ordem Eucopepoda. Mems Inst. Oswaldo Cruz, 42:449-472

OLIVEIRA, L.P.H. 1945b. Classificação hidrobiológica das à - 
guas do oceano Atlântico no litoral do Brasil. Mems Inst. Oswaldo Cruz, 42:191-206.

OLIVEIRA, L.P.H. 1946. Estudos sôbre o Micropláncton captura do durante a viagem do navio hidrográfico Lahmeyer nas baías de Ilha Grande e Sepetiba. Mems Inst. Oswaldo Cruz, 44:441-488.

OLIVEIRA, L.P.H. 1954. Sôbre a presença do copépodo Mesocy clops longisetus no plâncton de uma laguna litorânea. Mems Inst. Oswaldo Cruz, 52:239-244+2 estampas.

OLIVIER, S.R. 1955. A few aspects of the regional limnology of the Province of Buenos Aires. Verh.int.Verein. theor angew. Limnol., 12:296-301.

ORELLANA, J.A. 1967 Estudio limnológico de la Laguna Paiva (Provincia de Santa Fe, Argentina) Physis, B. Aires, 27: 169-186.

OSORIO TAFALL, B.0. 194l. Materiales para el estudio del microplancton del lago de Pátzcuaro (México) An.Esc.nac. Cienc.biol., México, 2:331-383.

OSORIO TAFALL, B.0. 1943. Observaciones sobre la fauna acuática de las cuevas de la región de Valles, San Luis de Po tosí (México) Revta Soc. mexicana Hist.nat., 4:49-71.

OSORIO TAFALL, B.0. 1944. Biodinámico del lago de Pátzcua ro. I. Ensayo de interpretación de sus relaciones trofi cas. Revta Soc. mexicana Hist. nat., 5:197-227.

OWRE, H.B., \& M. FOYO 1964a. Plankton of the Florida Cur rent. Part IX. Additions to the list of Copepoda, with descriptions of two rare species.Bull.mar.Sci.Gulf Caribb 14:342-358.

OWRE, H.B. \& M. FOYO 1964b. Report on a collection of Copepo da from the Caribbean Sea. Bulz.mar.Sci.Gulf Caribb., 14 : $359-372$.

OWRE, H.B. \& M. FOYO 1967. Copepods of the Florida Current Fauna Caribaea, No. 1. Crustacea, Fart 1: Copepoda. 137p. Institute of Marine Science, Univ.Miami, Florida.

OWRE, H.B. \& M. FOYO 1972. Studies on Caribbean zooplankton. Description of the program and results of the first cruise. Bull.mar. Sci. Gulf Caribb., 22:483-52I.

PAGGI, J.C. \& S.J PAGGI 1974. Primeros estudios sobre el zooplancton de las aguas loticas del Parana medio. Physis, $B$. Aires, Sec. $B, 33: 91-114$.

PALLARES, R.E. 1968. Copepodos marinos de la ría Deseado. 125 p. Servicio de Hidrografía Naval, Armada Argentina, H. 1024 . Buenos Aires.

PEARSE, A.S. 1911. Report on the Crustacea collected by the University of Michigan - Walker Expedition in the State of Vera Cruz, Mexico. Rep.Michigan Acad.Sci., 13:108-113

PEARSE, A.S. 1916. An account of the Crustacea collected by the Walker Expedition to Santa Marta, Colombia. Proc. U. S. natn.Mus., 49:531-556 + 5 pranchas.

PEARSE, A.S. 1922. Crustacea from Lake Valencia, Venezuela. Proc.U.S.natn.Mus., 59:459-462.

PEARSE, A.S. 1938. Fauna of the caves of Yucatan. Chapt. 11. Copepoda from Yucatan caves. Publs Carnegie Instn Washing ton, 491:153-154.

PENNAK, R.W. 1963. Species identification of the fresh-water 
cyclopoid Copepoda of the United States.Trans.Am.microsc. Soc., 82:353-359.

PENNAK, R.W. 1978. Fresh-water Invertebrates of the United States. 2 a edição. $803 \mathrm{p}$. John Wiley \& Sons, Inc., Nova York.

PESTA, 0. 1927. Ein Beitrag zur Kenntnis der Copepodenfauna von Argentinien. Zool. Anz., 73:67-80.

PETKOVSKI, T.K. 1963. Metacyclops mendocinus (Wierzejski) von Terceira - Azoren Inseln (Copepoda Cyclopoida).Fragm. balcan., 5:13-18.

PEZZANI, S. 1978. Copepoda. P. 139-144 In Aquatic Biota of Southern South America. S.H. Hurlbert, ed. 342p. San Diego State Univ., San Diego, California.

PICADO, C. 1913. Les Broméliacées epiphytes considérés comme milieu biologique. Bull.scient.France Belgique, 47:215 $-360+19$ pranchas.

PLESA, C. 1961. New cyclopoids (Crustacea, Copepoda) of the interstitial fauna from the beaches of Ghana. Jl W.Afr. Sci.A88, 7:1-13.

PLESA, C. 1963. Etude sur la faune interstitielle littorale de la Mer Noire. III. Résultats préliminares des récher ches sur la côte roumaine, avec aperçu spécial sur les cy clopoldes gnathostomes (Crustacea, Copepoda) Vie Milieu, $14: 775-813$.

PLESA, C. 1964. Un ciclopod nou pentru fauna interstifiala litorală a Mării Negre Paraeuryte remanei Herbst s. lato (Crustacea, Copepoda) Lucr. Inst.speleol. "Emil Racovifă". 3:405-410. (Na lîngua romena, com resumo em francês.)

PLESA, C. 1973. Un nouveau Cyclopide interstitiel de la mer des Caralbes: Neocyclops improvisus n. sp. (Crustacea, Co pepoda). Résult. Expéd.biospéol.cubano-roumaines à Cuba, $1: 119-122$.

PLESA, C. 1981. Cyclopides (Crustacea, Copepoda) de Cuba. Ré sult. Expéd.biospéol. cubano-roumaines à Cuba, 3:17-34.

PRICE, J.L. 1958. Cryptic speciation in the vernalis group of Cyclopidae. Can.J.Zool., 36:285-303.

REDDELL, J.R. 1965. A checklist of the cave fauna of Texas I. The Invertebrata (exclusive of Insecta) Texas J.Sci., 17:143-187.

REED, E.B. \& M.A. MC QUAID. 1966. A new record of Mesocy clops tenuis (Marsh) with a description of the male (Cope poda: Cyclopoida). Proc.biol.Soc. Washington, 79:153-164.

REHBERG, H. 1880. Beitrag zur Kenntniss der freilebenden Suls swasser Copepoden. Abh.naturw.Ver.Bremen, $6: 533-554+\bar{I}$ prancha.

REID, J.W. No prelo. Semiterrestrial meiofauna inhabiting a wet campo in central Brazil, with special reference to the Copepoda (Crustacea). Devs.Hydrobiol.

RICHARD, J. 1895. Sur quelques Entomostracés d'eau douce d'Haiti. Mém.Soc. zool. France, 8:189-199.

RICHARD, J 1897a. Entomostracés de l'Amérique du Sud, re cueillis par MM U. Dieters, H. von Ihering, G.W. Muller et C.0. Poppe. Mém. Soc.zool. France, 10:263-301.

RICHARD, J. 1897b. Sur quelques Entomostracés d'eau douce des environs de Buenos Aires. An.Mus.nac.Hist.nat.B. Ai - 
res, $5: 321-332$.

RINGUELET, R.A. 1955. Ubicación zoogeogräfica de las islas Malvinas. Revta Mus. La Plata, N.S.,Zool., 6:419-464.

RINGUELET, R.A. 1958a. Los Crustäceos Copépodos de las aguas continentales de la República Argentina. Sinopsis sistemá tica. Contrnes cient.Fac. Cienc.exact.fis.nat.Univ.B. Ai = res, 2002., 1:35-126.

RINGUELET, R.A. 1958b. Primeros datos ecológicos sobre Copépodos Dulciacuícolas de la República Argentina. Physis, $B$. Aires, 21:14-31.

RINGUELET, R.A. 1959a. Novedaders sobre copépodos de agua dul ce de la Argentina. Physis, B.Aires, 21:314. (Resumo.)

RINGUELET, R.A. 1959b. Datos de fecundidad en Copépodos dulciacuícolas. Physis, B.Aires, 21:316-317

RINGUELET, R.A. 1962. Rasgos faunísticos de las reservas naturales de la Provincia de Buenos Aires. Physis, B. Aires, 23:83-92.

RINGUELET, R.A. 1968. Biogéographie des copépodes d'eau douce de l'Argentine. Biol. Amérique australe, 4:261-267

RINGUELET, R.A. 1972. Ecologia y biocenologia del habitat la gunar o lago de tercer orden de la region neotropica templada (Pampasia sudoriental de la Argentina). Physis, $B$. Aires, 31:55-75.

RINGUELET, R.A.; J MORENO \& E. FELDMAN 1965. El zooplancton de las lagunas de la pampa deprimida y otras aguas superficiales de la llanura Bonaerense (Argentina) Physis, $B$. Aires, 27:187-200.

RINGUELET, R.A.; S.R. OLIVIER; S.A. GUARRERA \& R.H. ARAMBURU 1955. Observaciones sobre antoplancton y mortandad de peces en Laguna del Monte (Buenos Aires, República Argentina). Notic.Mus.Eva Peron, 18:71-80.

RIOJA, E. 1940a. Observaciones acerca del plancton del lago de Pätzcuaro. An. Inst. Biol. Univ. México, 11:417-425.

RIOJA, E. 1940b. Notas acerca de los Crustäceos del lago de Pätzcuaro. An. Inst. Biol. Univ. México, 11:469-475.

RIOJA, E. 1942. Observaciones acerca del plancton de la lagu na de San Felipe Xochiltepec (Puebla) An. Inst.Biol. Univ. México, $13: 519-526$.

ROCHA, C.E.F 1981. As espécies de Halicyclops Norman, 1903 (Copepoda, Cyclopoida Gnathostoma) do rio Pomonga (Sergipe-Brasil), com referência especial à taxonomia. Instituto de Biociências, Univ. São Paulo. Tese de doutoramento (mimeografado)

ROCHA, C.E.F. 1983. Halićyclops glaber, a new cyclopoid cope pod from the Pomonga River, Brazil, with comments on $H a l \underline{i}$ cyclops korodiensis Onabamiro, $1952 \mathrm{~J}$ Crustacean Biol., $3: 636-643$.

ROCHA, C.E.F. No prelo. Four new species of the genus Halicy clops Norman, 1903 (Copepoda, Cyclopoida) from the Pomonga River (Brazil). Hydrobiologia.

ROCHA, CrE.F 1984. A new species of Halicyclops (Copepoda : Cyclopoida) from the Amazon Basin, Brazil. Acta Amazoni ca, 13. No prelo.

ROCHA, 0. \& MATSUMURA-TUNDISI 1976. Atlas do Zooplancton (Re presa do Broa, São Carlos) Vol. I. Copepoda. 68p. Cen 
tro de Ciências e Tecnologia, Univ. São Carlos.

ROSENDORN, I. 1917. Die Gattung Oithona. Wiss.Ergebn.deutsch. Tiefoee-Exped. "Valdivia" 1898-1899, 23:1-58.

RYLOV, V.M. 1948. Crustacea. Freshwater Cyclopoida. Fauna SSSR, 3:1-314. English Translation from Russian, Israel Program for Scientific Translations, publ. National Scien ce Foundation, 1963. TT 63-11163, National Technical In = formation Service, U.S. Dept. of Commerce, Springfield, VA 22161.

SANDER, F. \& E.A. MOORE 1978. A comparative study of inshore and of fshore copepod populations at Barbados, W.I. Crusta ceana, 35:225-240.

SANTOS, J.J 1970. Plâncton da Baía de Todos os Santos, com especial referéncia aos copépodos. $49 \mathrm{p}$. Instituto de Biociencias, Univ. São Paulo. Tese de mestrado (mimeografa do).

SARS, G.0. 1863. Oversigt af de indenlandske Ferskvandscopepoder, af Stud. Forh.Videnskselsk. Christiana, Aar 1862 : 212-262.

SARS, G.0. 1913. Parts III and IV, Cyclopidae (continued) P. 33-56 In An Account of the Crustacea of Norway. Vol. VI. Copepoda Cyclopoida. G.0. Sars. $225 \mathrm{p}$. + 118 pranchas. Bergen Museum.

SARS, G.0. 1914. Parts V and VI. Cyclopidae (continued) P. 57-80 In An Account of the Crustacea of Norway. Vol. VI. Copepoda Cyclopoida. G.0. Sars. $225 \mathrm{p} .+118$ pranchas. Ber gen Museum.

SAUNDERS, J.F, III \& A. INFANTE 1981. A distribution record for Mesocyciops leuckarti (Claus) (Copepoda: Cyclopoida) in South America.Papéis Avulsos Zool., S.Paulo, 34:115-119.

SCHUBART, 0. 1938. Consideraçōes sōbre as investigaçōes nas águas de Pernambuco. Archos Inst.Pesq.agron., Pernambuco, $1: 26-57$.

SCOTT, T. 1894. Report on Entomostraca from the Gulf of Guinea. Trans.Linn.Soc.London, Zool., 6:1-161+15 pranchas.

SCOTT, $T$ 1914. Remarks on some Copepoda from the Falkland Islands collected by Mr. Rupert Vallentin, F.L.S. Ann Mag.nat.Hist., Ser.8, 8:1-11 + 2 pranchas.

SENDACZ, S. 1978. Alguns aspectos do zooplâncton da Represa Billings. Instituto de Biociências, Univ. São Paulo. $84 \mathrm{p}$. Tese de mestrado (mimeografado).

SENDACZ, S. No prelo. A study of the zooplankton community of Billings Reservoir - São Paulo. Devs.Hydrobiol.

SENDACZ, S. \& E. KUBO 1982 Copepoda (Calanoida e Cyclopoi da) de reservatónios do Estado de Säo Paulo. Bolm Inst. Pesca, 9:51-89.

SENDACZ, S.; E. KUBO \& L.P. FUJIARA No prelo. Further stu dies on the zooplankton community of an eutrophic reser voir in southern Brazil. Verh.int.Verein.theor.angew. Limnol., 22.

SEWELL, R.B.S. 1948. The free-swimming planktonic Copepoda Geographical distribution. Scient.Rep.John Murray Exped $1933-34,8: 317-592$.

SEWELL, R.B.S. 1957(1964). A review of the subgenus Thermocy 
clops Kiefer of the genus Mesocyclops Sars, with a des cription of a new form of Mesocyclops (The rmocyclops) schmeili Poppe and Mrázek (Crustacea: Copepoda). Rec. Indian Mus., 55:69-119.

SHUVALOV, V.S. 1980. Crustáceos copépodos - Cyclopoida da família Oithonidae dos oceanos do mundo. opred. Faune SSSR, 125:1-194. (Na lingua russa.)

SMITH, K.E. \& C.H. FERNANDO 1978. The freshwater calanoid and cyclopoid Crustacea of Cuba. Can.J.Zool., 56:2015 2023.

SMITH, K.E. \& C.H. FERNANDO 1980. Guia para los copépodos (Calanoida y Cyclopoida) de las aguas dulces de Cuba.28p. Academia de Ciencias de Cuba, Havana.

STEINITZ-KANNAN, M. 1979. Comparative limnology of Ecuado rian lakes: a study of species number and composition of plankton communities of the Galapagos Islands and the equatorial Andes. Ohio State Univ., Columbus. Ph.D. dis sertation (mimeografado).

STEINITZ-KANNAN, M.; P.A. COLINVAUX \& R. KANNAN 1983. Limnological studies in Ecuador: 1. A survey of chemical and physical properties of Ecuadorian lakes. Arch. Hydrobiol., Sypp l. 65 (Monogr. Beitr.), 1:61-105.

STRASKRABA, M. 1969. Lista de los crustāceos dulciacuícolas de Cuba y sus relaciones zoogeográficas. Acad.Cienc.Cuba,

Ser. Biol.; 8:1-37.
STRASKKRABA, M.; M. LEGNER; J FOTT; J HOLČIK; K. KOMARKOVA LEGNEROVA; K. HOLCIKOVA \& M. PEREZ EIREZ 1969. Primera contribución al conocimiento limnológico de las lagunas y embalses de Cuba. Acad. Cienc. Cuba, Ser.Biol., $4: 1-44$.

TEIXEIRA, C.; J TUNDISI \& M. B. KUTNER 1965. Plankton stu dies in a mangrove environment. II. The standing stock and some ecological factors. Bolm Inst.oceanogr., S Pau 20, 14:13-41.

TEIXEIRA, C.; J TUNDISI \& J. SANTORO YCAZA 1969. Plankton studies in a mangrove environment. VI. Primary production, zooplankton standing-stock and some environmental fac tors. Int. Revue ges.Hydrobiol. Hydrogr., 54:289-301.

THIEBAUD, M. 1914. Copépodes de Colombie et des Cordillères de Mendoza. Mém.Soc.neuchāteloise Sci.nat., 5:160-175.

THOMASSON, K. 1955. Studies on South American fresh-water plankton. 3. Plankton from Tierra del Fuego and Valdivia. Acta Horti gothoburg., 19:193-225.

THOMASSON, K. 1956. Reflections on arctic and alpine lakes Oikos, 7:117-143.

THOMASSON, K. 1957. Studies on South American fresh-water plankton. 1. Notes on the plankton from Tierra del Fuego and Valdivia. Annis Soc.Reb. Nat.invest.Univ.Tartu, N.S. , $1: 52-64$.

THOMASSON, K. 1959. Nahuel Huapi. Plankton of some lakes in an Argentine National Park, with notes on terrestrial vegetation. Acta phytogeogr.suec., 42:1-83.

THOMASSON, K. 1963. Araucanian Lakes. Plankton studies in North Patagonia, with notes on terrestrial vegetation. Acta phytogeogr.suec., 47:1-139. 
THOMSON, G.M. 1882. On the New Zealand Copepoda. Trans.New Zealand Inst., 15:93-116 + 11 pranchas.

TORRES, P.; C. ROMAN; L. FIGUEROA \& R. FRANJOLA 1980. Plerocercoids of Diphy Zlobothrium (Cobbold) in fishes and identification of copepods in plankton from Calafquen Lake, Chile. Indian J.Parasit., 4:207-208.

TUNDISI, J. 1963. Nota sobre Oithona ovalis (Copepoda, Cyclo poida) e sua distribuição. Ciēnc.Cult., 15:298. (Resumo.)

TUNDISI, J.G. 1970. O plâncton estuarino. Contrễes Inst. oceanogr. Univ. S Paulo, Sér. Oceanogr.biol., 19:1-22

TUNDISI, J., \& T. MATSUMURA-TUNDISI 1968. Plankton studies in a mangrove environment. $V$. The salinity tolerances of some planktonic crustaceans. Bolm Inst.Oceanogr., S Pau20, 17:57-65.

TURNER, J.T 1981. Latitudinal patterns of calanoid and cy clopoid copepod diversity in estuarine waters of eastern North America. J.Biogeogr., 8:369-382.

TURNER, J.T 1982. The annual cycle of zooplankton in a Long Island estuary. Estuaries, 5:261-274.

UENO, M. 1939. Zooplankton of Lago de Pàtzcuaro, Mexico. Annotnes zool.jap., 18:105-114.

VAN DE VELDE, I. 1978. Thermocyclops ouadanei n.sp. (Crustacea: Copepoda) from Mauretania (North-West Africa) Bydrobiologia, 61:33-37

VAN DE VELDE, I. 1984. Revision of the African species of the genus Mesocyclops Sars, 1914 (Copepoda: Cyclopidae) Hydrobiologia, 109:3-66.

VAN DOUWE, C. 1912. Zur Kenntnis der SUsswasser - Copepoden von Brasilien. Arch. Hydrobiol. Planktonk., 7:309-321.

VERVOORT, W. 1964. Free-living Copepoda from Ifaluk Atoll in the Caroline Islands with notes on related species. Butl. U.S.natn.Mus., $236: 1-431$.

WELLERSHAUS, S. 1970 . On the taxonomy of some Copepoda in Cochin Backwater (a South Indian estuary). Verbff. Inst MeeresForsch. Bremerhaven, 12:463-490.

WELLS, J.B.J 1967. The littoral Copepoda (Crustacea) of Inhaca. Island, Mozambique. Trans.R.Soc.Edinburgh, 67:189358 .

WIERZEJSKI, A. 1892. Skorupiaki i wrotki (Rotatoria) slodkowodnie zebrane u Argentynie. Anz.Akad. Wis8.Krakau, 24:229 $-246+3$ pranchas. ("Süsswasser-Crustaceen- und Rotato rien gesammelt in Argentinien", resumo extensivo do artigo, P. 185-188.)

WILSON, C.B. 1936. Copepods from the cenotes and caves of the Yucatan Peninsula, with notes on Cladocerans. Publs Carnegie Instn Washington, 457:77-88.

WILSON, C.B. 1942. The copepods of the plankton gathered during the last cruise of the "Carnegie" Publs Carnegie Instn Washington, $536: 1-237$

WILSON, C.B. 1950. Contributions to the biology of the Phi lippine Archipelago and adjacent regions. Copepods gathered by the USA Fisheries Steamer "Albatross" from 18871907 in the Pacific. BulZ.U.S.natn.Mus., 14: ix + 141-441. WILSON, M.S. 1958. The copepod genus Halicyclops in North America with a description of a new species from Lake 
Pontchartrain, Louisiana and the Texas coast.Tulane Stud. Zool., 6:176-189.

WILSON, M.S. \& H.C. YEATMAN 1959. Free-living Copepoda. P. 735-861 In Ward \& Whipple's Fresh-water Biology. 2a edi ção. W.T. Edmondson, ed. 1248p. John Wiley \& Sons, Inc., Nova York.

WYNGAARD, G. \& C.C. CHINNAPPA 1982. General biology and cyto logy of cyclopoids. P. 485-533 In Developmental Biology of Freshwater Invertebrates. Alan R. Liss, Inc.,150 Fifth Avenue, Nova York.

YEATMAN, H.C. 1944. American cyclopoid copepods of the viridis - vernalis group (including a description of Cyclops carolinianus n. sp.). Am.Midl. Nat., 32:1-90.

YEATMAN, H.C. 1959. Free-living Copepoda: Cyclopoida. P. 795 -815 In Ward \& Whipple's Fresh-water Biology. 2 a edição W.T. Edmondson, ed. 1248p. John Wiley \& Sons, Inc., Nova York.

YEATMAN, H.C. 1963. Some redescriptions and new records of littoral copepods from the Woods Hole, Massachusetts re gion. Trans. Am.microsc.Soc., 82:197-209.

YOUNGBLUTH, M.J 1979. The variety and abundance of zooplank ton in the coastal waters of Puerto Rico. Northeast Gulf Sci., 3:15-26.

ZACARIAS, D. \& E. ZOPPI DE ROA 1981. Desarrollo larval y postlarval de Oithona hebes Giesbrecht (Copepoda:Cyclopoi da) Acta biol,venez., 11:109-123.

$\mathrm{ZO}, \mathrm{Z}$. 1982. The sequential taxonomic key: an application to some copepod genera. Hydrobiologia, 96:9-13.

ZOPPI DE ROA, E. 1961. Distribución vertical del zooplancton en el Golfo y extremo este de la Fosa de Cariaco. Boln Inst.oceanogr., Univ. Oriente, 1:219-247

ZOPPI DE ROA, E. 1972 Zooplancton de la Laguna de Campoma, Edo. Sucre, Venezuela. Cuad.oceanogr., Univ. Oriente, 3:4953.

ZOPPI DE ROA, E. 1974 Comparación de algunas característi cas del plancton entre las lagunas costeiras de Tacarigua y Unare, Venezuela. Boln Inst.oceanogr., Univ.Oriente, 13: $129-146$.

ZUNIGA, L.R. \& P. DOMINGUEZ T 1977 Observaciones sobre el zooplancton de lagos chilenos. An.Mus.Hist.nat., Valparai so, $10: 107-120$.

ZUNIGA, L.R. \& P. DOMINGUEZ T. 1978. Entomostracos planctoni cos del lago Riñihue (Valdivia, Chile): Distribución temporal de la taxocenosis. An.Mus.Hist.nat., Valparaiso, 11 :89-95.

Figuras 1-3: 1, Trichodiaptomus coronatus (Calanoida), habi tus em vista dorsal; 2, Attheyella sp. (Harpacticoidea), habitus em vista dorsal; 3, Microcyclops anceps (Cyclopoida), habitus em vista dorsal. Escalas $=100 \mu \mathrm{m}$. 


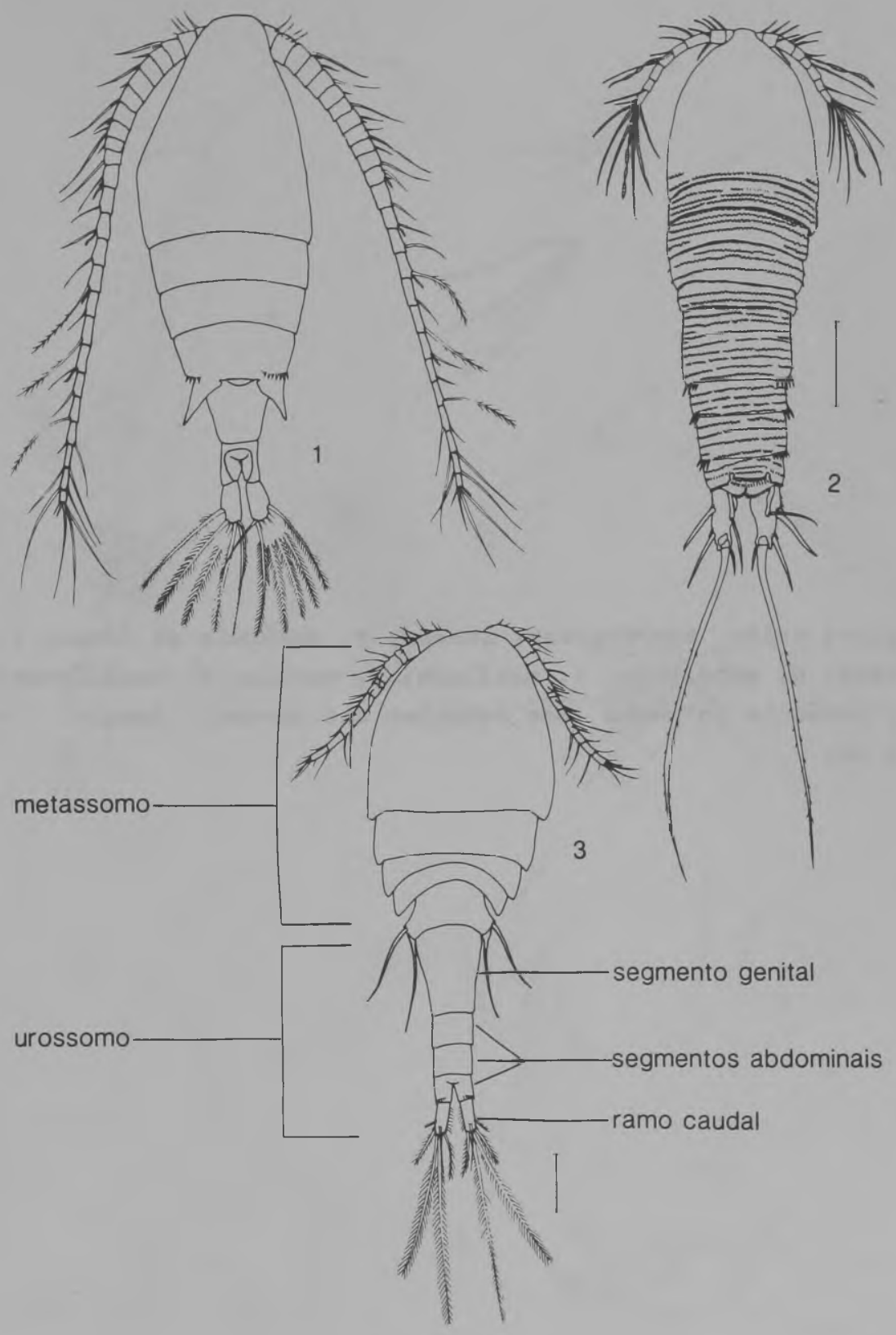


Figuras 4-10: Microcyolops anceps; 4, antênula da fêmea; 5, antena; 6, mandíbula; 7, maxilula; 8, maxila; 9, maxilipede; 10, antênula do macho (sem detalhes das cerdas). Escala = $100 \mu \mathrm{m}$. 


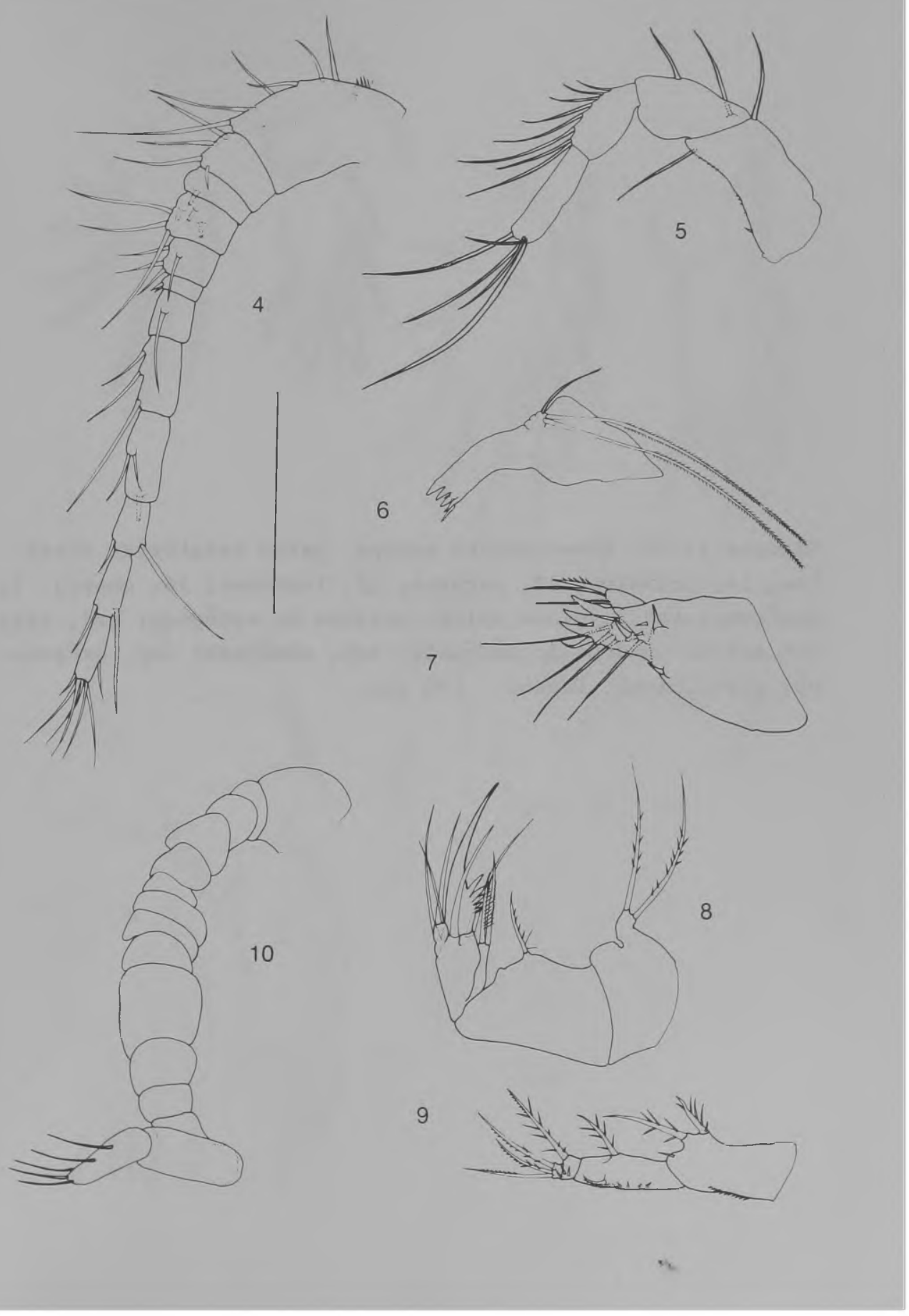


Figuras 11-14: Microcyclops anceps, patas natatōrias direi tas; 11, primelra; 12, segunda; 13, terceira; 14, quarta. b, basípodo; eae, espinho apical externo do endópodo; eai, espi nho apical interno do endópodo; enp, endōpodo; exp, exōpodo; pb, placa basal. Escala $=100 \mathrm{\mu m}$. 


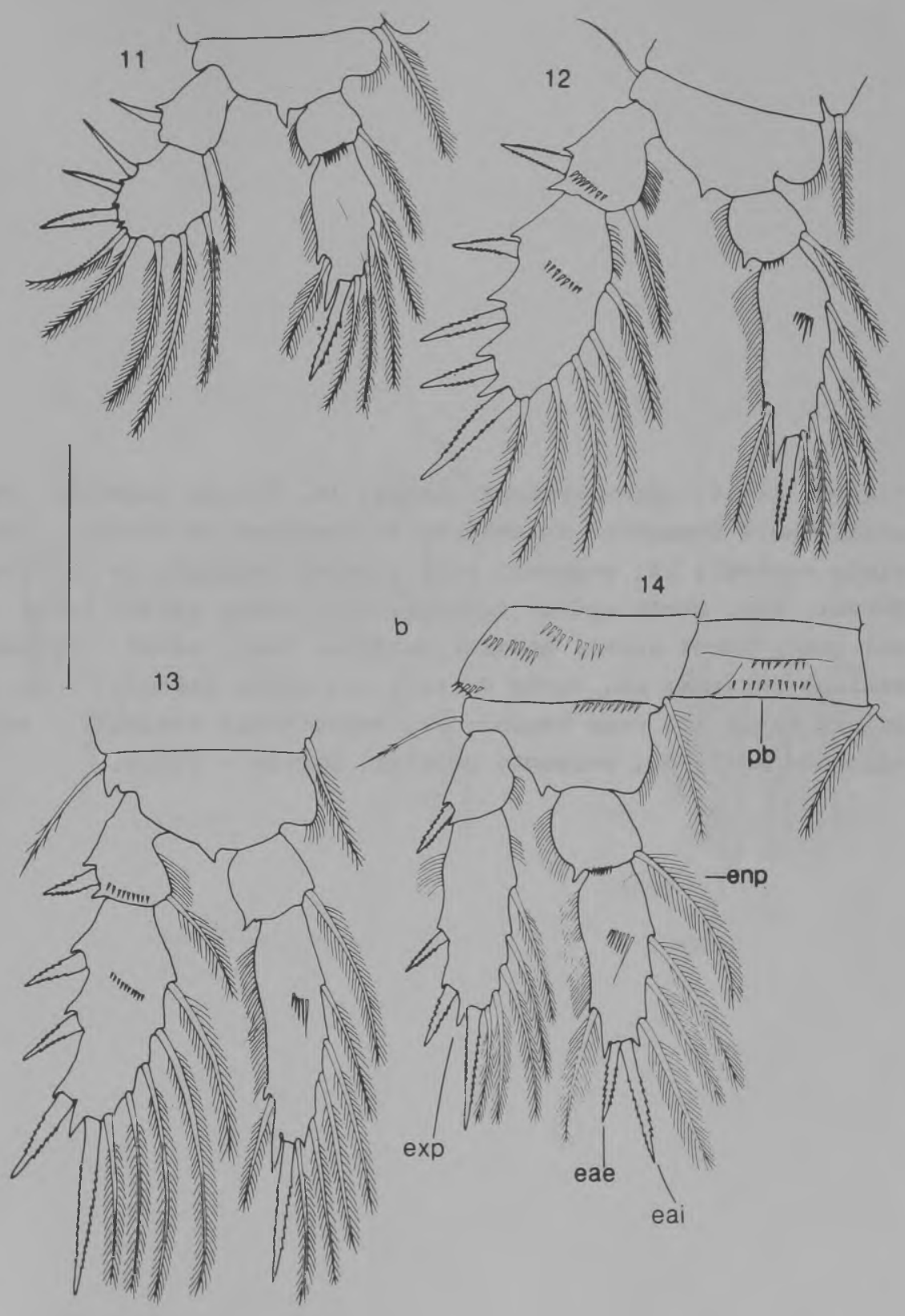


Figuras 15-16: Nicrocyclops anceps; 15, ültimo segmento do metassomo e segmentos anteriores do urossomo da fêmea, em vista ventral; 16, segmento anal e ramos caudais, em vista dorsal. cae, cerda apical externa; cai, cerda apical inter na; came, cerda apical mediana externa; cami, cerda apical mediana interna; cd, cerda dorsal; cl, cerda lateral; qp , quinta pata; rc, ramo caudal; rs, receptáculo seminal; sa, segmento aral; sg, segmento genital. Escala $=100 \mu \mathrm{m}$. 

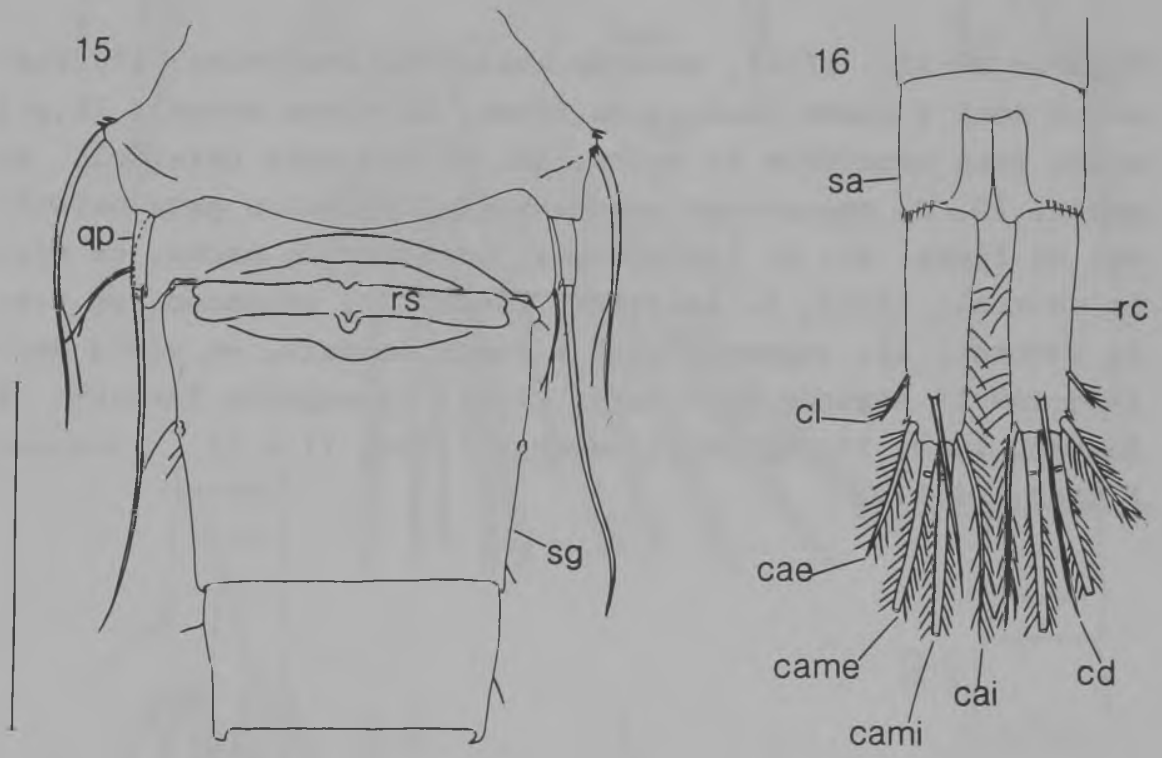
Figuras 17-23: 17-19, Oithona amazonica amazonica: 17, segmento anal e ramos caudais da fêmea, em vista dorsal; 18 ,prí. meira pata natatória do macho; 19, quarta pata natatória do macho; 20 , 0 . amazonica continentalis, primeira pata natatória da fêmea; 21, 0 . bjornbergae, urossomo do macho, em vista ventral; 22-23, 0 . gessneri, fêmea: 22, urossomo, em vista ventral; 23, segmento anal e ramos caudais, em vista dorsal. (17-19 segundo Burckhardt, 1913; 21 segundo Ferrari \& Bowman, 1980; 20 segundo Lindberg, 1954a; 22 e 23 segundo Kiefer, 1956). 


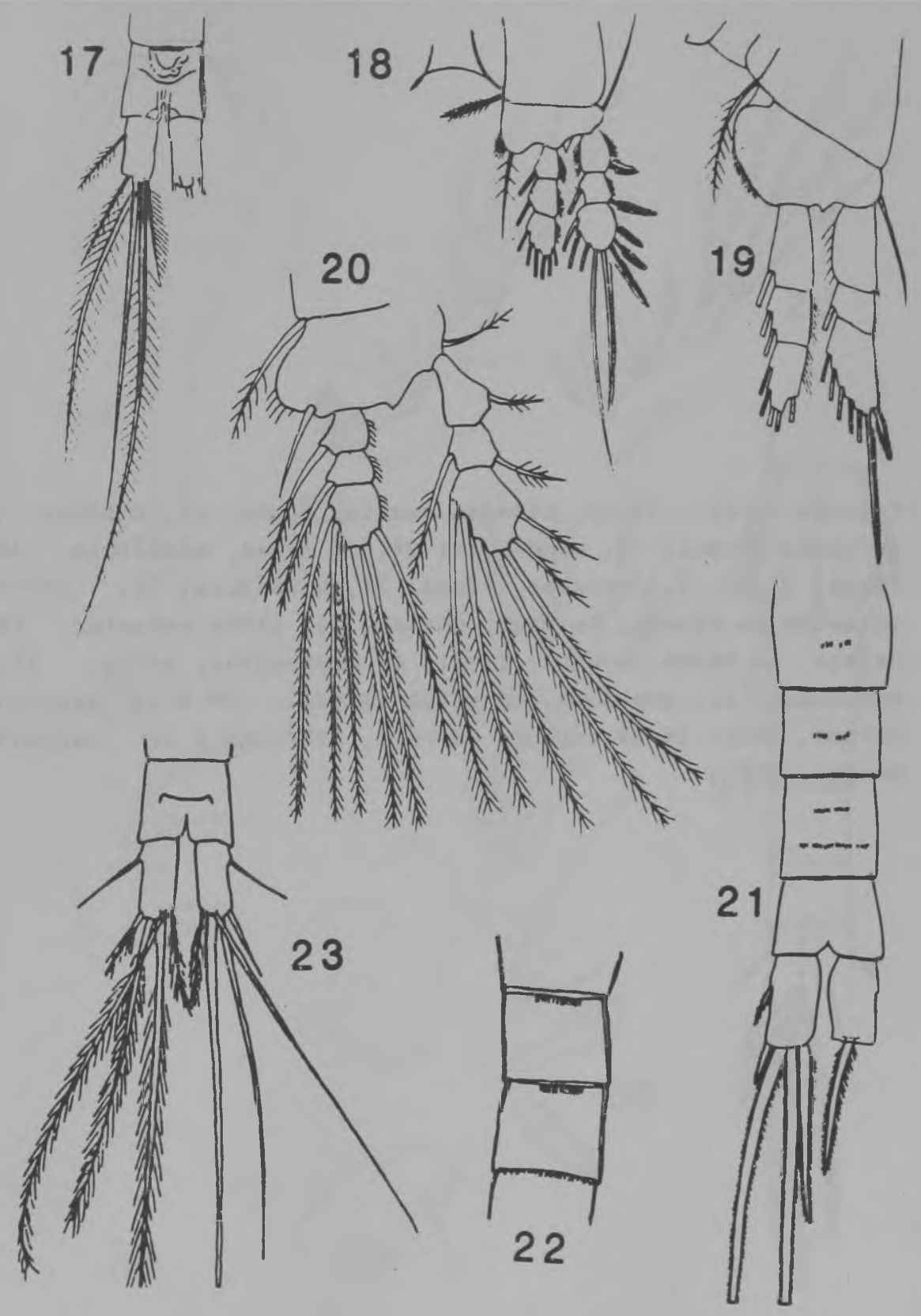


Figuras 24-31: 24-25, Oithona ovalis, fêmea: 24, habitus, em vista dorsal; 25, mandíbula; 26,0 . hebes, mandibula da fêmea; 27-29, 0 . fonsecae, fêmea: 27, mandíbula; 28 , parte anterior da cabeça, em vista dorsal; 29, parte anterior da cabeça, em vista lateral; 30-31, 0. neotropica, macho: 30 , mandíbula; 31 , urossomo, em vista ventral. ( 24 e 25 segundo Herbst, 1955; 26-29 segundo Ferrari, 1977; 30 e 31 segundo Herbst, 1967) 


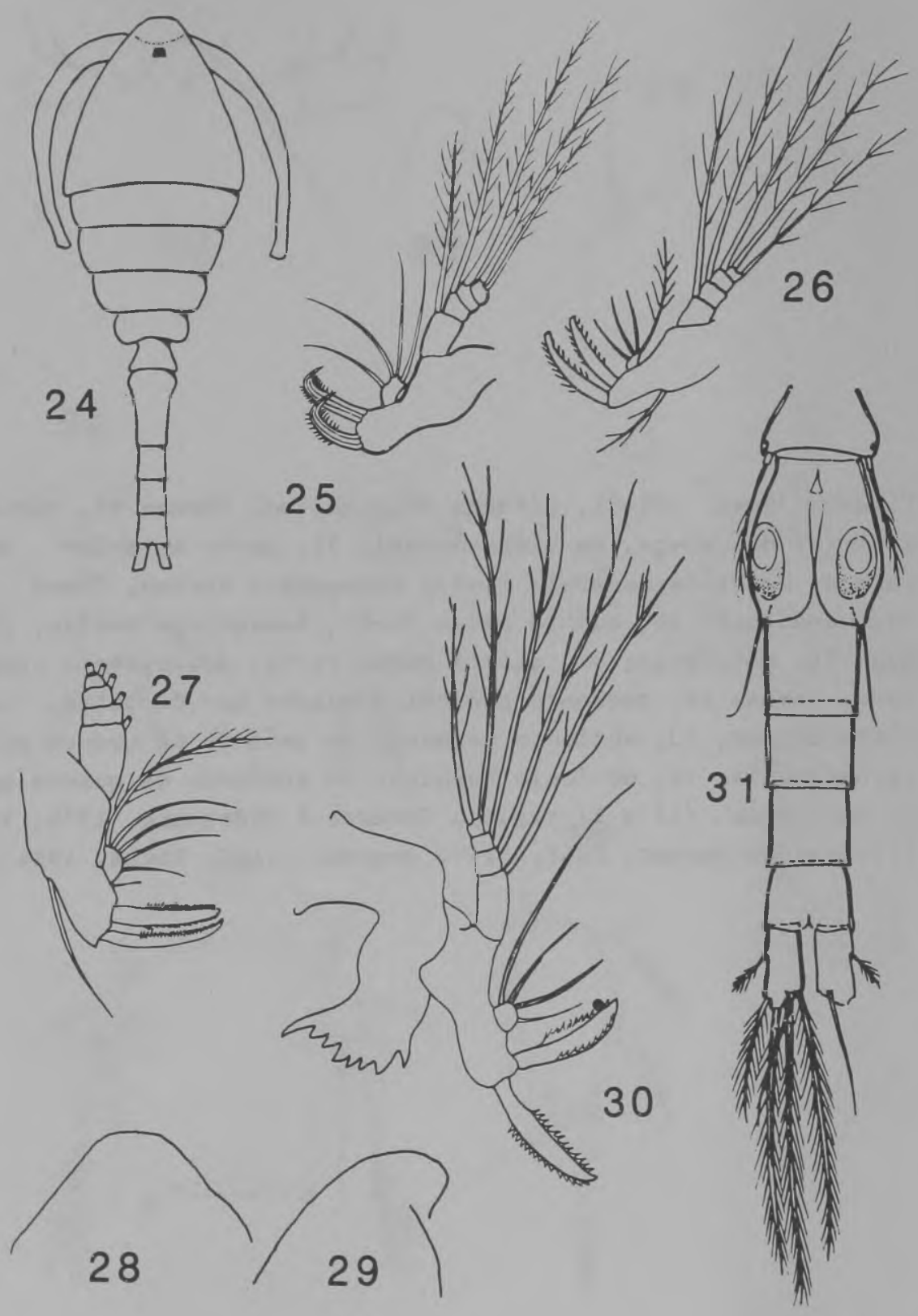


Figuras 32-40: 32-33, Oithona oligohalina, fêmea: 32, parte anterior da cabeça, em vista dorsal; 33, parte anterior da cabeça, em vista lateral; 34-35, Paraeuryte vicina, fêmea : 34, mandibula; 35, quinta pata; 36-37, Neocyclope medius, fê mea: 36, mandíbula; 37, quinta pata; 38-40, Halicyclopo aber rans, fémea: 38 , segmento genital e quinto par de patas, em vista dorsal; 39, artículo terminal do exópodo da quarta pata natatōria; 40, artículo terminal do endópodo da quarta pa ta natatória. (32 e 33 segundo Fonseca \& Björnberg, 1976; 34 -37 segundo Herbst, 1955; 38-40 segundo C.E.F Rocha, 1984). 

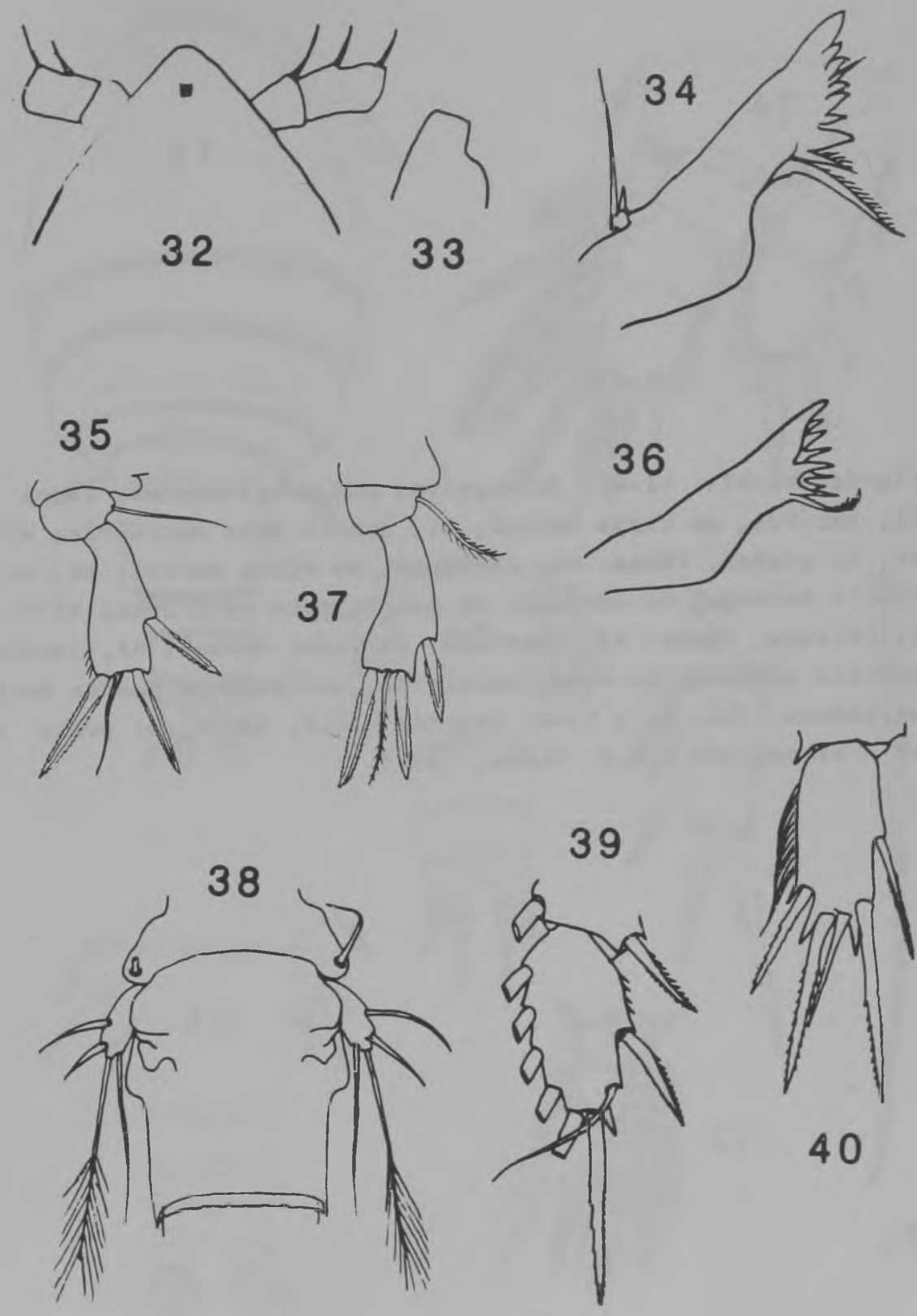
Figuras 4I-47: 41-42, Halicyclops paradenticulatus, fêmea: 41, habitus, em vista dorsal; 42, quarta pata natatôria; 4344, H. glaber, fêmea: 43, urossomo, en vista dorsal; 44, articulo terminal do endópodo da quarta pata natatória; 45-47, H. pizosus, fêmea: 45, urossomo, em vista dorsal; 46, cerdas apicais medianas do ramo caudal; 47 , endópodo da quarta pata natatória. ( 41,42 e 45-47 segundo C.E.F Rocha, no prelo; 43 e 44 segundo C.E.F Rocha, 1983). 


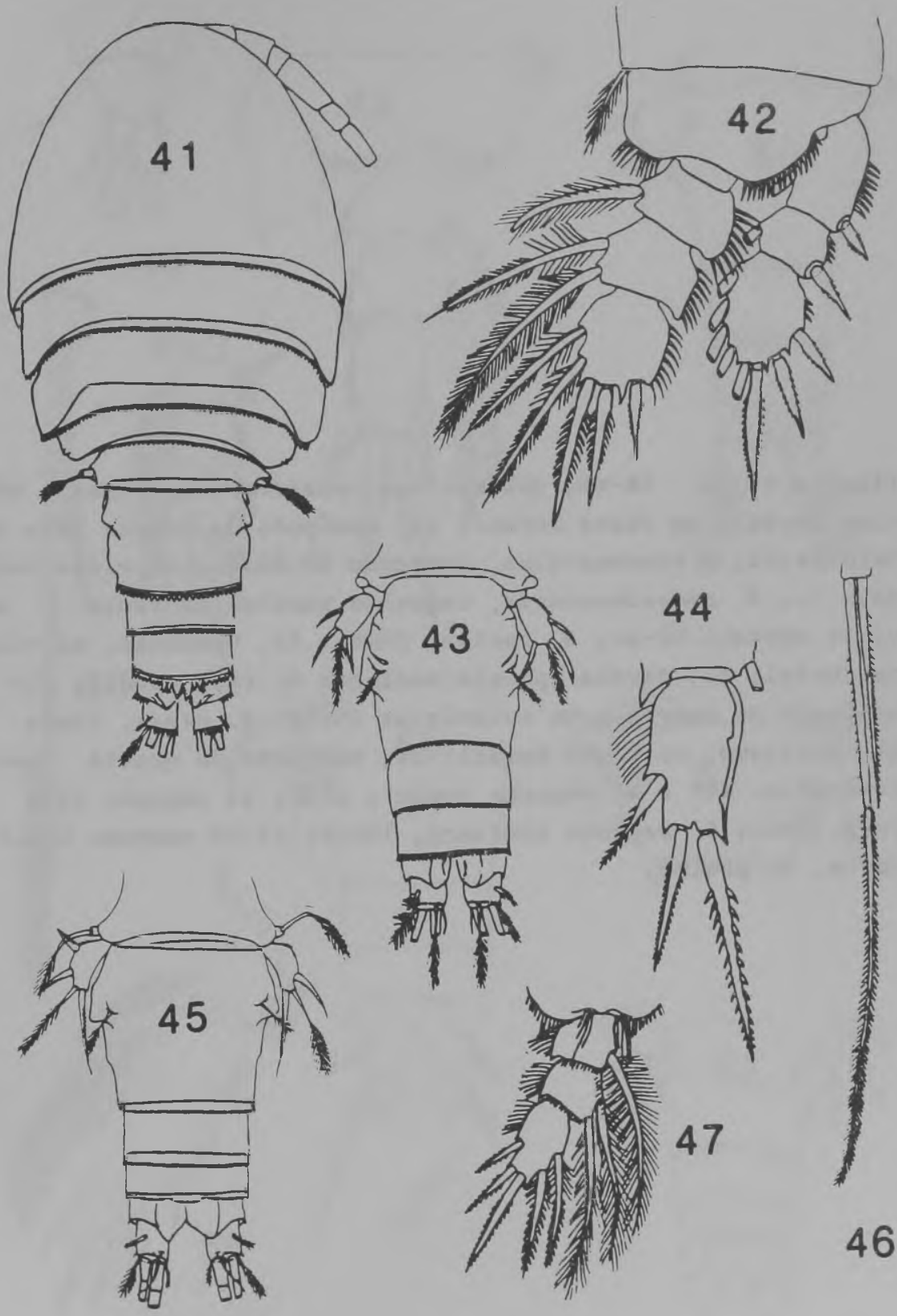


Figuras 48-56: 48-49, Halicyclops craseicornis, fêmea: 48, ramo caudal, em vista dorsal; 49, endôpodo da quarta pata na tatōria;50, H.thermophilus, urossomo da fêmea, em vista dor8al; 51, $H$. oraecburnensis, segmento genital da fêmea, em vista dorsal; 52-54, H. ovatua, fêmea: 52, urossomo, em vista dorsal; 53, cerdas apicals medianas do ramo caudal; 54 , endōpodo da quarta pata natatōria; 55-56, H. verae, fêmea : 55, urossomo, em vista dorsal; 56, endōpodo da quarta pata natatória. (48 e 49 segundo Herbst, 1955; 50 segundo Lind berg, 1952; 51 segundo Lindberg, 1957a; 52-56 segundo C.E.F Rocha, no prelo). 


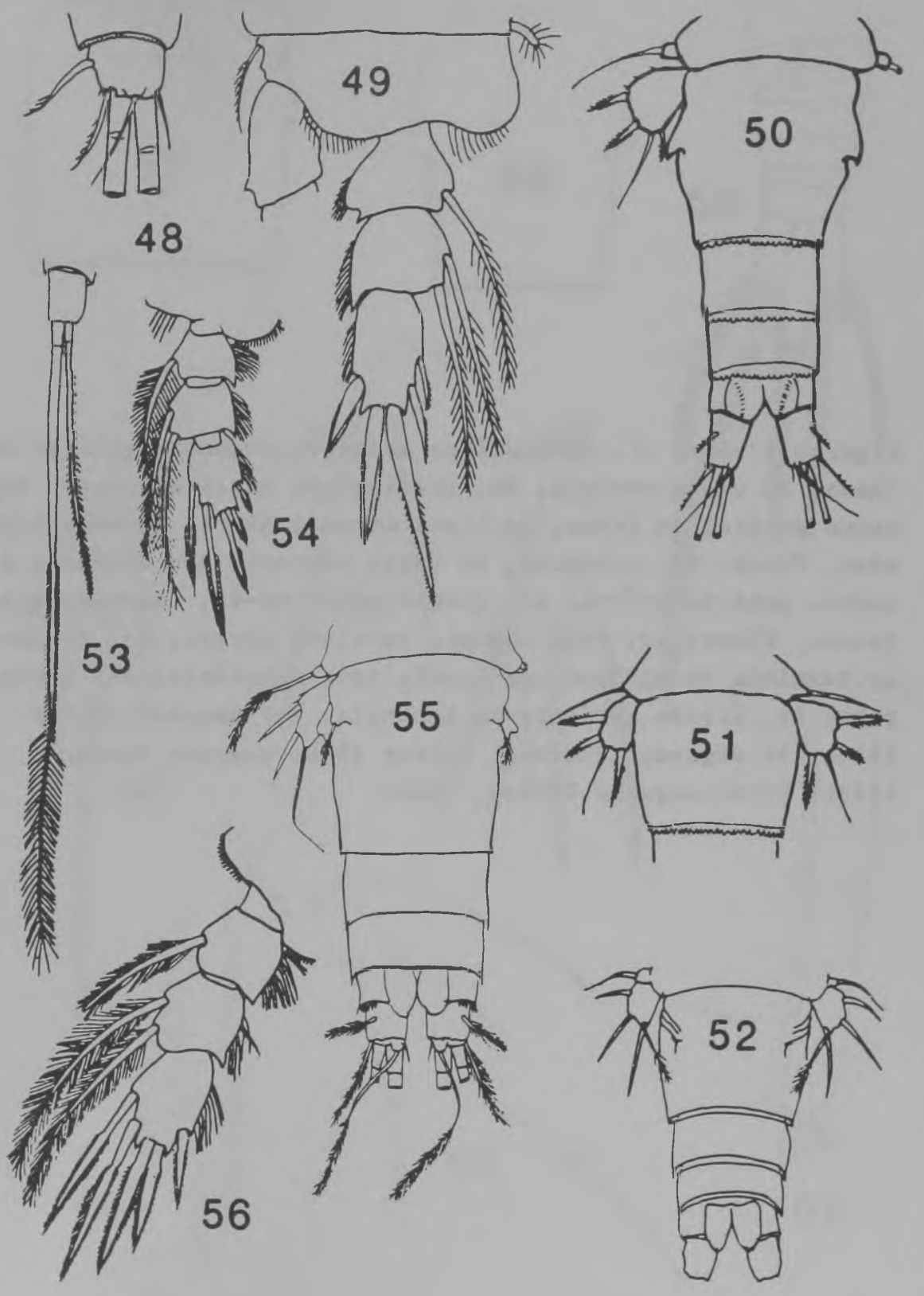


Figuras 57-65: 57, Balicyclops exiguus, segmento genital da fêmea, em vista ventral; 58, Halioyolopo venezuelaensis, seg mento genital da fêmea, em vista dorsal; 59-61, Homooyolops ater, fêmea: 59, urossomo, em vista ventral; 60, endôpodo da quarta pata natatória; 61, quinta pata; 62-65, Macrocuclops fuscus, fêmea: 62, ramo caudal, em vista dorsal; 63, artículo terminal do endópodo da quarta pata natatória; 64, quinta pata; 65, último artículo da antênula. (57 segundo Kiefer, $1936 a$; 58 segundo Lindberg, 1954a; 59-61 segundo Kiefer, 1933b; 62-65 segundo Gurney, 1933). 


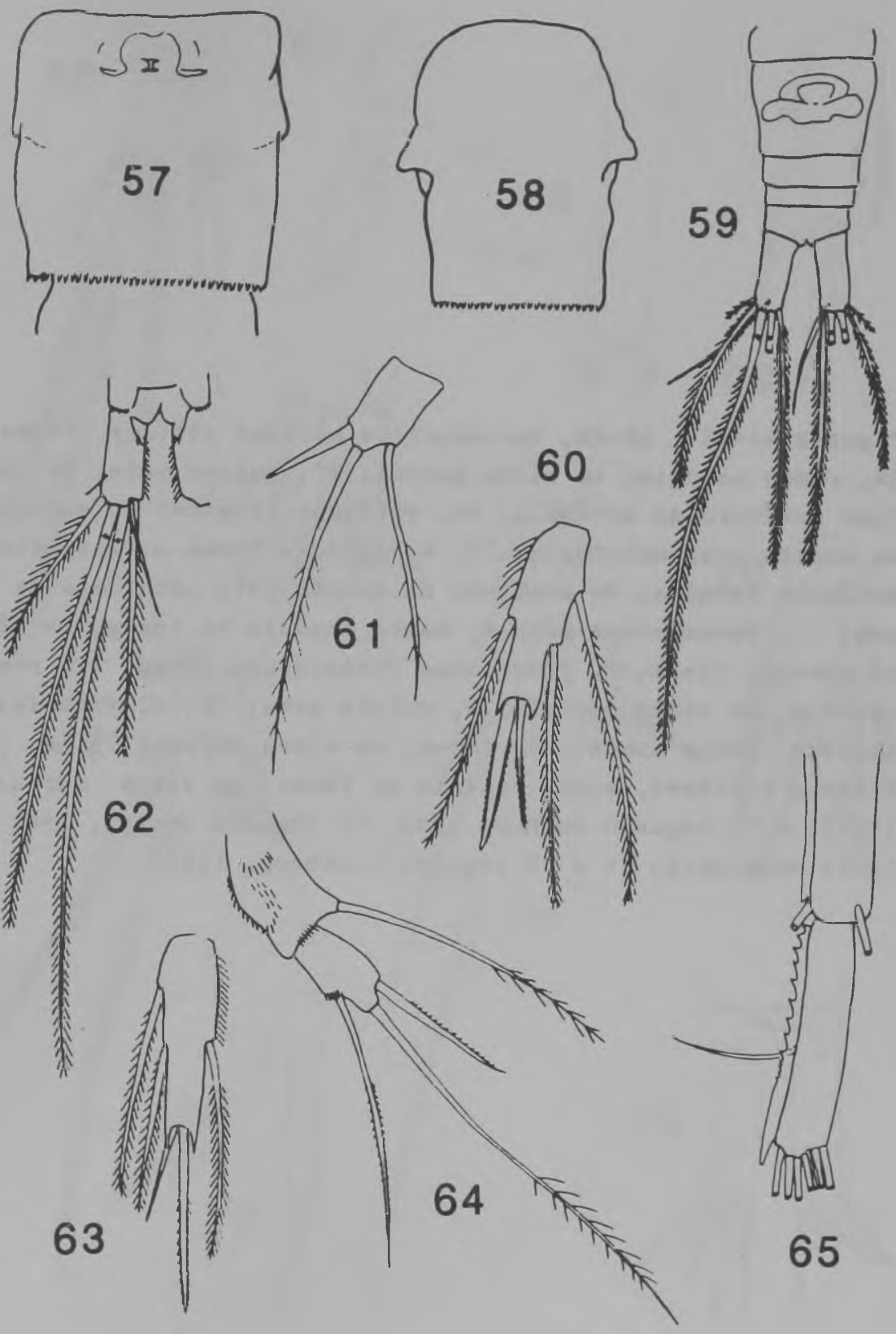


Figuras 66-75: 66-69, Macroovolops albidus albidus, fêmea : 66, ramos caudais, em vista dorsal; 67, quinta pata; 68, ültimo artículo da antênula; 69, articulo terminal do endópodo da quarta pata ratatória; $70, M . a l b i d u s$ forma prinoipalis. articulo terminal do endópodo da quarta pata natatōria da fê mea; 71, Farayclops poppei, ramos caudais da fêmea, em vista dorsal; 72-73, P. fimbriatus fimbriatus, fêmea: 72, ramos caudais, em vista dorsal; 73, quinta pata; 74, P. fimbriatue andinus, ramos caudais da fêmea, em vista dorsal; $75, P$ fim briatus ohiitoni, ramos caudais da fêmea, em vista dorsal (66-69 e 71 segundo Gurney, 1933; 70 segundo Kerbst, 1962 ; 72-73 originais; 74 e 75 segundo Lindberg, 1958) 


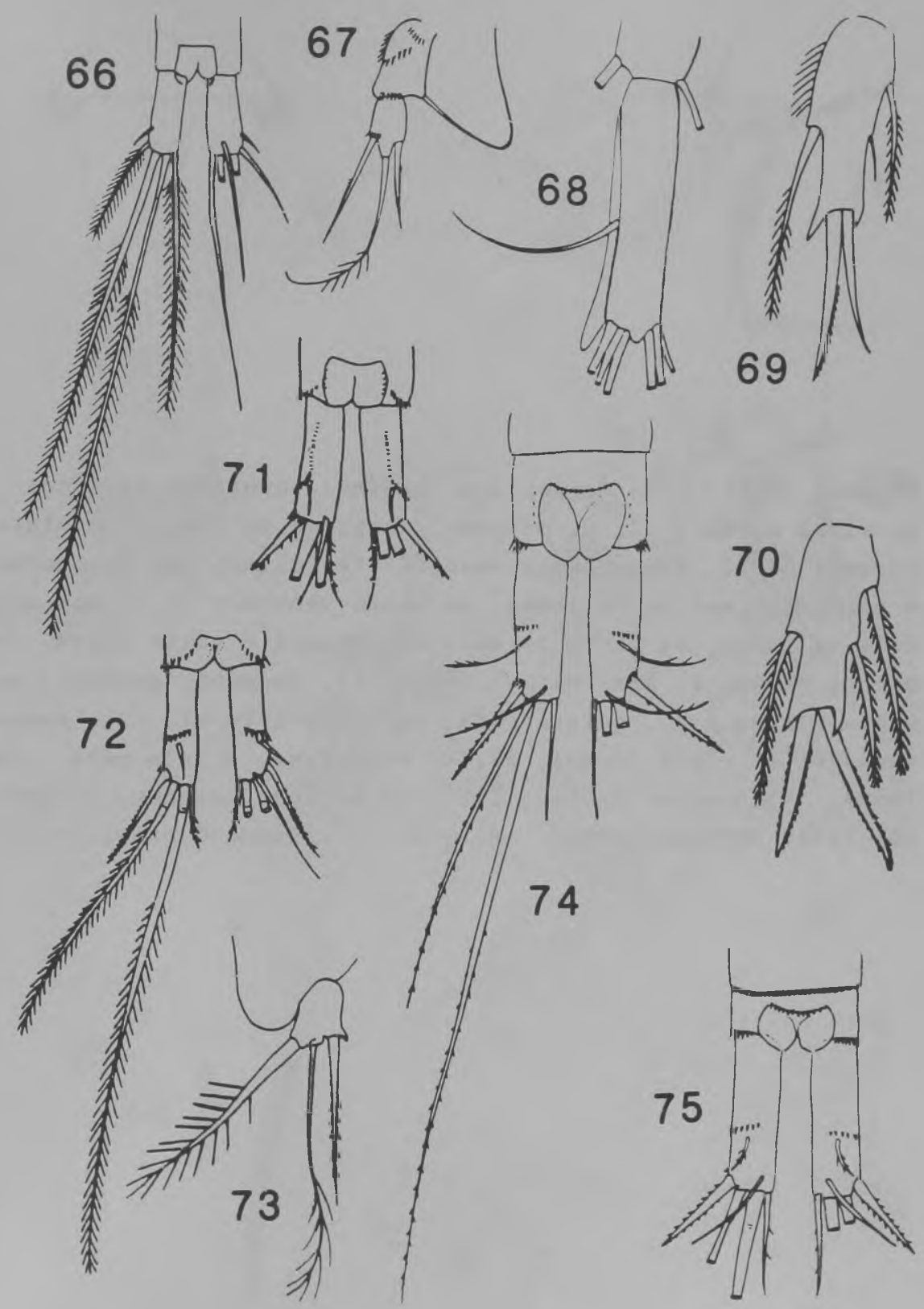


Figuras 76-84: 76, Paracyclops andinus, urossomo da fêmea, em vista dorsal; 77, P. pilosus, urossomo da fêmea, em vista dorsal; 78-80, Eotocyolopo herbsti: 78, quinto par de patas e segmento genital da fémea, em vista ventral; 79 , ramos cau dais da fêmea, em vista dorsal; 80 , quinta e sexta patas do macho; 81-83,E. phaleratus, fēmea: 81, segmento genital, em vista ventral; 82 , quinta pata, em vista lateral; 83, ramos caudais, em vista dorsal; 84, E. rubescene, quinta pata da fêmea. (76 segundo Kiefer, 1957 ; 77 segundo Dussart, no pre10; 78-80 segundo Herbst, 1959; 81-84 segundo Gurney, 1933). 


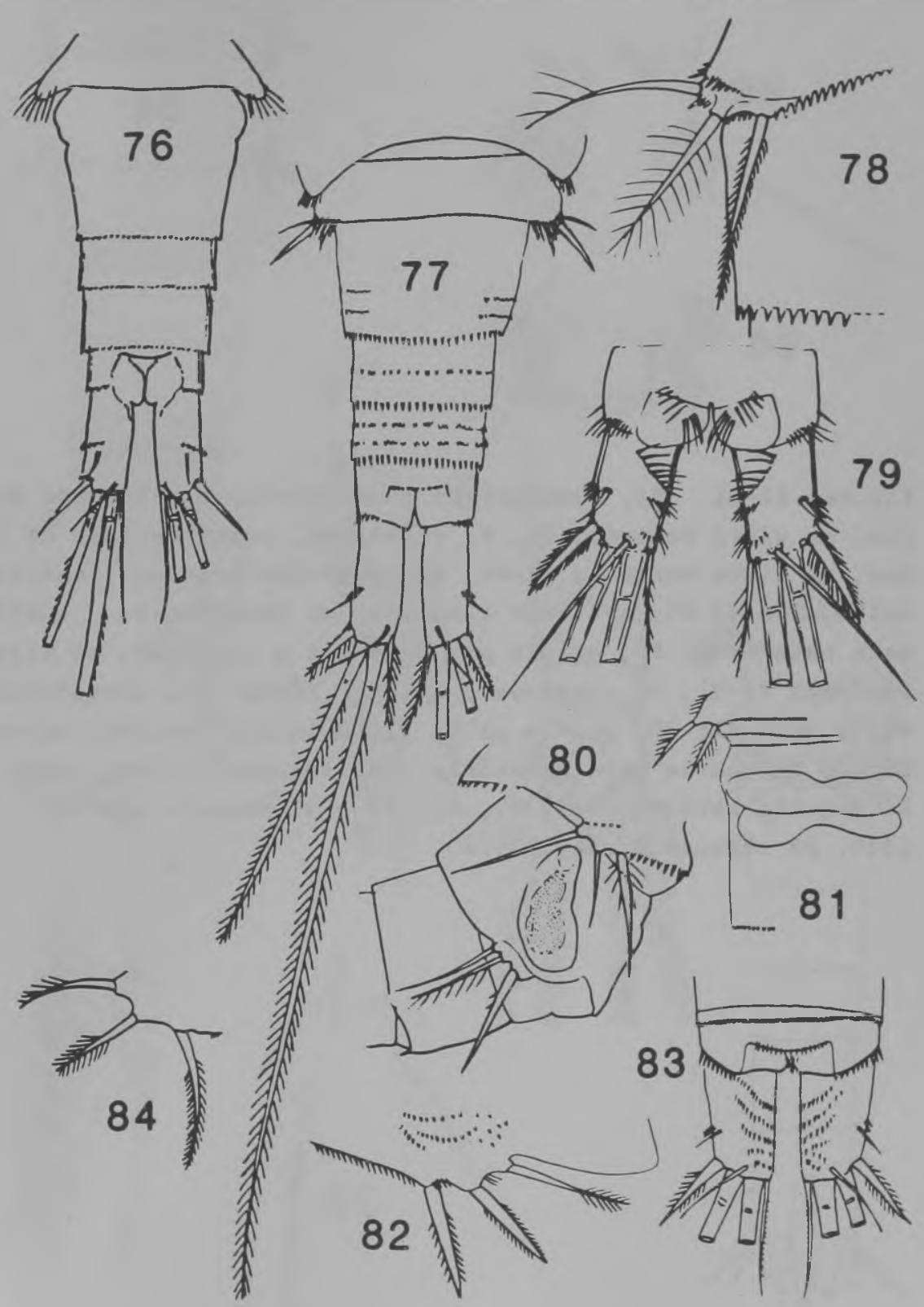


Figuras 85-91: 85, Ectocyolope bromelicola, urossomo do macho, em vista ventral; $86, E$. otrenskei, ramos caudais da fê mea, em vista ventral; 87-88, Tropocyclopo prasinus meridionalis, fêmea; 87, artículo terminal do endōpodo da quarta pata natatória; 88 , quinto par de patas e urossomo, em vista ventral; 89-91, $P$ prasinus prasinus, fêmea: 89, urossomo,em vista ventral; 90, quinta pata; 91, articulo terminal do endópodo da quarta pata natatōria. (85 segundo Kiefer, $1935 \mathrm{~b}$; 86 segundo Herbst, $1959 ; 87,88,90$ e 91 segundo Kiefer, 1956 ; 89 segundo Gurney, 1933 ). 


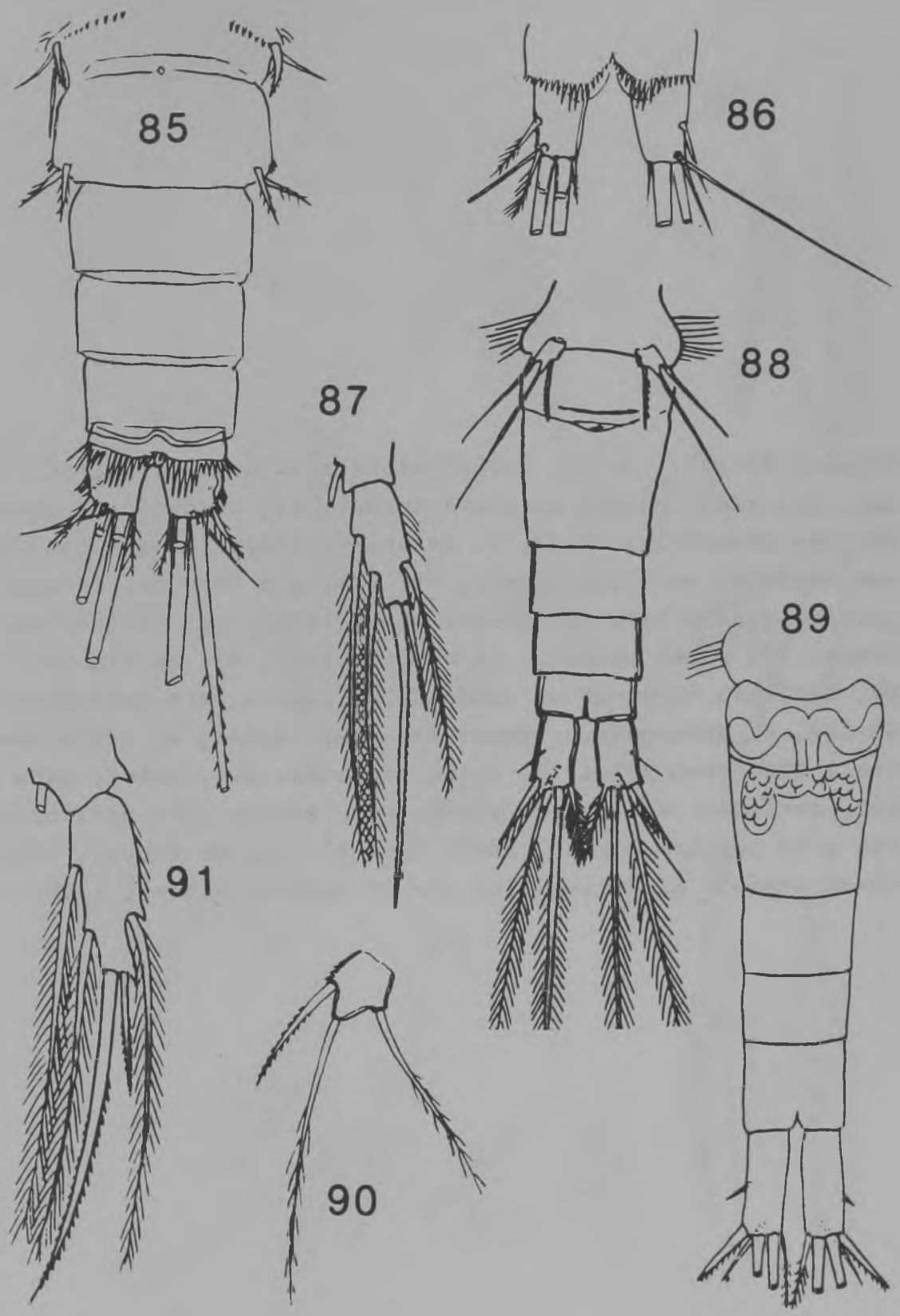


Figuras 92-102: 92-93, Tropocyclops sohubarti schubarti, fê mea: 92, ramo caudal, em vista dorsal; 93, endópodo da quarta pata natatôria; 94-95, $T$ schubarti dispar, fêmea: $94, r \underline{\text { }}$ mos caudais, em vista dorsal; 95, artículo terminal do endōpodo da quarta pata natatória; 96-98, Eucyclops neotropicus, fêmea: 96, ramos caudais, em vista dorsal; 97 , quinta pata; 98, artículo terminal do endópodo da quarta pata natatooria; 99-102, $E$. delachauxi, fêmea: 99, ramo caudal, em vista ventral; 100, ramo caudal de outro espécime; 101, quinta pata; 102, artículo terminal do endôpodo da quarta pata natatöria. (92 e 93 segundo Herbst, 1959; 94 e 95 segundo Herbst, 1962; 96-98 segundo Kiefer, 1936b; 99-102 segundo Kiefer, 1926b). 


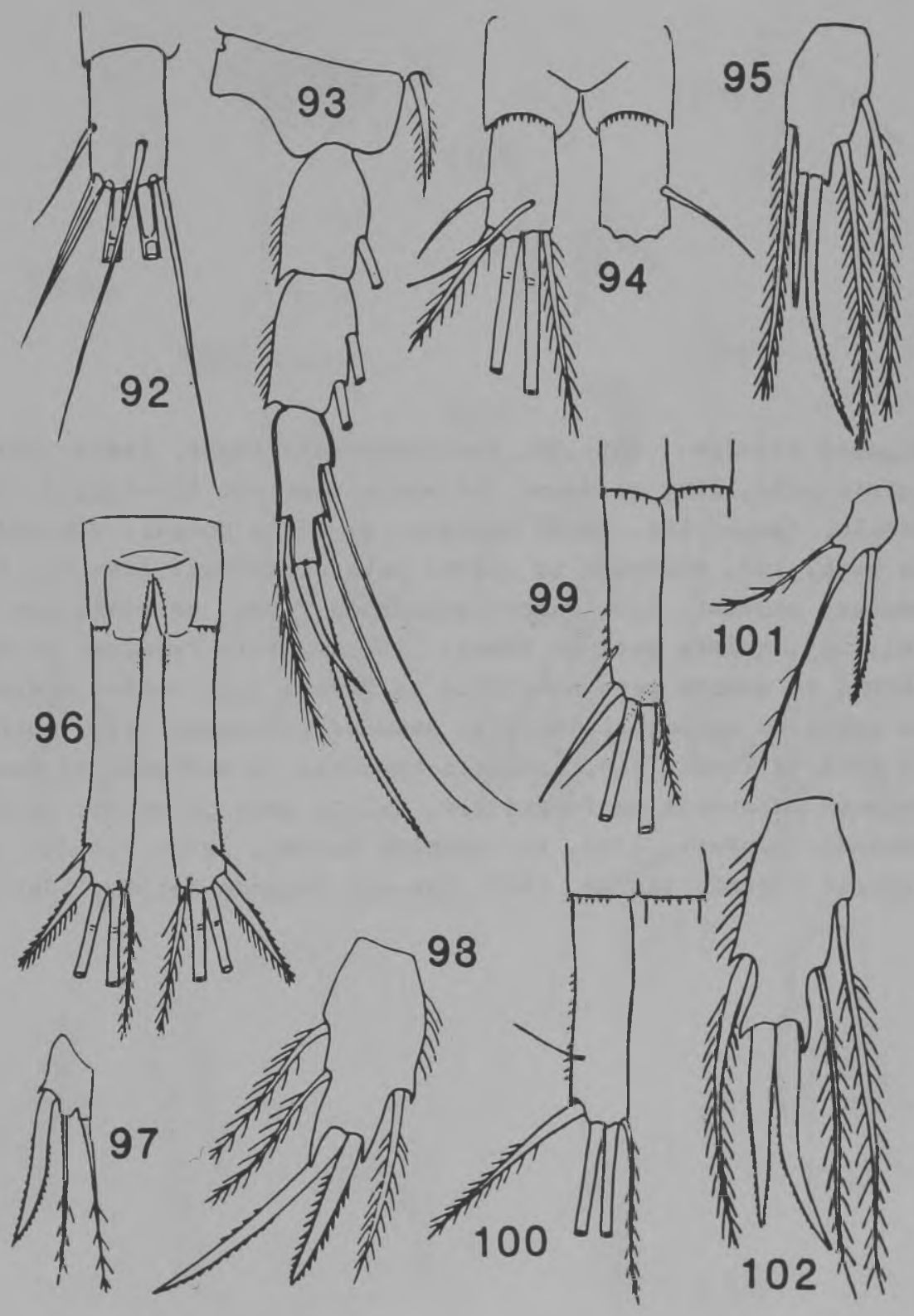


Figuras 103-114: 103-104, Eucyclops serrulatus, fêmea: 103, quinta pata; 104, urossomo, em vista ventral; 105-107, E. a ticola, fêmea: 105, ramos caudais, em vista dorsal; 106,quin ta pata; 107, endópodo da quarta pata natatória; 108-111, $E$. neumani neumani: 108, ramos caudais da fêmea, em vista dor sal; 109, quinta pata da fêmea; 110, artículo terminal do en dópodo da quarta pata natatöria da fêmea; 111, quinta e sexta patas do macho; $112-114, E$. neumani titicacae: 112, quinta pata da fêmea; 113, artículo terminal do endópodo da quar ta pata natatória da fêmea; 114 , quinta pata do macho. (103 segundo Dussart, 1969; 104 segundo Gurney, 1933; 105-107 e 112-114 segundo Kiefer, 1957; 108-111 segundo Herbst, 1962). 


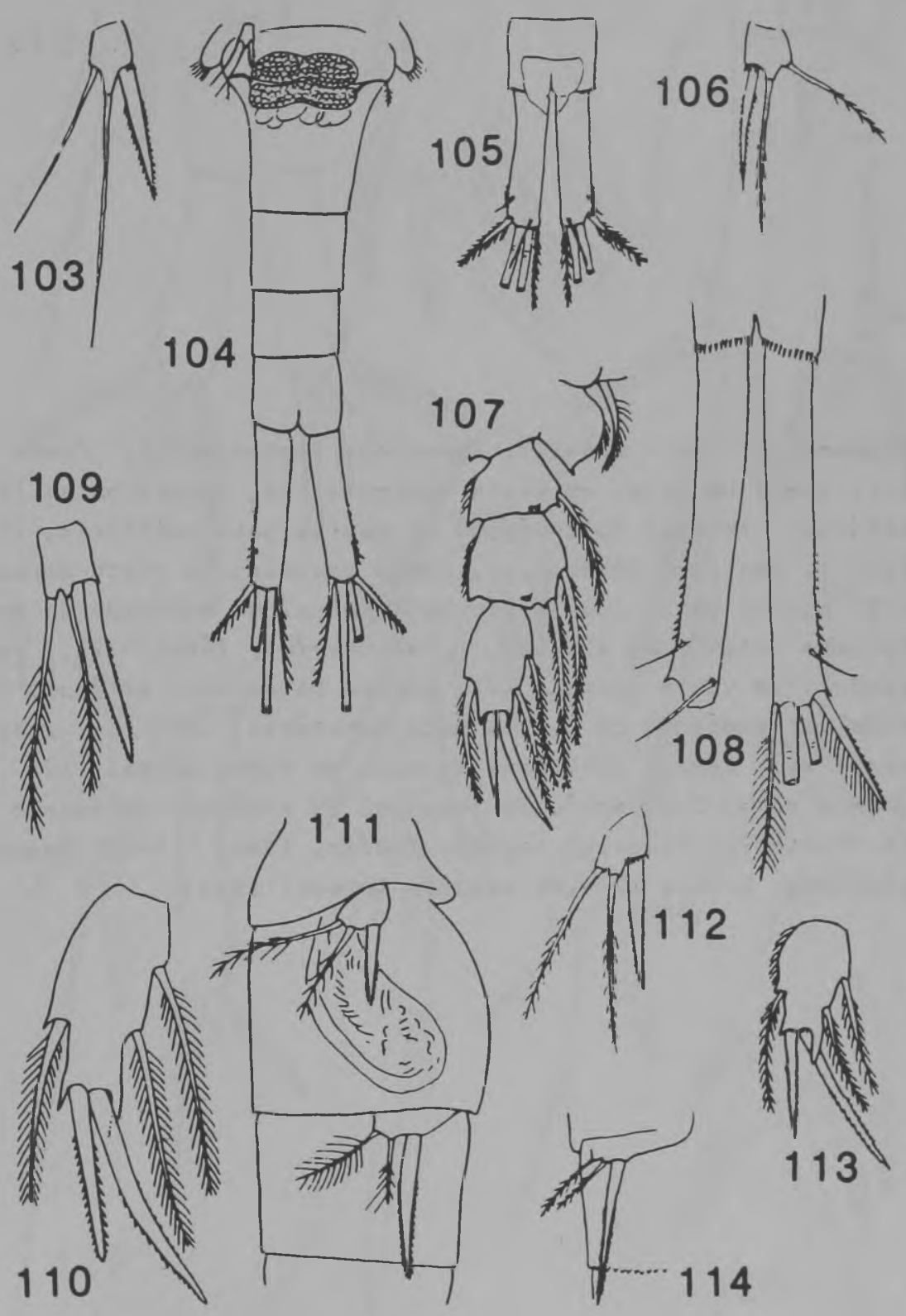


Figuras 115-126: 115-117, Eucyclops leptacanthus, fêmea: 115 , ramos caudais, em vista ventral; 116, quinta pata; 117 , articulo terminal do endópodo da quarta pata natatória; 118 120, E. ensifer, fèmea: 118, ramos caudais, em vista dorsal; 119, quinta pata; 120, artículo terminal do endópodo da quar ta pata natatória; $121-123, E$. solitarius, fêmea: 121, ramo caudal, em vista dorsal; 122, quinta pata; 123 , artículo ter minal do endópodo da quarta pata natatöria; 124-126, Eucy clops sp.. fémea: 124, ramo caudal, em vista dorsal; 125 . quinta pata; 126, artículo terminal do endópodo da quarta pa ta natatória. (115-117 segundo Kiefer, 1956; 118-120 segundo Lindberg, 1954a; 121-126 segundo Herbst, 1959). 


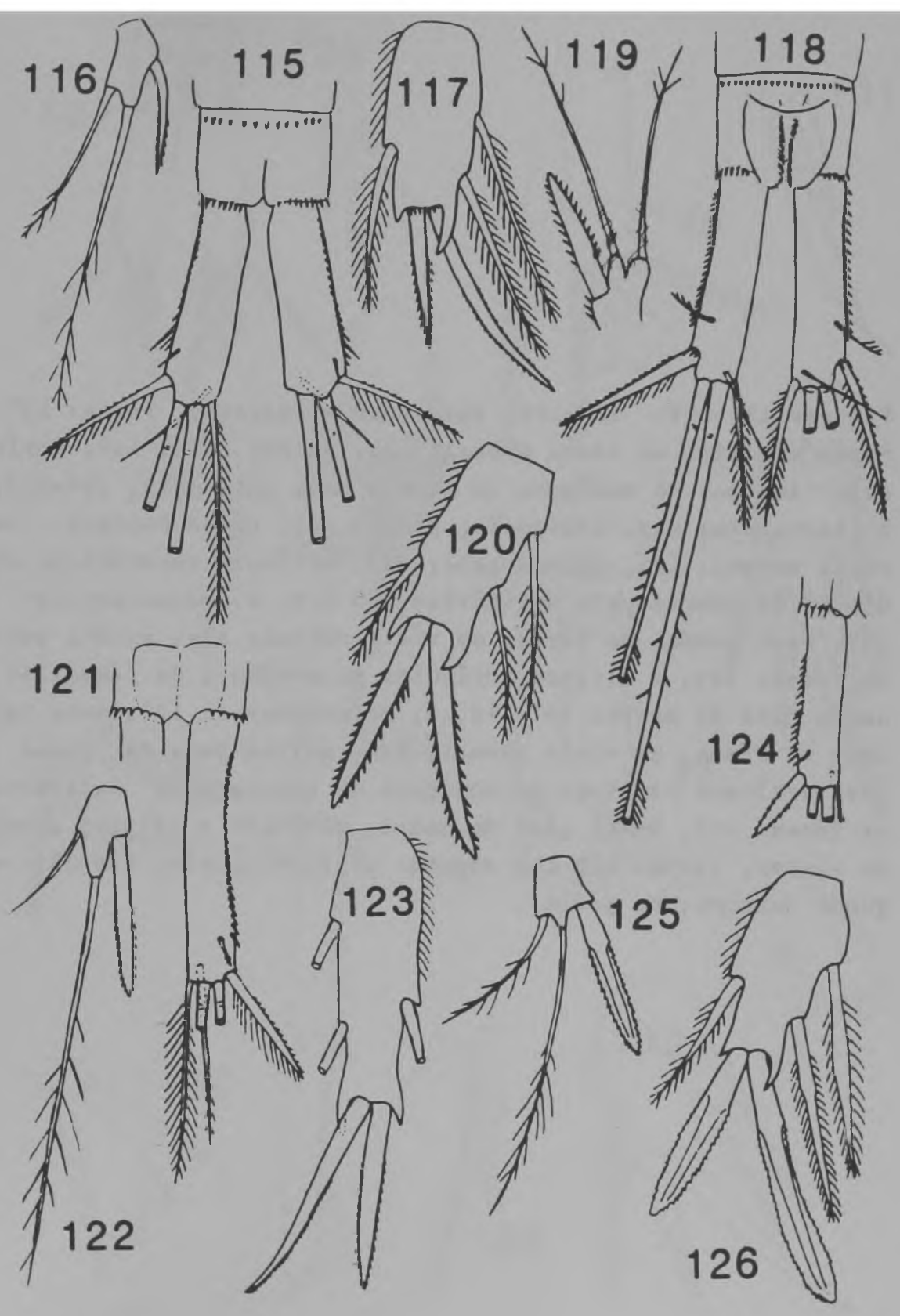


Figuras 127-140: 127-129, Euoyclops silvestrit, fêmea: 127 , ramos caudais, en vista dorsal; 128, quinta pata; 129, articulo terminal do endōpodo da quarta pata natatórias 130-132, E. serrulatus var. ohilensis, fêmea: 130, ramos caudais, em vista dorsal; 131, quinta pata; 132, artículo terminal do en dópodo da quarta pata natatória; 133-136, E. pseudoenoifer : 133, ramo caudal da fêmea, em vista dorsal; 134, quinta pata da fêmea; 135, 3 ültimos artículos da antênula da fêmea;136, sexta pata do macho; 137-140,E. prionophorus: 137 , ramos cau dais da fêmea, em vista dorsal; 138, quinta pata da fêmea; 139, artículo terminal do endópodo da quarta pata natatória da fêmea; 140 , sexta pata do macho. (127-129 e 137-140 segun do Kiefer, 1936e; 130-132 segundo Ldffler, 1961a; 133-136 8e gundo Dussart, no prelo). 


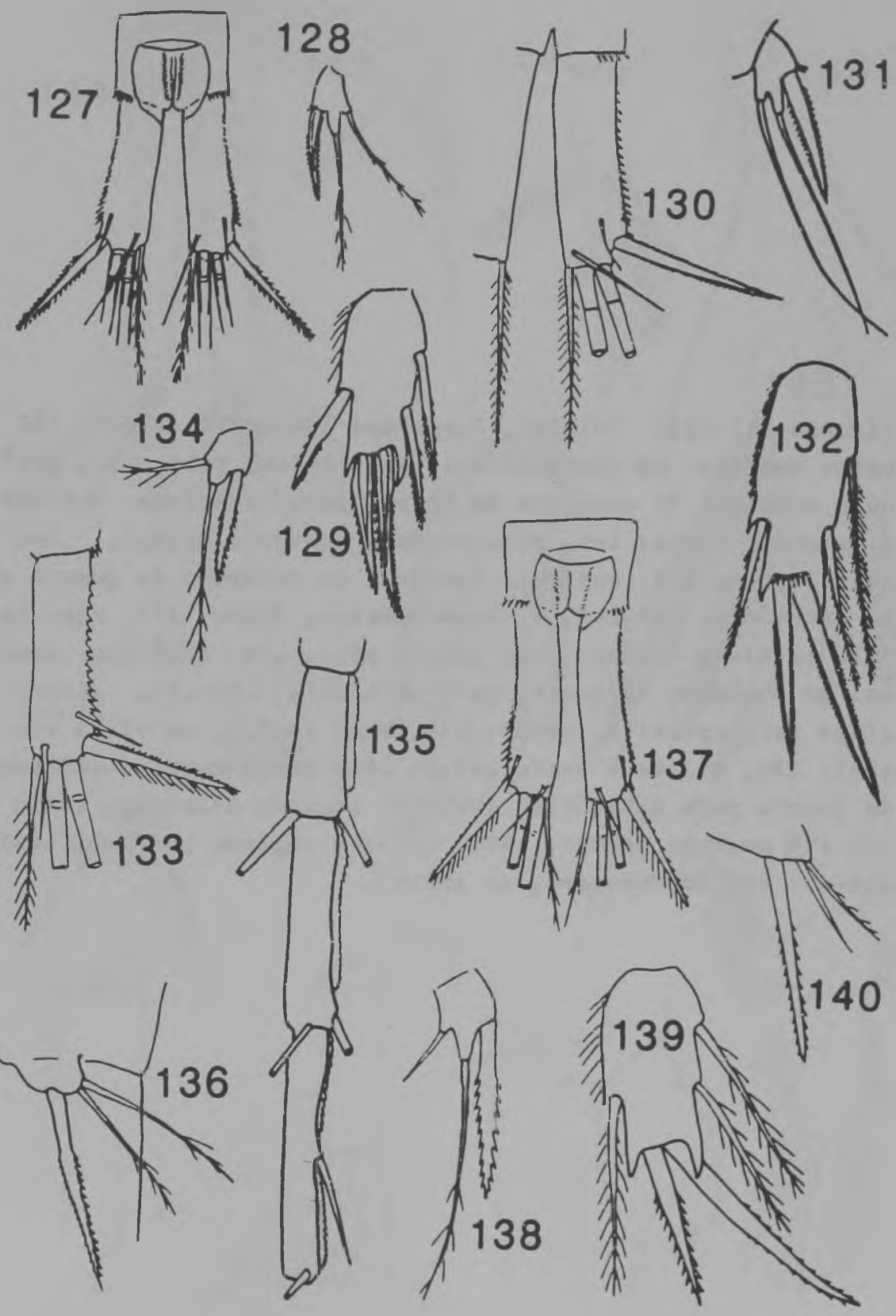


Figuras 141-152: 141-143, Eucyolops demacedoi, fêmea: 141 , ramos caudais, em vista dorsal; 142, quinta pata; 143, articulo terminal do endöpodo da quarta pata natatória; 144-146, $E$. oiolii, fêmea: 144, ramo caudal, em vista dorsal; 145 , quinta pata; 146, artículo terminal do endópodo da quarta pa ta natatória; 147-149, E. breviramatus, fêmea: 147, ramo cau dal, em vista dorsal; 148, quinta pata; 149, articulo terminal do endópodo da quarta pata natatória; 150-152, Al200y clopo neotropicalis, macho: 150, ramo caudal, em vista ven tral; 151, quinta e sexta patas; 152, placa basal e endópodo da quarta pata natatória. (141-143 segundo Lindberg, 1957b; 144-146 segundo Herbst, 1962: 147-149 segundo Loffler, 1963; 150-152 segundo Dussart, no prelo). 


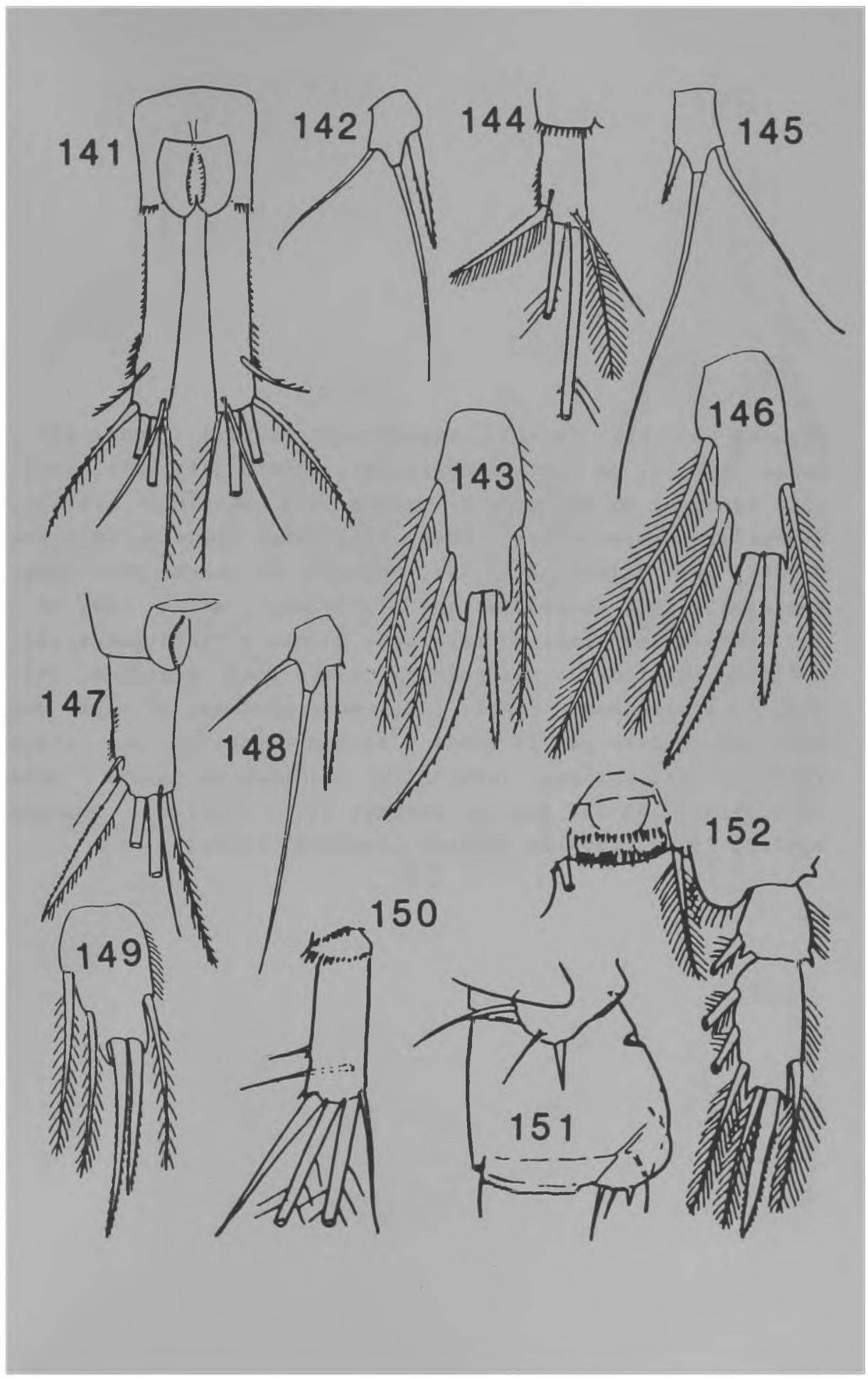


Figuras 153-164: 153-155, Megacyolops viridis, fêmea: 153 , ramos caudais, em vista dorsal; 154 , quinta pata; 155, articulo terminal do endópodo da quarta pata natatōria; 156-158, Diacyclops uruguayencis, fêmea: 156, ramos caudais, em vista dorsal; 157, quinta pata; 158 , endópodo da quarta pata natatória; 159-161, Acanthocyolopo skottobergi, macho: 159, ra mos caudais, em vista dorsal; 160, quinta e sexta patas;161, artículo terminal do endópodo da quarta pata natatöria: 162164, A. michasloeni, fêmea: 162, ramos caudais, em vista dor 8al; 163, quinto par de patas e segmento genital, em vista ventral; 164, artículo terminal do endópodo da quarta pata natatöria. (153-155 segundo Gurney, 1933; 156-158 8egundo Kiefer, 1935a , 159-164 segundo Lindberg, 1949a). 


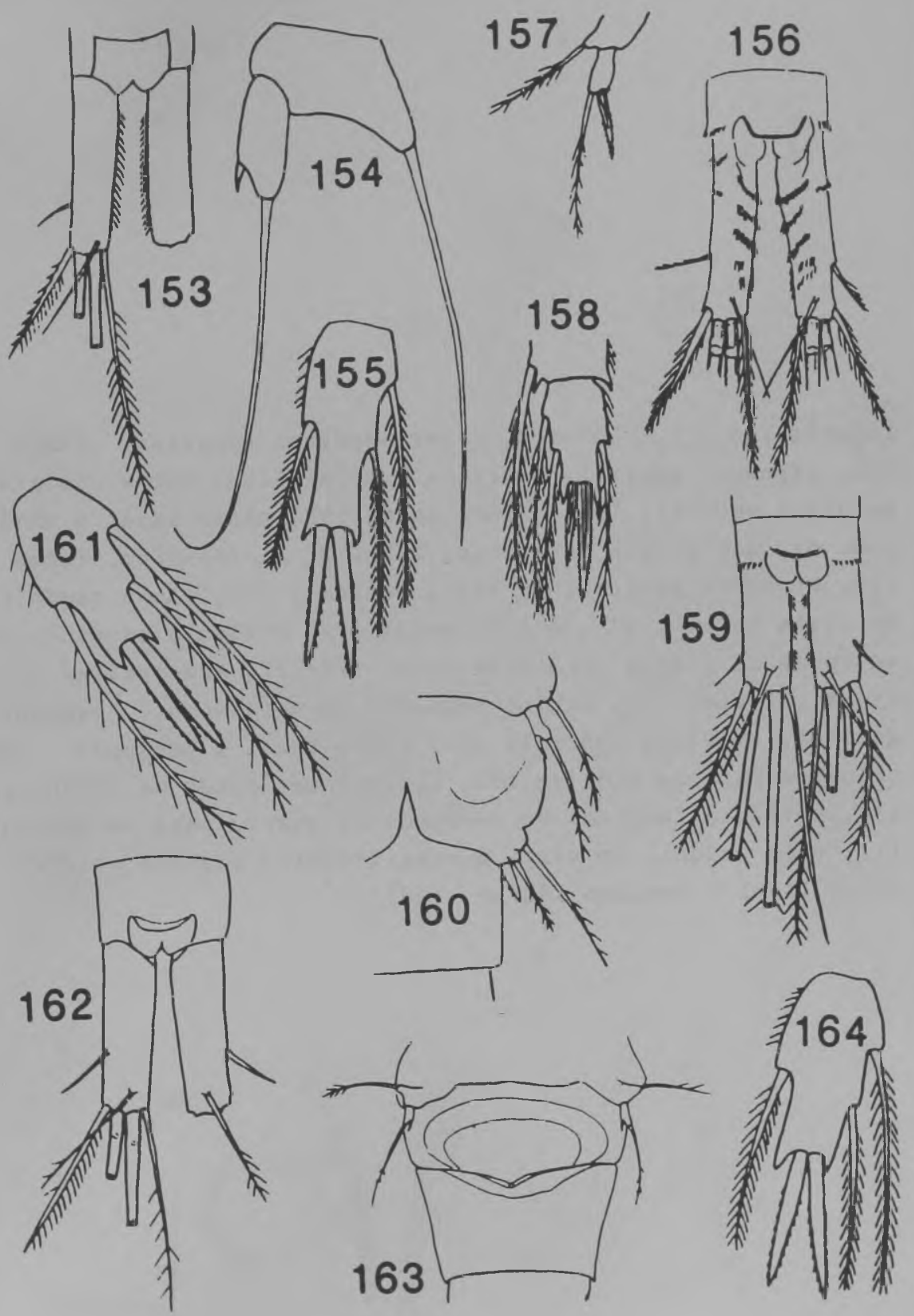


Figuras 165-177: 165-168, Acanthocyclops robustus, fêmea : 165, segmento genital, em vista ventral; 166, ramos cauda1s, em vista ventral; 167 , quinta pata; 168, placa basal e endōpodo da quarta pata natatória; 169-172, A. vernalis, fêmea : 169, segmento genital, em vista ventral; 170 , ramos caudais, em vista dorsal; 171, quinta pata; 172, articulo terminal do endôpodo da quarta pata natatória; 173-177, Mesocyolopo Zeuokarti, fêmea: 173, ûltimo segmento do metassomo e segmento genital, em vista ventral; 174, placa basal e basipodo da primeira pata natatória; 175, ûltimos artículos da antênula; 176, articulo terminal do endópodo da quarta pata natatória; 177, ramo caudal, em vista dorsal. (165-172 segundo Klefer, 1976 ; 173-177 segundo Kiefer, 1981). 

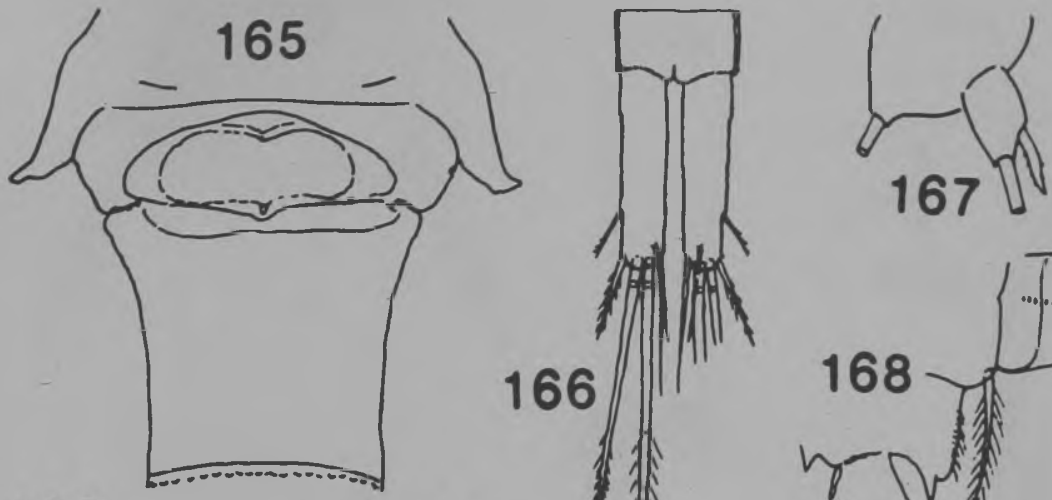

169
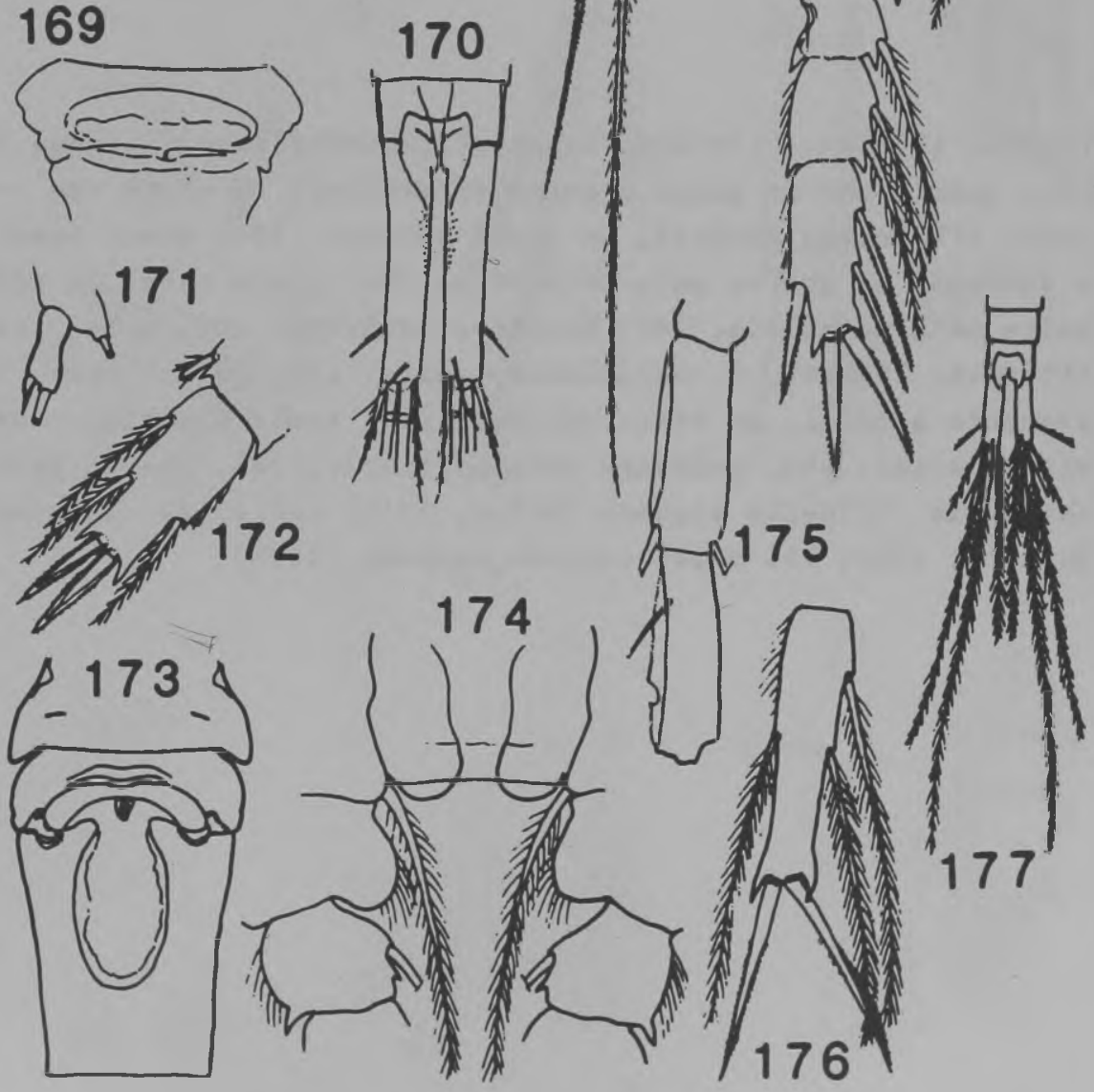

66
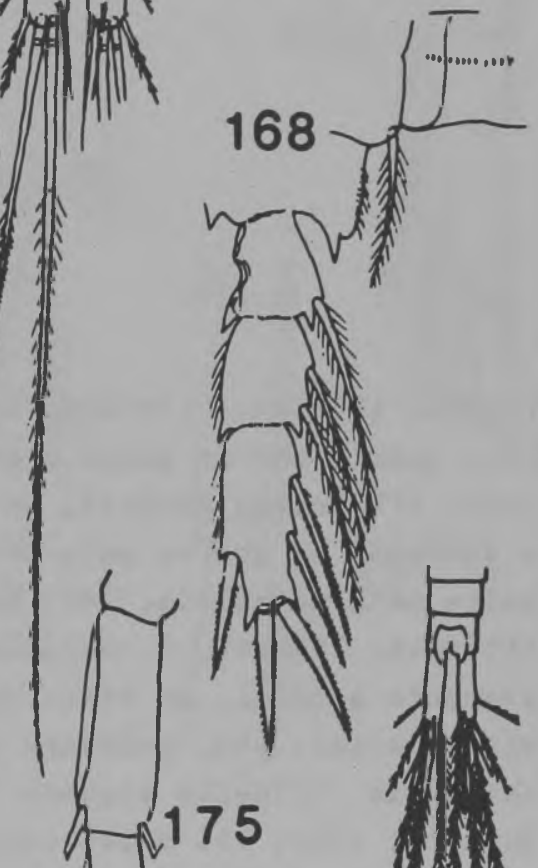

175

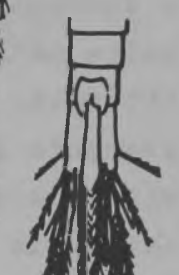


Figuras 178-186: 178-182, Mssocyclops brasilianus, fêmea : 178, quinto par de patas e segmento genital, em vista ven tral; 179, ramos caudais, em vista ventral; 180, placa basal e endópodo da quarta pata natatória; 181, placa basal da pri meira pata natatória; 182, ûltimo e penûltimo artículos da antênula; $183-186$, M. meridianus, fêmea: 183, quinta pata e segmento genital, em vista ventral; 184, ramos caudals, em vista dorsal; 185, primeira pata natatôria; 186, quarta pata natatöria. (178-182 segundo Kiefer, 1956; 183 e 184 segundo Harding, 1955 ; 185 e 186 segundo Lowndes, 1934) 

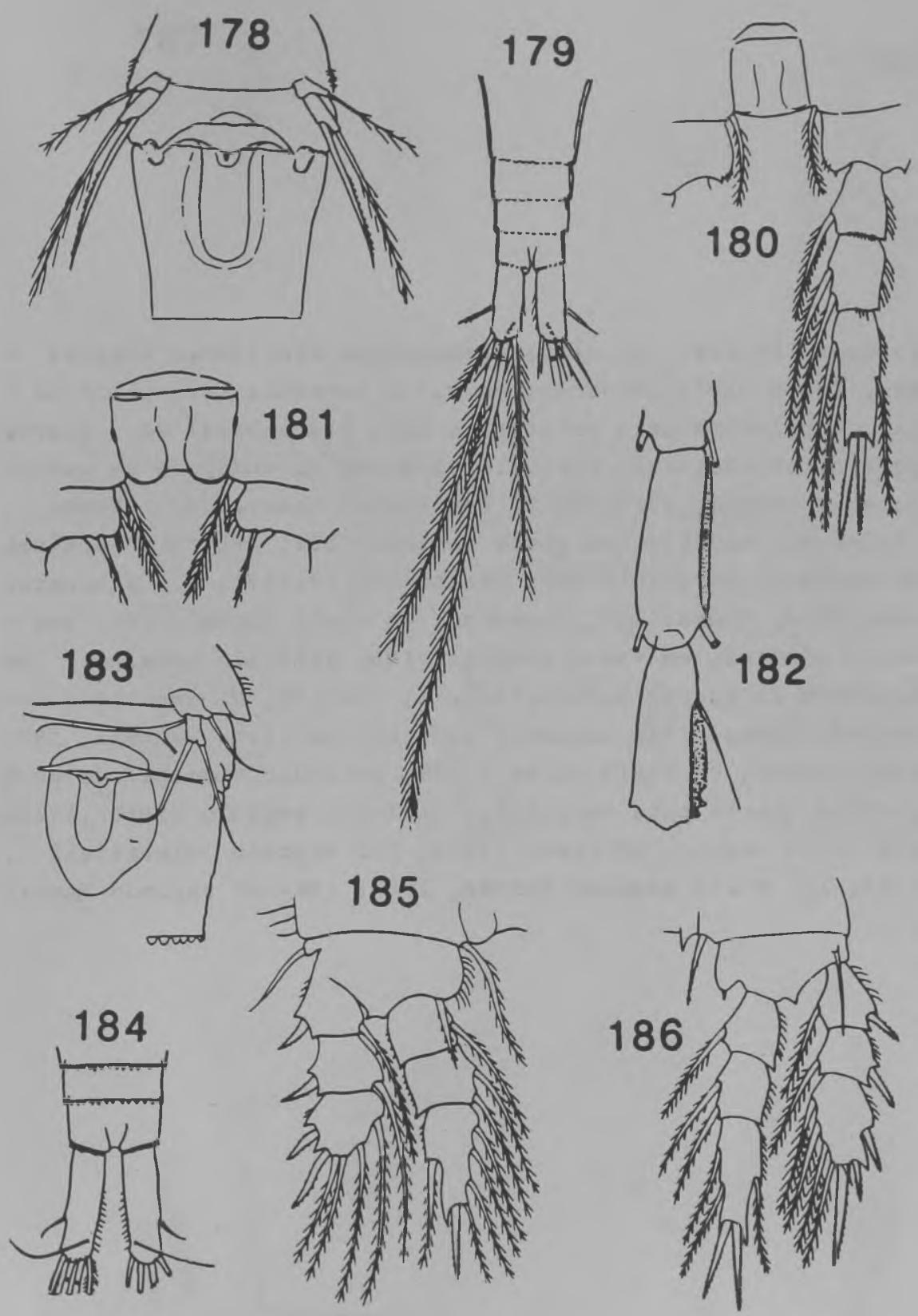
Figuras 187-198: 187-190, Mesocyclops Longisetus Zongise tus, fêmea: 187, urossomo, em vista ventral; 188, placa ba sal da primeira pata natatória; 189, placa basal da quarta pata natatōria; 190, artículo terminal do endōpodo da quarta pata natatória; 191-192, M. Zongisetus araucanus, fêmea : 191, ramos caudais, em vista ventral; 192, articulo terminal do endópodo da quarta pata natatória; $193-195, M$. annuzatus annulatus, fêmea: 193, urossomo, em vista dorsal; 194, seg mento genital, em vista ventral; 195, articulo terminal do endópodo da quarta pata natatória; 196-198, $M$. annuzatus diversus, fêmea: 196, segmento genital, em vista ventral; 197 , ramo caudal, em vista dorsal; 198 , articulo terminal do endó podo da quarta pata natatōria. (187-190 segundo Kiefer,1936a; 191 e 192 segundo Loffler, 196la; 193 segundo Wierzejski. 1982; 194 e 195 segundo Kiefer, 1957; 196-198 segundo Herbst, 


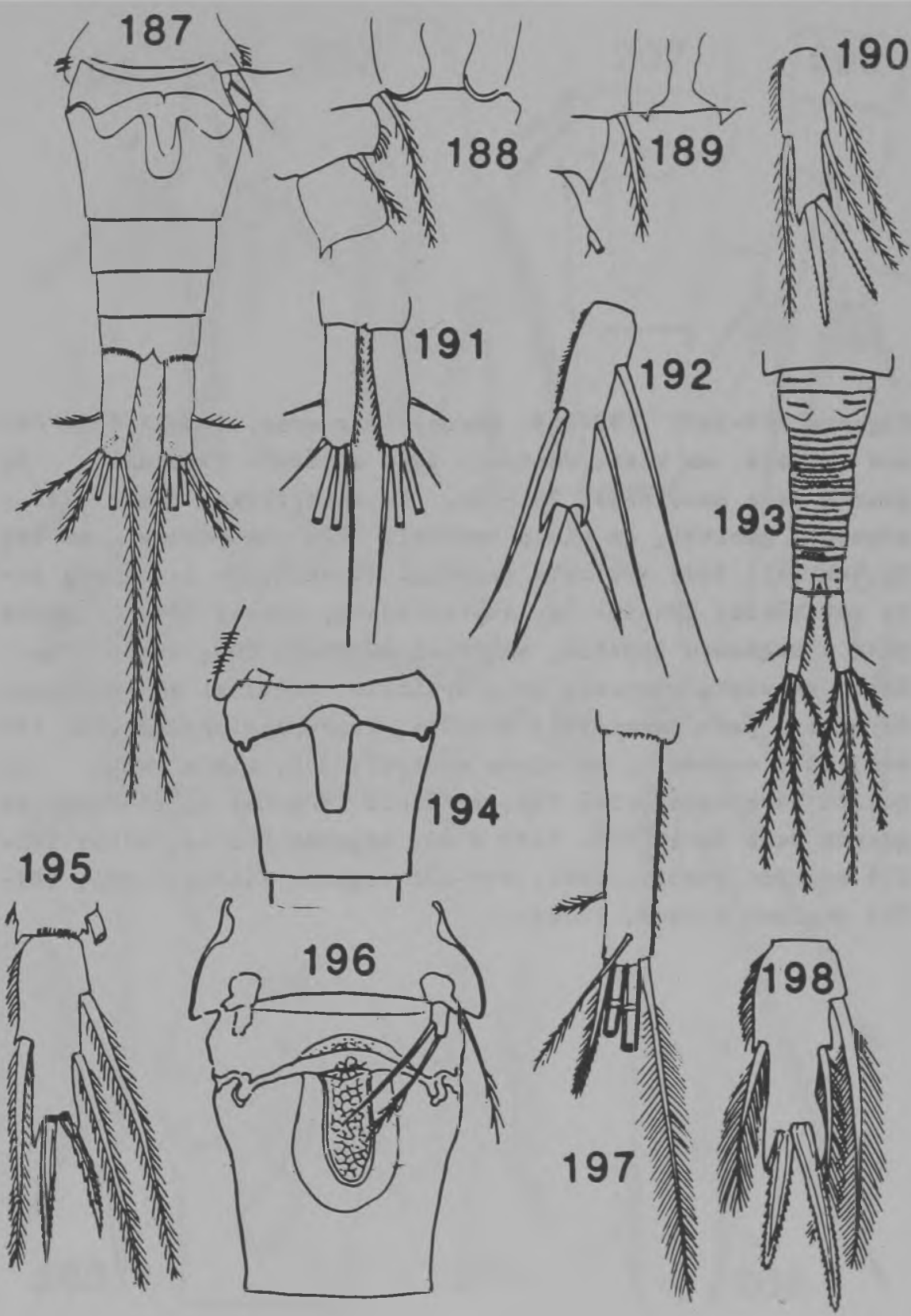


Figuras 199-209: 199-200, Mesocyolops edax, fêmea: 199, ramos caudais, em vista ventral; 200, articulo terminal da quarta pata natatôria; 201-203, M. ellipticus, fêmea: 201 . segmento genital, em vista ventral; 202, ramo caudal, em vis ta ventral; 203, artículo terminal do endópodo da quarta pata natatôria; 204-206, M. aspericornie, fêmea: 204, quinta pata e segmento genital, em vista ventral; 205, ramos cau dais, em vista ventral; 206, articulo terminal do endópodo da quarta pata natatōria; 207-209, Thermocyclops tenuis, fêmea; 207, urossomo, em vista ventral; 208, placa basal da quarta pata natatória; 209, artículo terminal do endópodo da quarta pata natatória. (199 e 200 segundo Forbes, 1890; 201 203 segundo Herbst, 1962; 204-206 segundo Kiefer, 1981; 207209 segundo Kiefer, 1936d). 


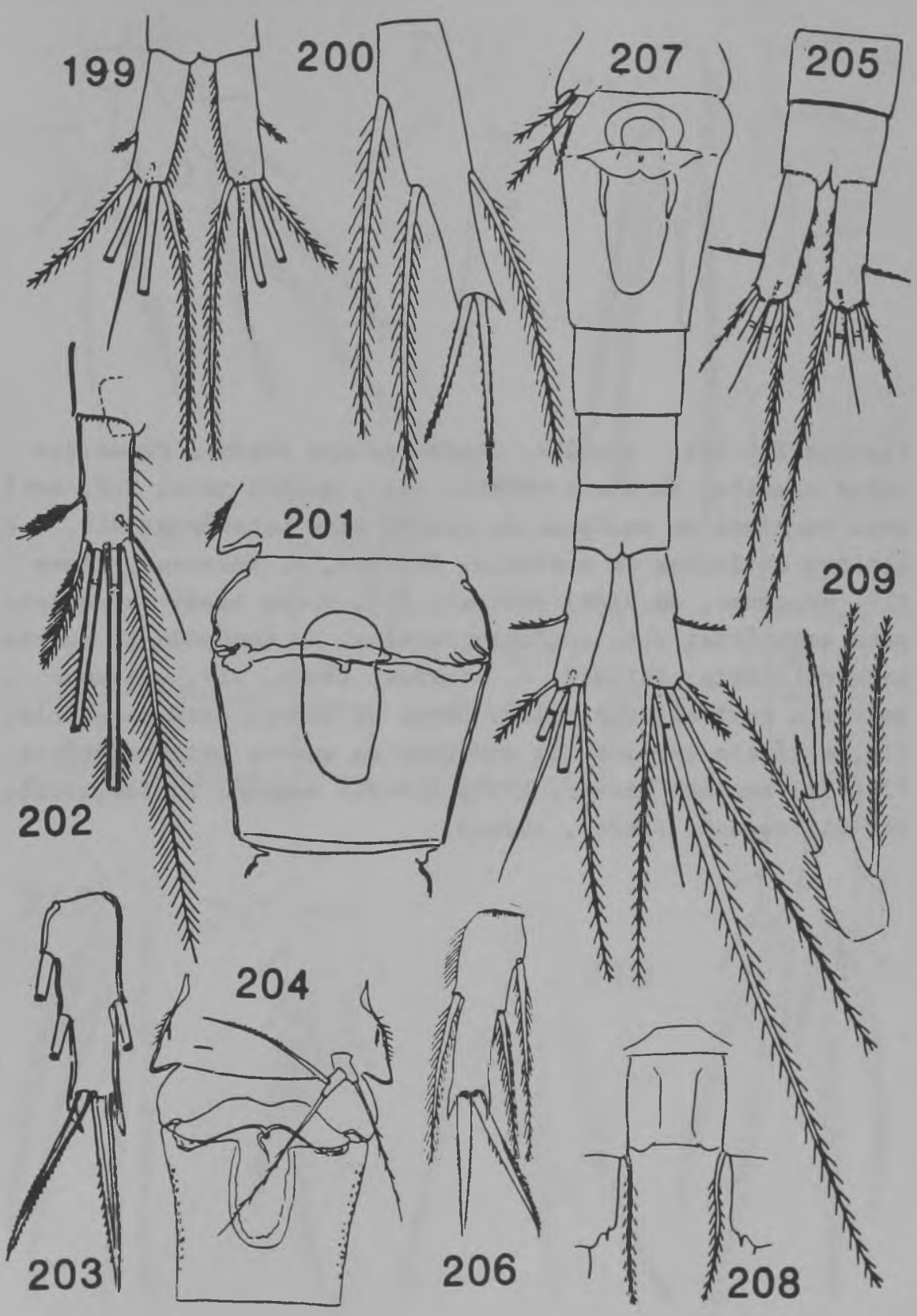


Figuras 210-219: 210-213, Thermocyclops brehmi, fêmea:210, ramos caudais, em vista ventral; 211, quinta pata; 212, arti culo terminal do endópodo da quarta pata natatória; 213,3 ültimos artículos da antênula; 214-216, T. inveraus, fêmea : 214, urossomo, em vista ventral; 215, placa basal da quarta pata natatória; 216, artículo terminal do endópodo da quarta pata natatôria; 217-219, T. minutus, fêmea: 217, urossomo, em vista ventral; 218, placa basal da quarta pata natatória; 219, articulo terminal do endópodo da quarta pata natatôria. (210-213 segundo Kiefer, 1927; 214-216 segundo Kiefer,1936b; 217-219 segundo Kiefer, 1936d). 


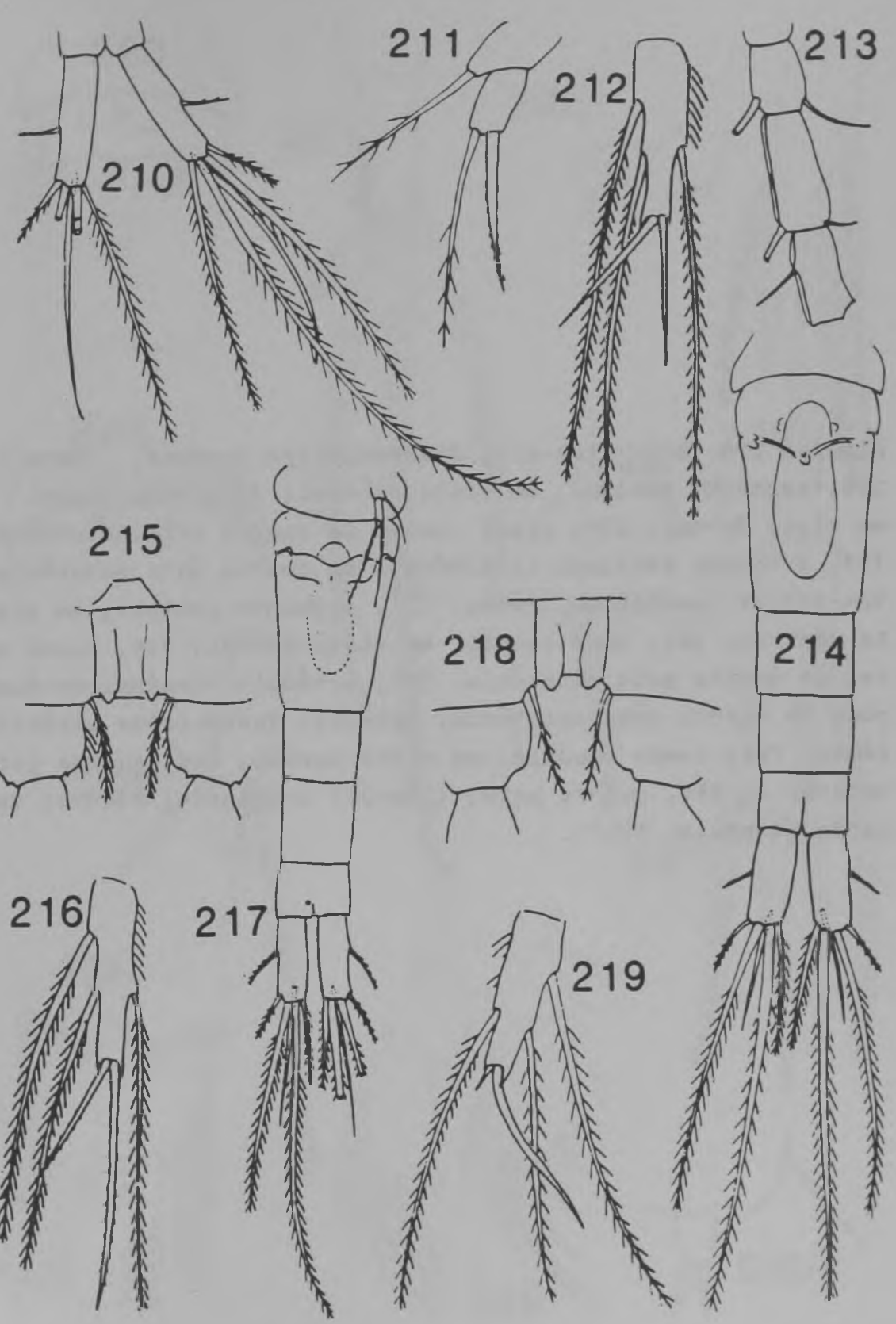


Figuras 220-230: 220-223, Thermocyclops crassus, fêmea : 220, segmento genital, em vista ventral; 221, ramo caudal, em vista dorsal; 222, placa basal da quarta pata natatória; 223 , artículo terminal do endópodo da quarta pata natatöria; 224-227, T deoipiens, fêmea: 224, segmento genital, em vista ventral; 225, ramo caudal, em vista dorsal; 226, placa ba sal da quarta pata natatória; 227, articulo terminal do endó podo da quarta pata natatória; 228-230, Menzelielza otaheli, fêmea: 228, ramos caudais, em vista dorsal; 229, quarta pata natatória; 230 , quinta pata. (220-227 originais; 228-230 segundo Chappuis, 1917 ). 


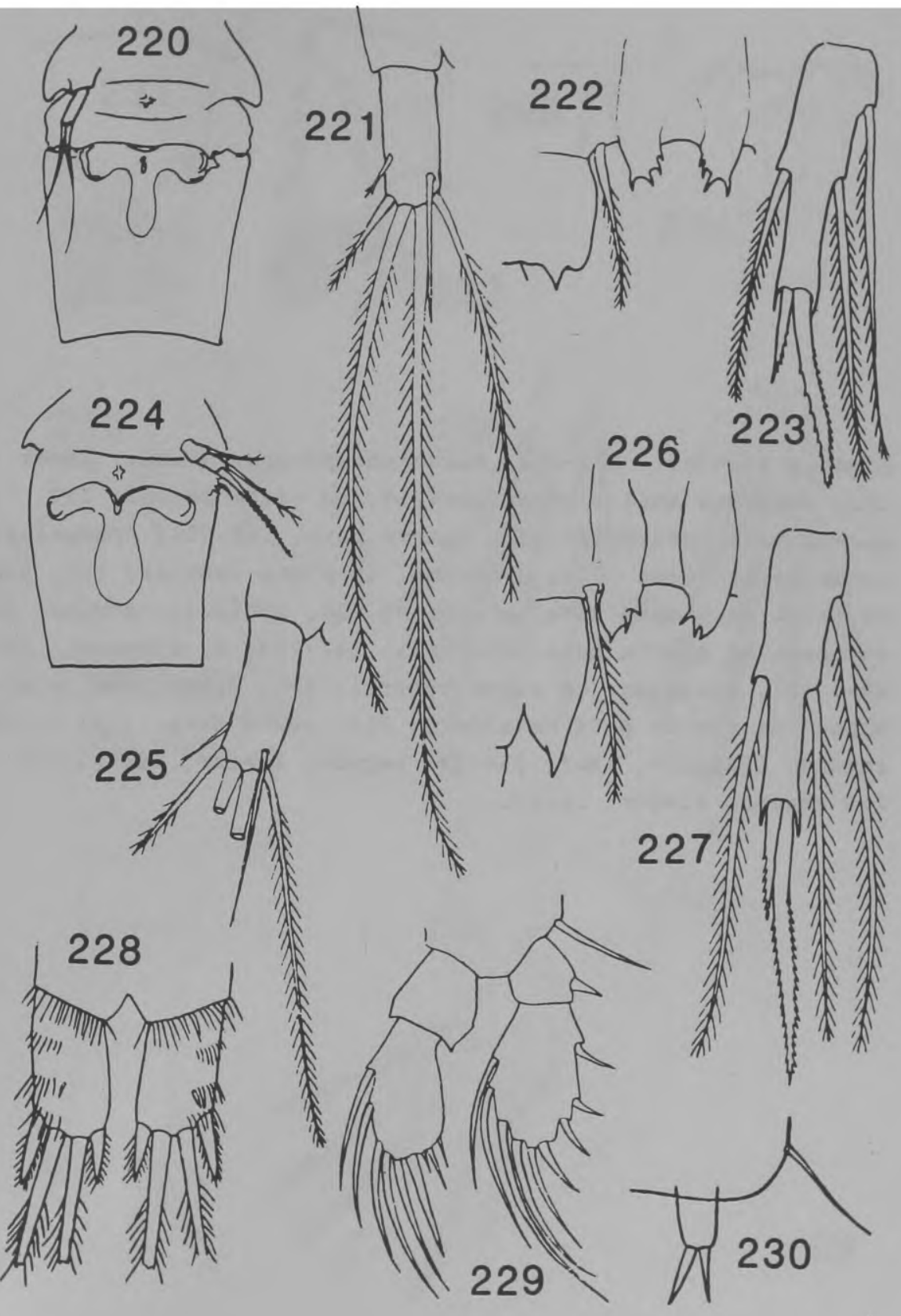


Figuras 231-239: 231-233, Muscocyclops operculatus, fêmea : 231, segmento anal e ramos caudais, em vista dorsal; 232 , quarta pata natatória; 233, quinta pata; 234-236, Apocyclops panamensio, fêmea: 234, urossomo, em vista ventral; 235 , pla ca basal da quarta pata natatória; 236, articulo terminal do endōpodo da quarta pata natatória; 237-239, A. distans, fêmea: 237, urossomo, em vista ventral; 238, placa basal e endópodo da quarta pata natatôria; 239 , sexta pata. (231 - 233 segundo Chappuis, 1917; 234-236 segundo Kiefer, 1936a; 237 239 segundo Kiefer, 1956 ). 

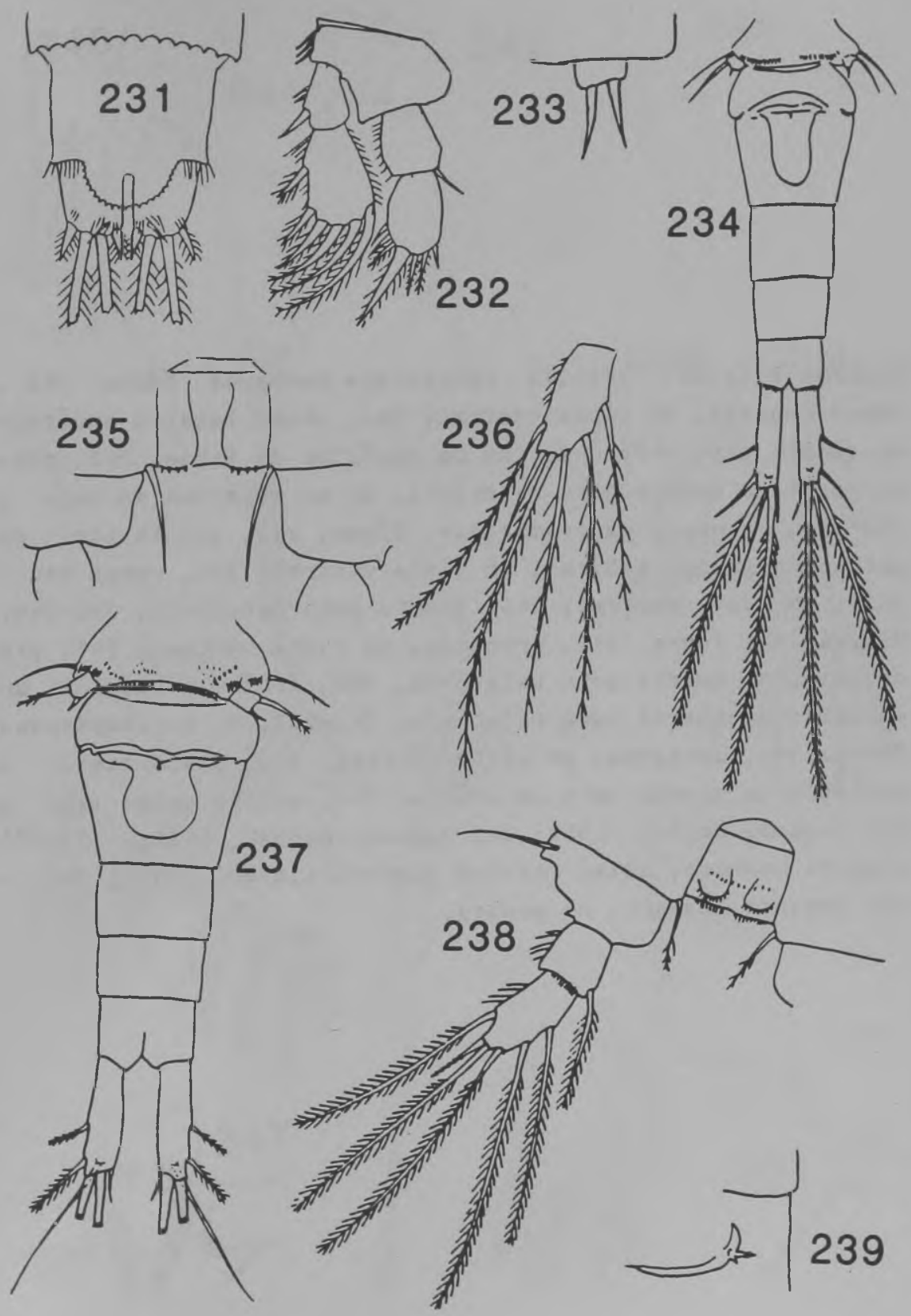
Figuras 240-251: 240-242, Apocyclops procerus, fêmea: 240 , ramos caudais, em vista ventral; 241, placa basal e endópodo da quarta pata natatória, de um espêcime da Bahia; 242, placa basal da quarta pata natatória, de um espécime do Peru ; 243-245, Netacyclops tredecimus, fémea, 243, quinto par de patas e segmento genital, em vista ventral; 244, ramos cau dais, em vista ventral; 245, quarta pata natatōria; 246-248, M. grandis, fêmea: 246, urossomo, em vista ventral; 247 , pla ca basal da quarta pata natatória; 248, artículo terminal do endópodo da guarta pata natatória; 249-251, M. curtiopinosus, fêmea: 249, urossomo, em vista ventral: 250 , placa basal e endópodo da quarta pata natatória; 251 , quinta pata. $(240$ e 241 segundo Herbst, 1955; 242 segundo Herbst, 1960; 243-245 segundo Lowndes, 1934; 246-248 segundo Kiefer, 1935a; 249 251 segundo Dussart, no prelo). 


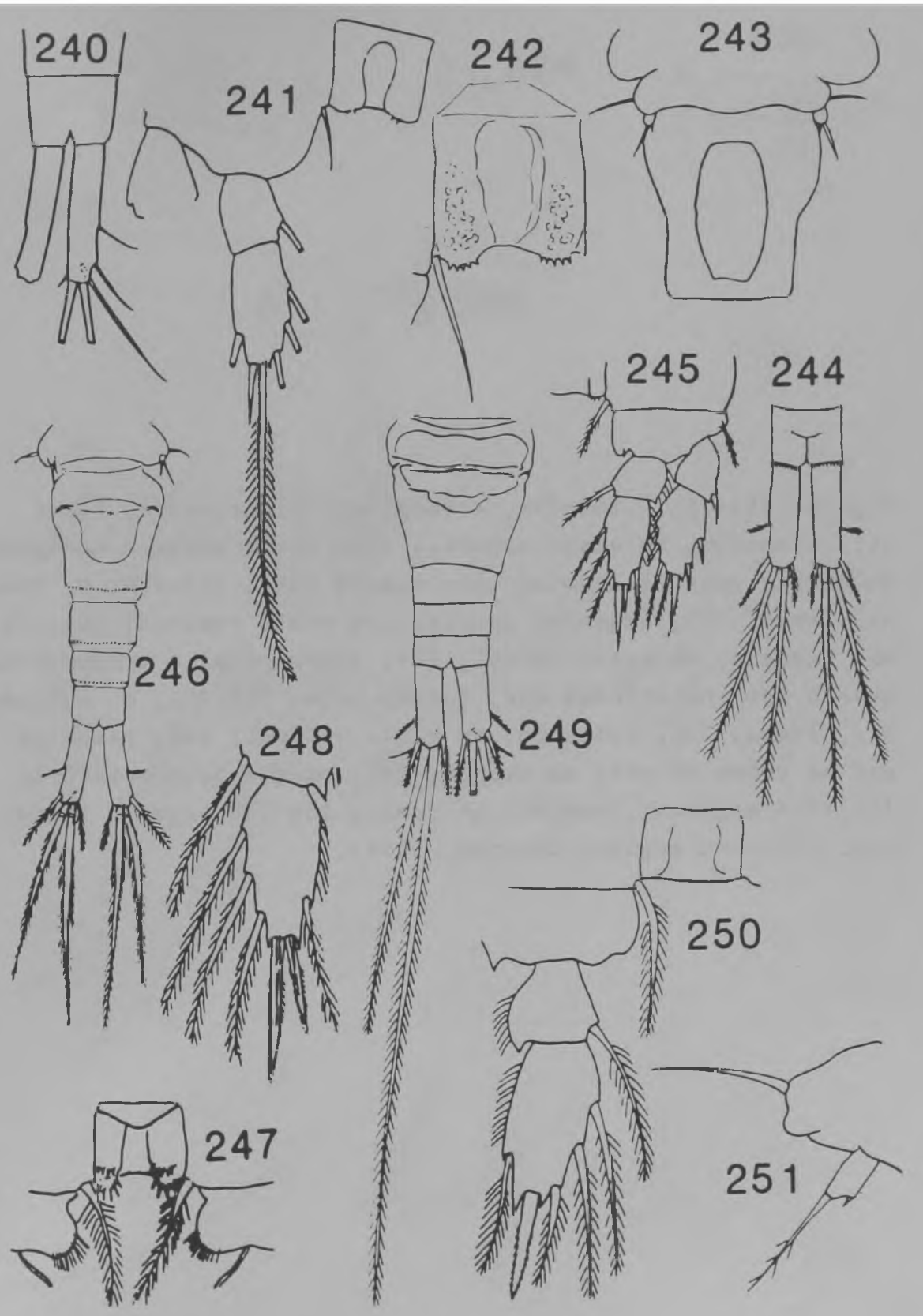


Figuras 252-261: 252-254, Metacyclops subaequalis, fêmea : 252, urossomo, em vista ventral; 253, placa basal e endōpodo da quarta pata natatória; 254, quinta pata; 255-258, M. brau ni, fêmea: 255 , segmento genital, em vista ventral; 256, ramos caudais, em vista dorsal; 257, placa basal e endöpodo da quarta pata natatória; 258, quinta pata; 259-261, M. Zaticor nis, fêmea: 259, urossomo, em vista ventral; 260, placa ba sal da primeira pata natatória; 261, quarta pata natatória (252-254 segundo Dussart, no prelo; 255-258 segundo Herbst, 1962; 259-261 segundo Lowndes, 1934). 


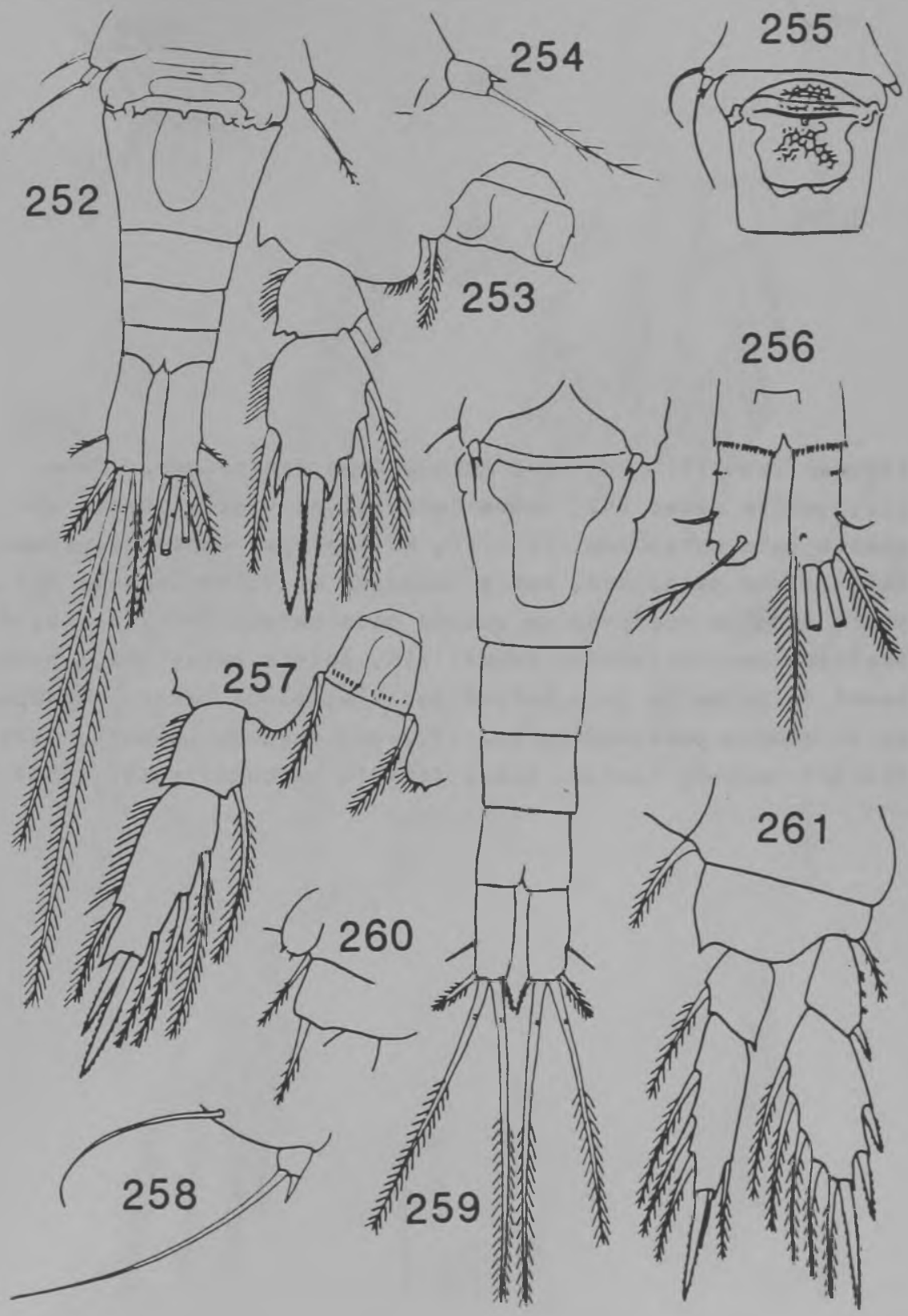


Figuras 262-270: 262-264, Metacyolops mendocinus, fêmea : 262, quinta pata; 263, ramos caudais, em vista dorsal; 264 , quarta pata natatória; 265-267, M. Zeptopus leptopus, fémea: 265, quinta pata; 266, ramos caudais, em vista dorsal; 267 . placa basal e endópodo da quarta pata natatória; 268-270, $M$. Zeptopus mucubajieneis, fêmea: 268, quinta pata; 269, placa basal da primeira pata natatória; 270 , placa basal e endópodo da quarta pata natatória. (262-264 segundo Lowndes, 1934; 265-267 segundo Kiefer, 1957; 268-270 segundo Kiefer,1956) 


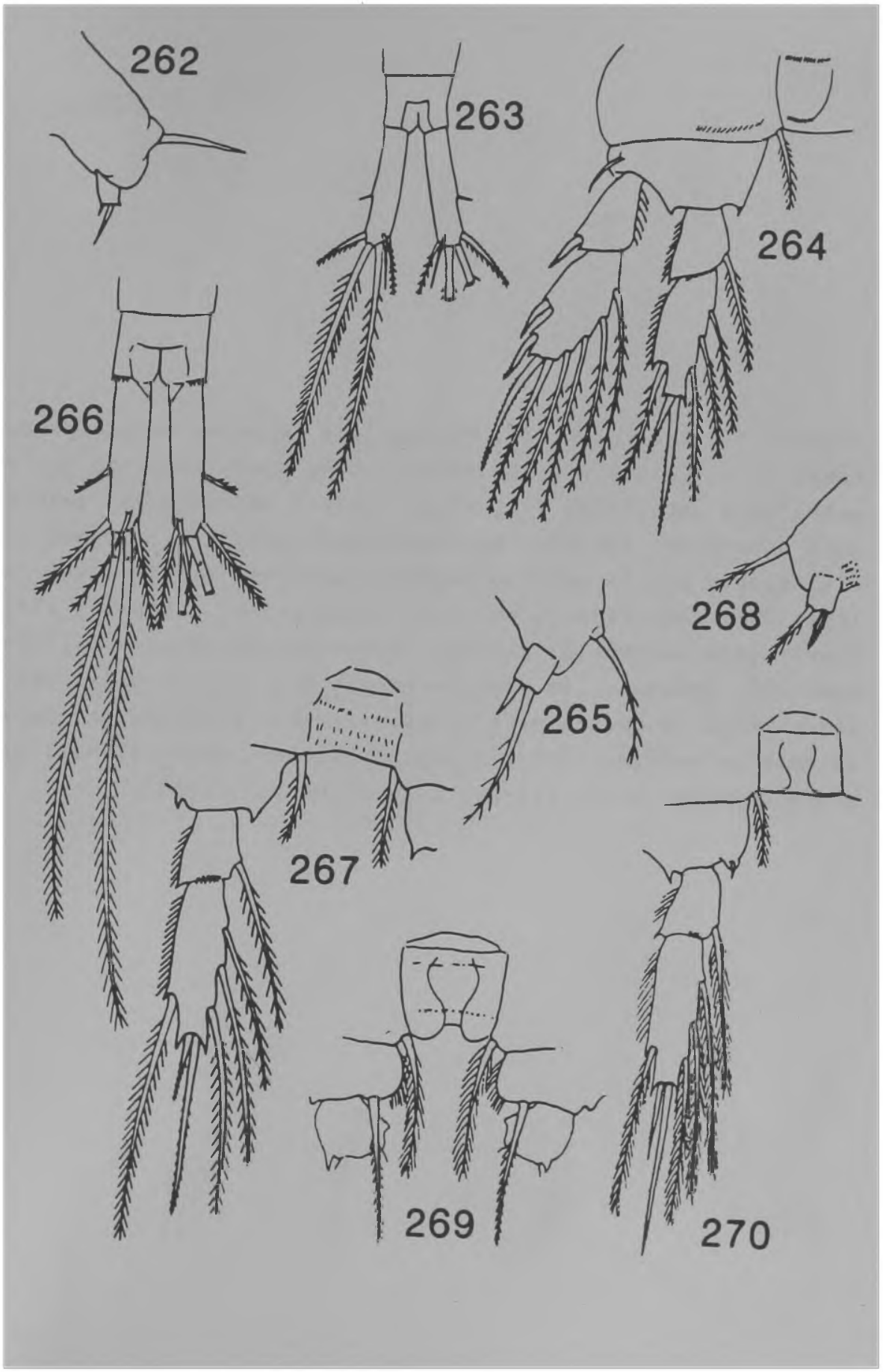


Figuras 271-281: 271-273, Netacyclope leptopus venesolanus, fêmea: 271, quinta e sexta patas; 272, placa basal da pri meira pata natatōria; 273, placa basal e endópodo da quarta pata natatôria; 274-277, Neutrocyclops brevifurca, fêmea : 274, quinto par de patas e segmento genital, em vista ven tral; 275, ramo caudal, em vista dorsal; 276, antênula; 277 , quarta pata natatôria; 278-281, Microcyclops paludicola, fêmea: 278, urossomo, em vista ventral; 279, quinta pata; 280 , placa basal da quarta pata natatória; 281, endópodo da quarta pata natatória. (271-273 segundo Kiefer, 1956; 274-277 se gundo Lowndes, 1934; 278-281 segundo Herbst, 1959). 


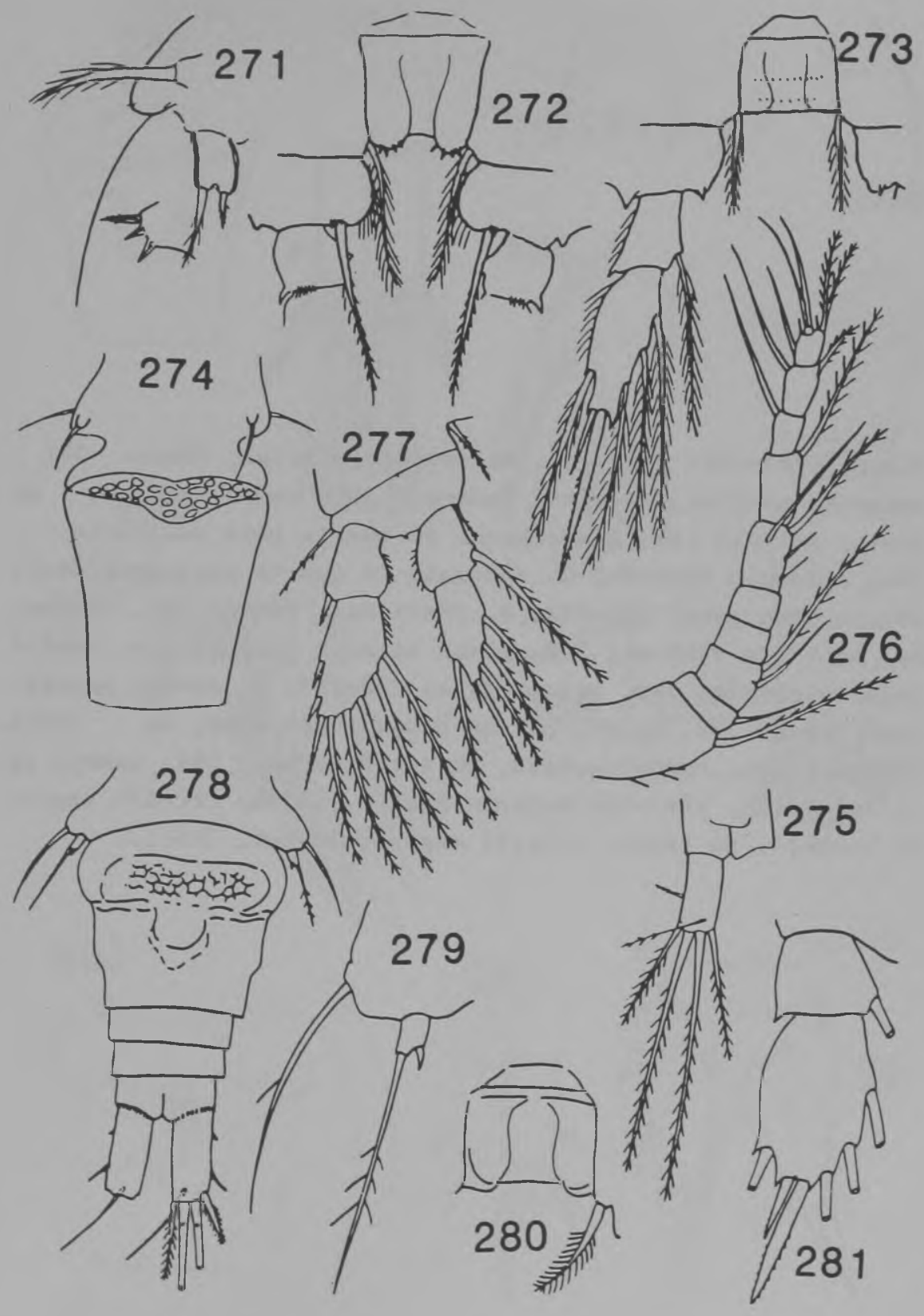


Figuras 282-292: 282-285, Microcyclops alius, fêmea: 282 , segmento genital, em vista ventral; 283 , ramos caudais, em vista ventral; 284 , placa basal da quarta pata natatória; 285, artículo terminal do endópodo da quarta pata natatōria; 286, quinta pata; 287-289, M. finitimus, fêmea: 287, urossomo, em vista ventral; 288, placa basal e endópodo da quarta pata natatória; 289, quinta pata; 290-292, M. anceps pauxensis, fêmea: 290, quinto par de patas e urossomo, em vista ventral; 291, ramos caudais, em vista dorsal; 292, quarta pa ta natatória. (282-286 segundo Kiefer, 1935a; 287-289 segundo Dussart, no prelo; 290-292 segundo Herbst, 1962). 


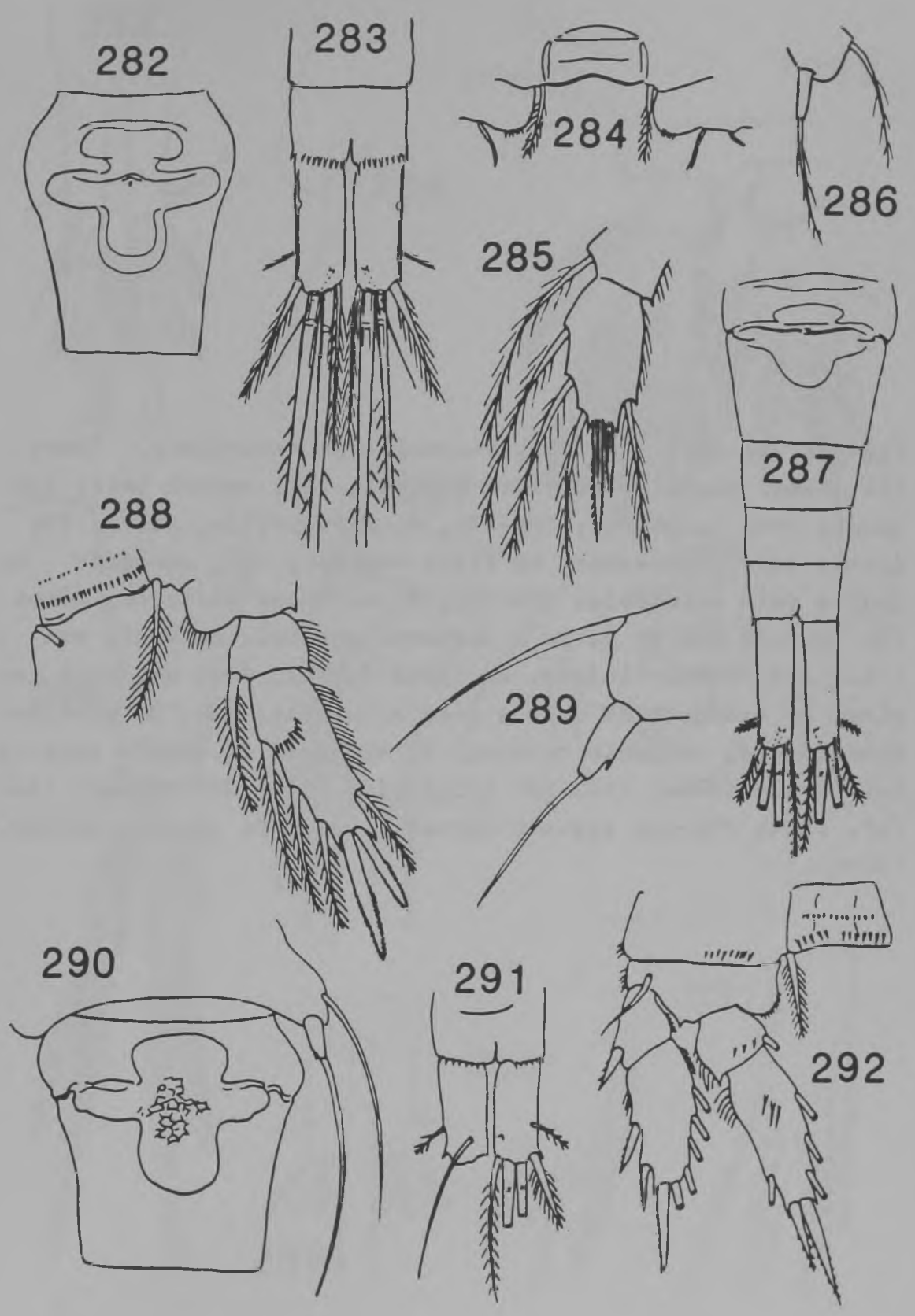


Figuras 293-301: 293-295, Nicrocyclope ceibaensio, fêmea : 293, ramos caudais, em vista ventral; 294, quinta pata; 295, quarta pata natatōria; 296-297,. . dubitabilis, fêmea: 296 , quinta pata e urossomo, em vista ventral; 297, endópodo da quarta pata natatória; 298-300, M. varicans varicans, fêmea: 298, quinto par de patas e segmento genital, em vista ven tral; 299, ramos caudais, em vista dorsal; 300 , articulo ter minal do endópodo da quarta pata natatória; $301, M$. varicans subaequalis, artículo terminal do endópodo da quarta pata na tatōria da fêmea. (293-295 originais; 296 e 297 segundo Kiefer, 1956; 298-300 segundo Gurney, 1933; 301 segundo Kiefer, 1929a). 

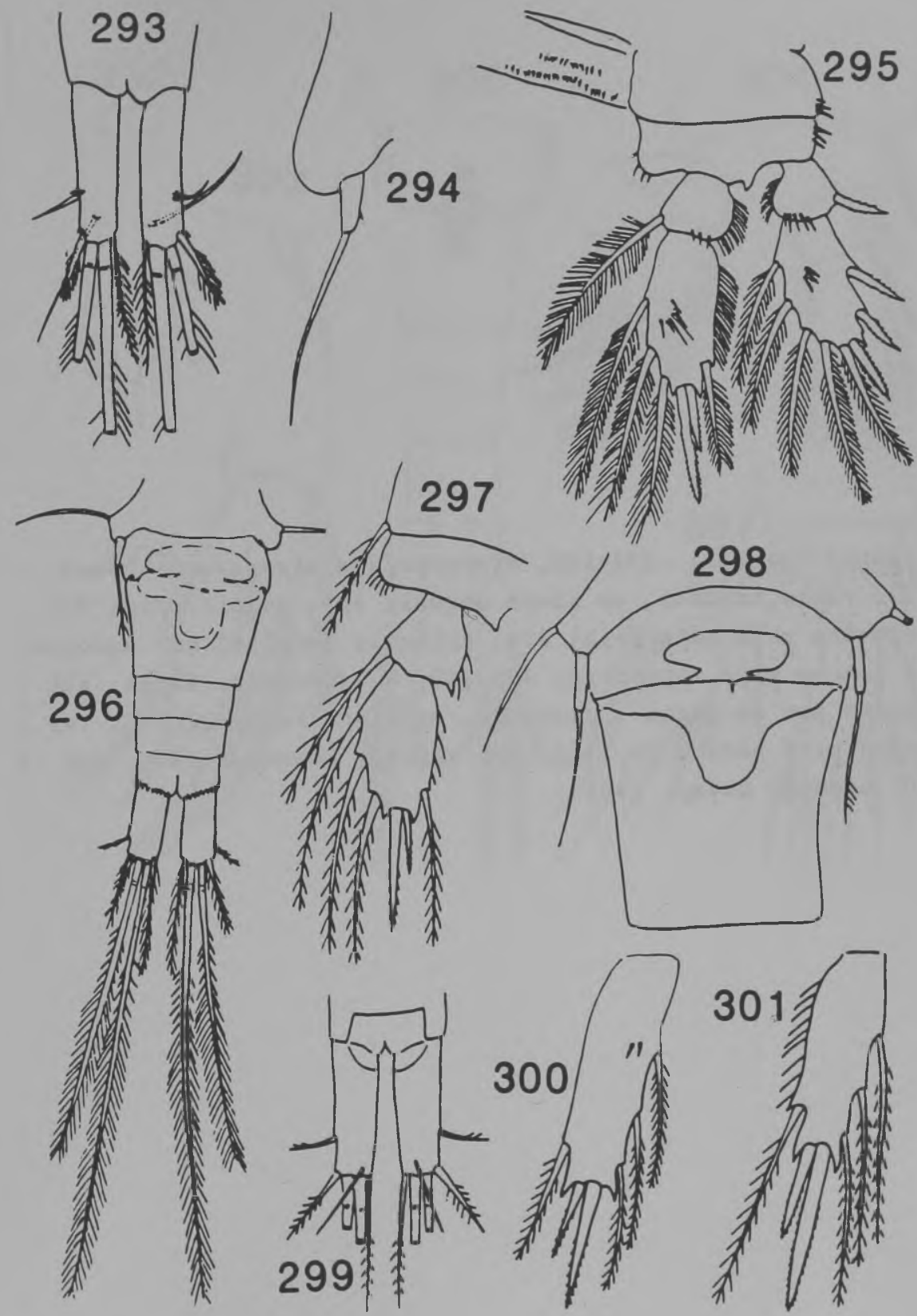
Figuras 302-307: 302-305, Microcyclops elongatus, fêmea : 302 , ramos caudais, em vista dorsal; 303 , quinta pata; 304 , primeira pata natatória; 305 , articulo terminal do endópodo da quarta pata natatória; 306-307, $M$. furcatus, fêmea: 306 , quinto par de patas e urossomo, em vista ventral; 307 , ter ceira pata natatória. (302-305 segundo Lowndes, 1934; 306 e 307 segundo Daday, 1905). 


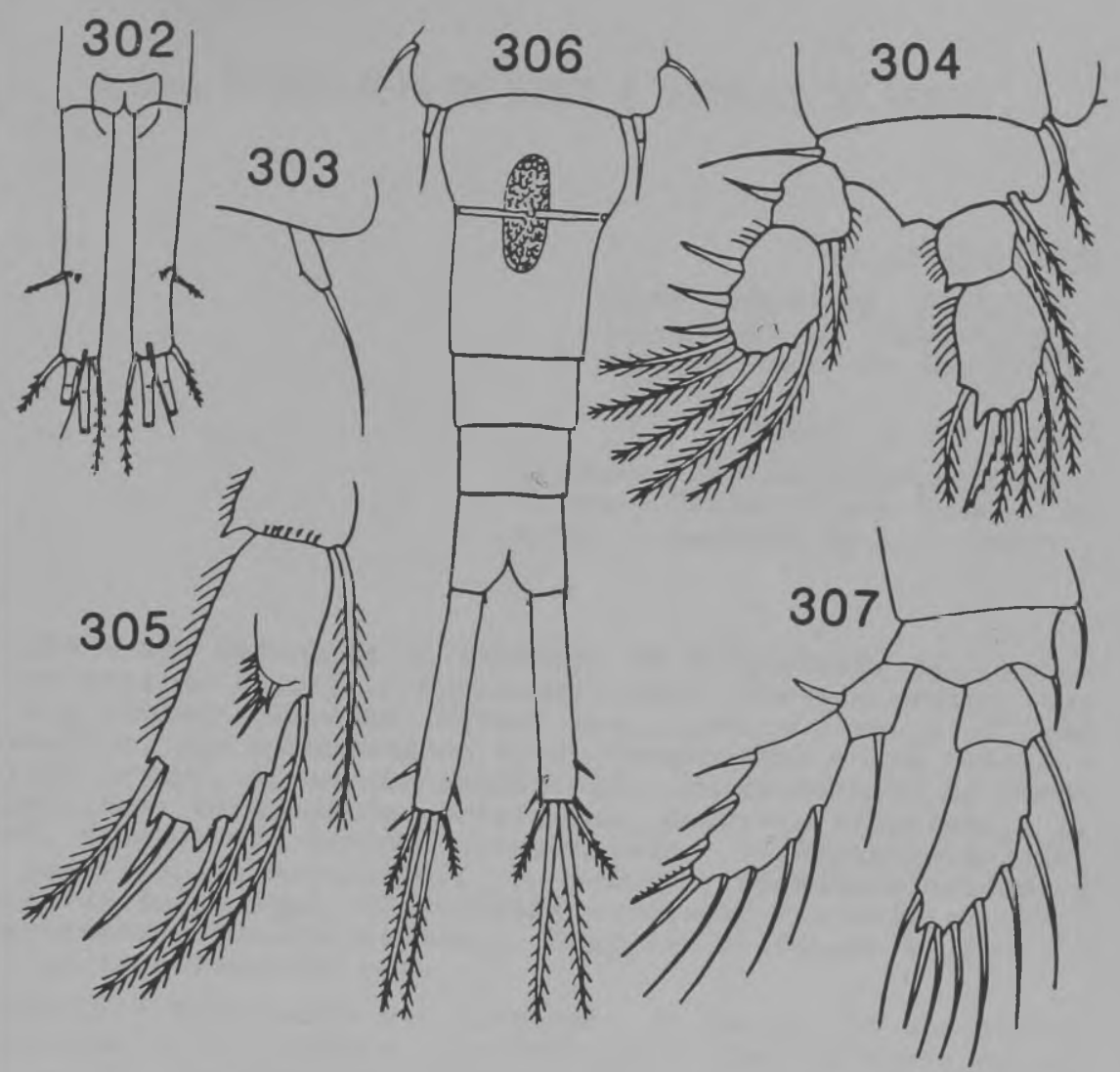


